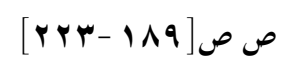

دراسة إمكانية تطبيق الشركات الصناعة المساهمة العامة

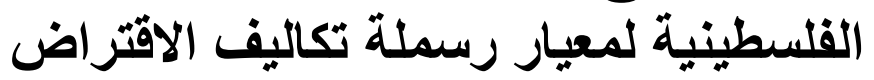

(در اسة تحليلية)

الدكتور ماهر موسى درغام

استاذ المحاسبة المساعد

قسم المحاسبة - كلية التجارة

الجامعة الاسلامية -غزة

Mdurgham2005@yahoo.com

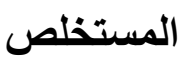

يهرف هذا البحث بشكل رئيس إلى دراسـة إمكانيـة تطبيق الشركات الصناعية المساهمة

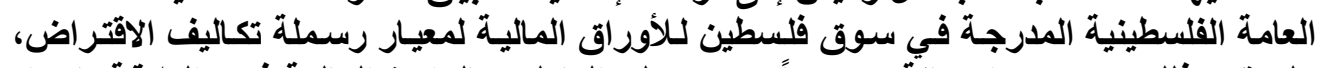

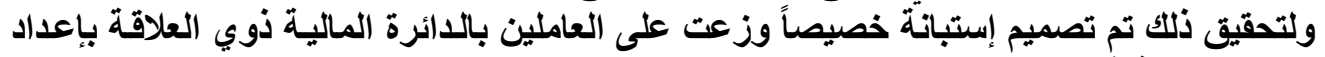

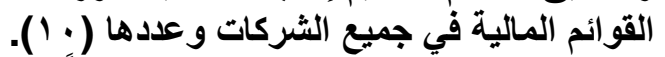

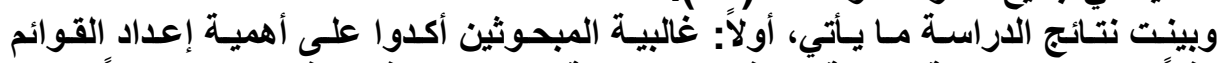

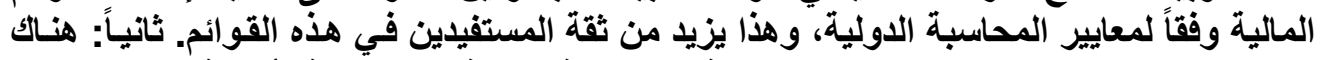

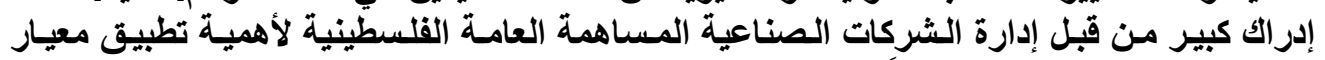

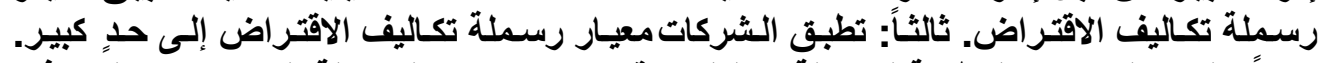

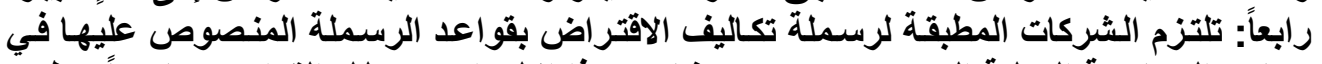

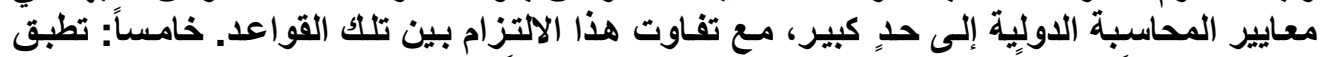

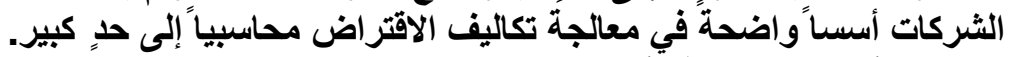

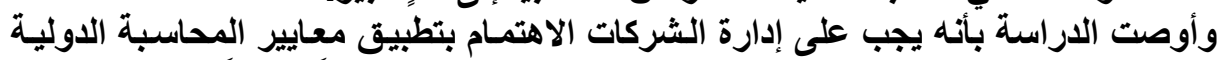
ومعايير التدقيق الدولية لكسب البيانات المالية مصداقية وشفافية أكبر محلياً ودولياً. 


\title{
The Study of the Possibility of Applying the Standard of Borrowing Costs by the Palestinian General Contributing Manufacturing Companies (PGCMC) (Analytical Study)
}

\author{
Mahir M. Durgam (PhD) \\ Assistant Professor \\ Department of Accounting \\ Islamic University - Gaza
}

\begin{abstract}
This search aims basically at studying the ability of applying the Standard of Borrowing Costs by the Palestinian General Contributing Manufacturing Companies (PGCMC). They were listed at Palestinian Securities Market. This done by doing a special questionnaire designed and distributed among employees who are working in the financial departments and responsible for preparing the financial statements in the ten examined companies. The results of the study revealed that:

1. Most of workers ensured the importance of preparing the financial statements according to the International Accounting Standards; this would increase the credibility of beneficiaries in these companies.

2. There is a wide awareness by the administration of the (PGCMC) to the essential of applying the Standard of Borrowing Costs.

3. There is a wide application of Standard of Borrowing Costs among examined companies.

4. The applied companies of the Standard of Borrowing Costs followed the rules of funding which are widely agreed the International Accounting Standards. The study recommended that the administration of companies should concern the application of international accounting standards and auditing standards to give the financial data more credibility locally and internationally.

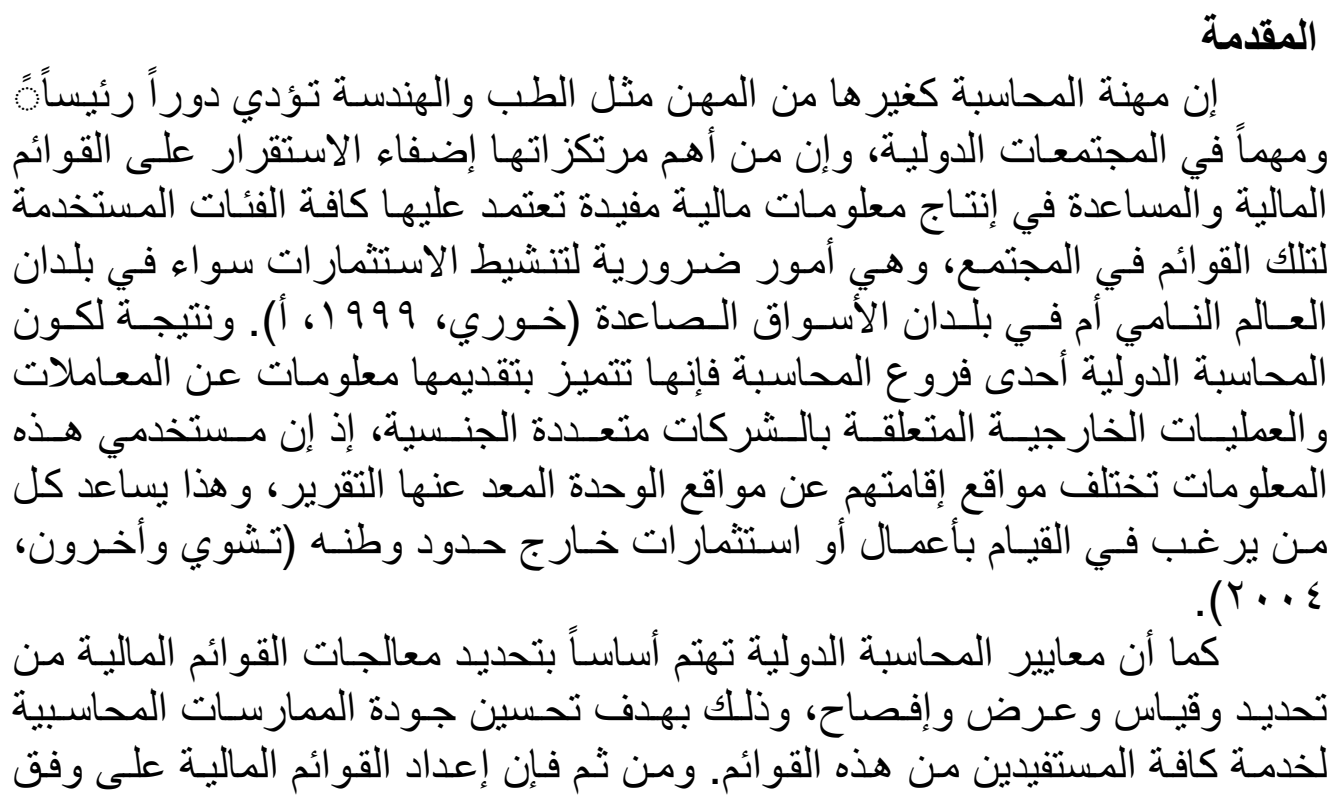




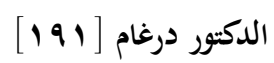

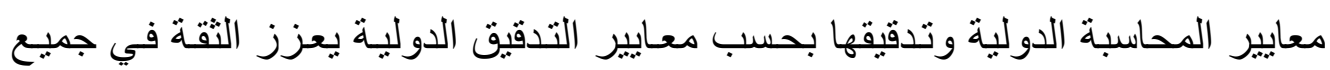
القطاعات منها القطاع الصناعي وبيياناته المالية من قبل كائل كافة المستفيدين.

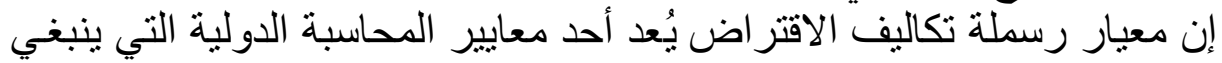

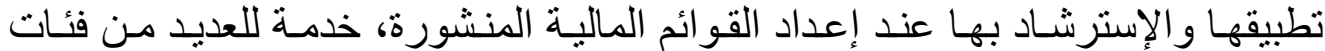

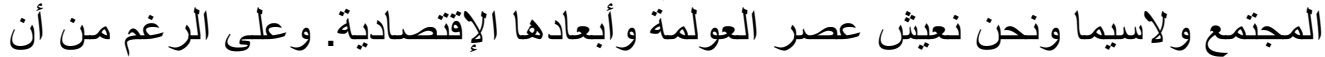

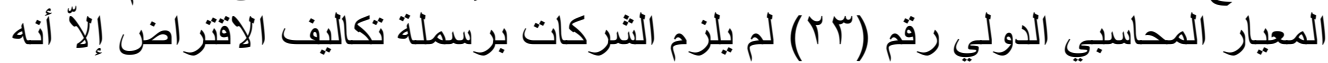

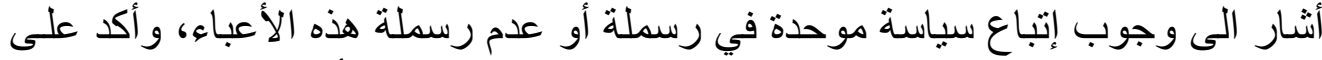

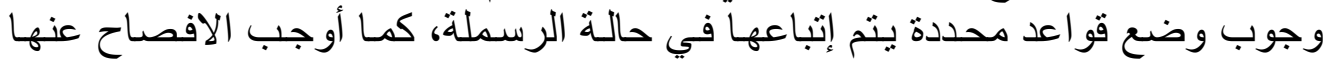

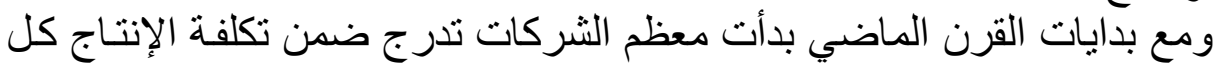

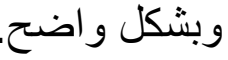

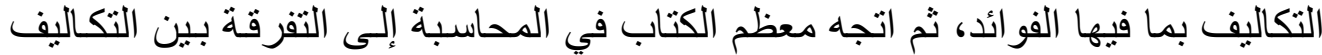

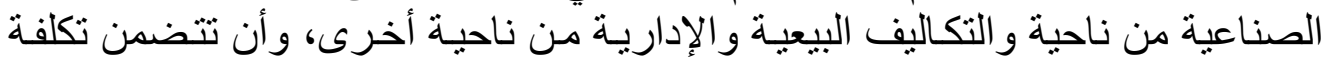

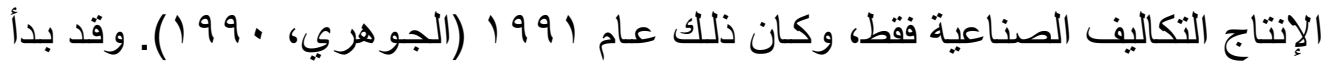

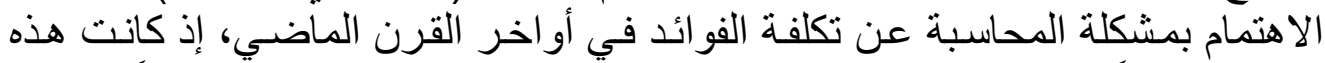

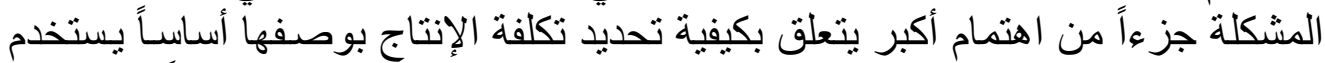

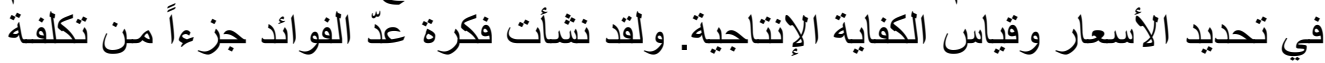

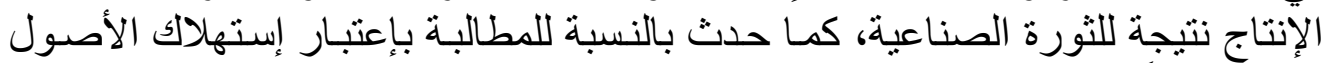

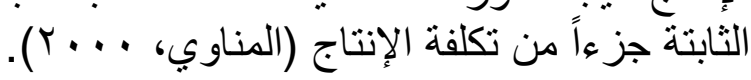

$$
\text { مشكلة البحث بكر مشكلة البحث في مجمو عة من التساؤلات الآتبة: }
$$

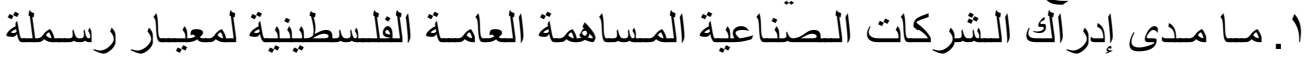

$$
\text { تكاليف الاقتر اض واض أهميته؟ }
$$

Y . مـا مدى تطبيق الشركات الصناعية المساهمة العامـة الفلسطينية لمعيـار رسملة

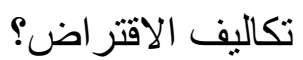

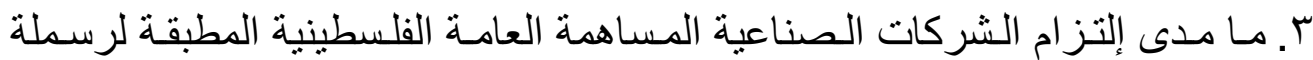

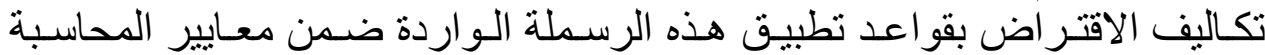

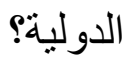
ع. هل تتبع الثركات الصناعية المساهمة العامة الفلسطينية أسساً واضحةً في معالجة تكاليف الاقتر اض محاسبياً؟

يهذف هذا البحث إلى در اسة إمكانية تطبيق الثركات الصناعية المساهمة العامة

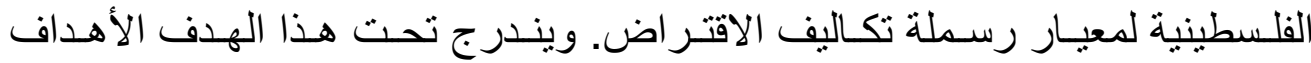

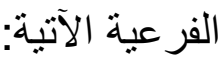
ا . قياس إدر الك الثركات الصناعية المساهمة العامة الفلسطينية لمعيار رسملة تكاليف

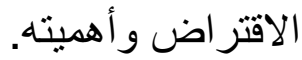


Y. . در اسـة إمكانيـة تطبيـق معيـار رسـملة تكـاليف الاقتر اض في الشركات الصناعية المساهمة العامة الفلسطينية.

ب. التعرف على مدى إلتز ام الشركات الصناعية المساهمة العامـة الفلسطينية المطبقة

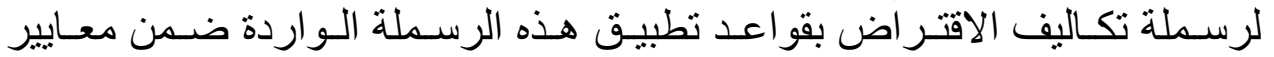
المحاسبة الدولية. ع. بيـان الأسـس المتبعـة في معالجـة تكـاليف الاقتـر اض محاسـبياً مـن قبـل الشركات الصناعية المساهمة العامة الفلسطينية.

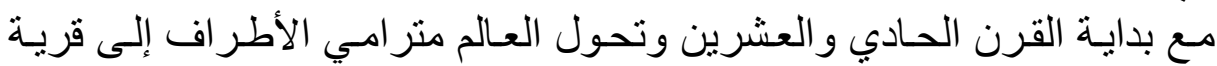
أهمية البحث

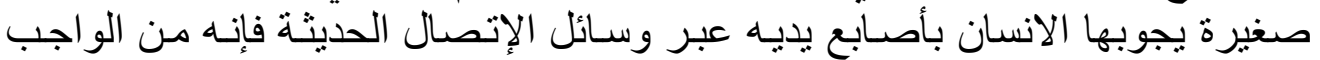

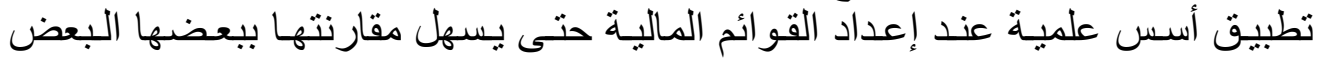

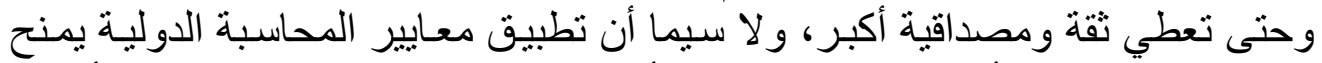

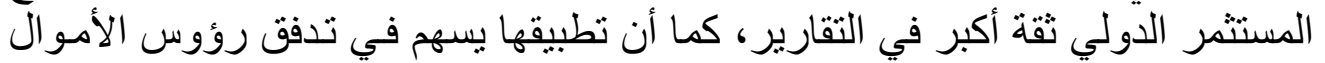

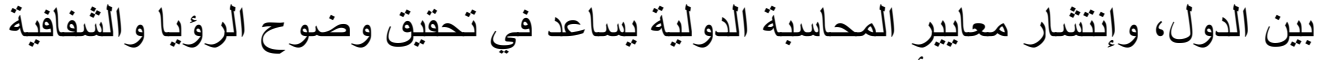

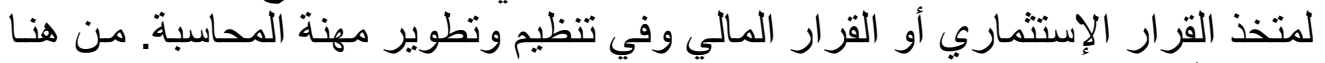

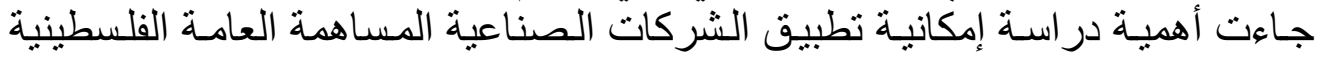
لمعيار رسملة تكاليف الاقتر اض اضك عند إعداد القوائم المالية.

لغرض تحقيق أهداف البحث، تم الاعتماد على الفرضيات الآتبة:

ا ـ تدرك إدارة الشركات الصناعية المساهمة العامـة الفلسطينية أهميـة معيار رسملة الأنة

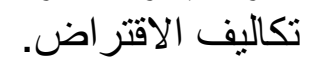

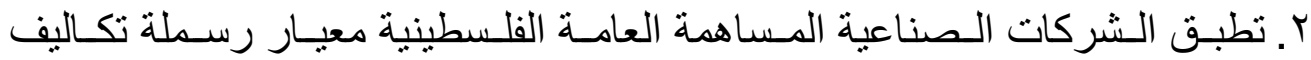

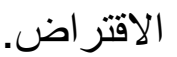

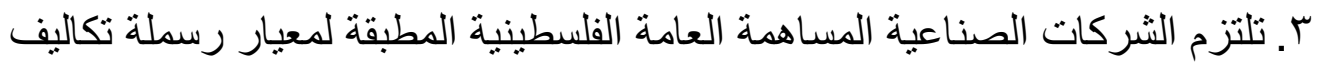

الاقتر اض بقو اعد تطبيق هذه الرسملة الواردة ضدمن العاية معايير المحاسبة الدولية.

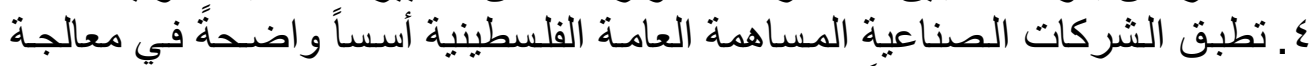
تكاليف الاقتر اض محاسبياً.

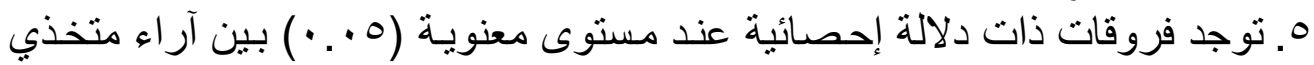

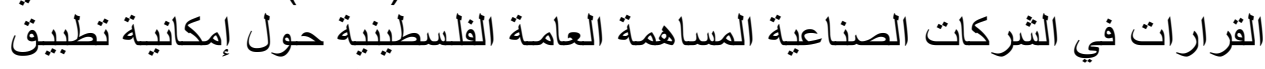

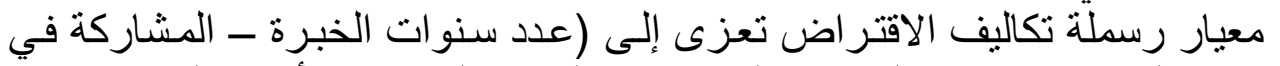
اتخاذ القرار ات ـ عدد الدورات التدرييية - القناعة الثخصية بأهمية المعايير). الار اسات السابقة

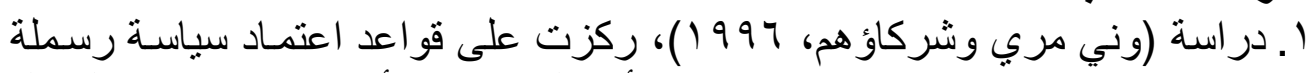
تكاليف الاقتر اض، إذ إنه إذا كان إعداد الأصول يتم على أجز أجلى اء وكان استعمال كل 


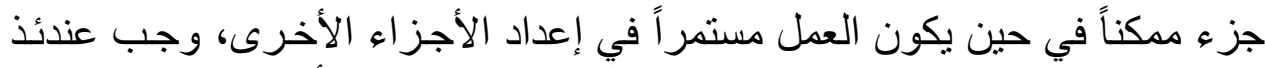

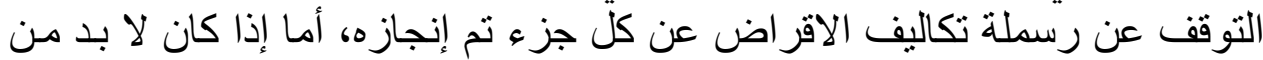

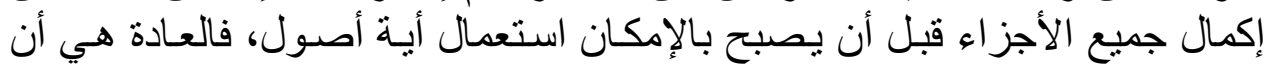

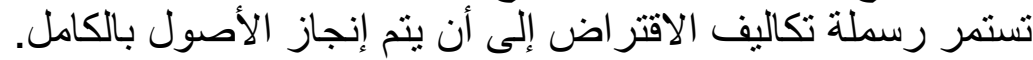

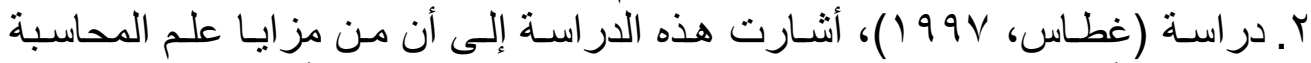

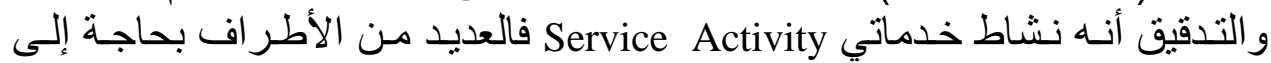

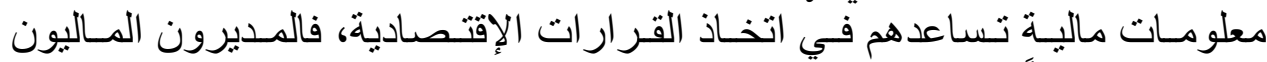

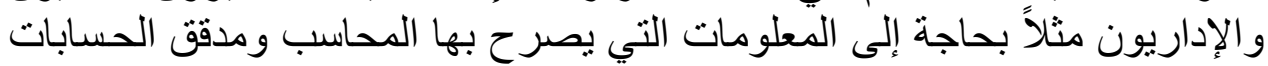

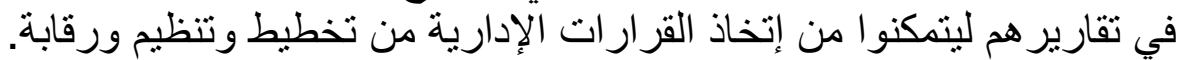

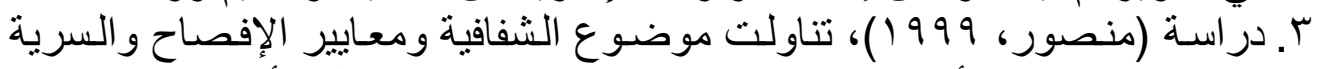

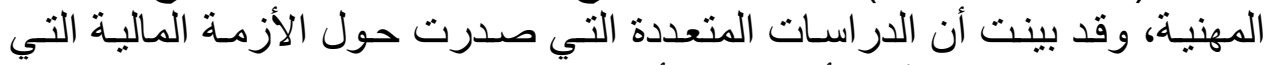

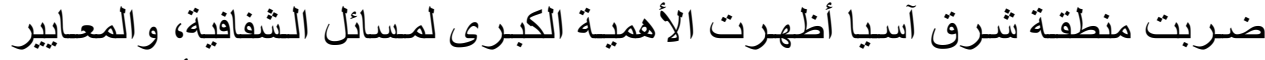

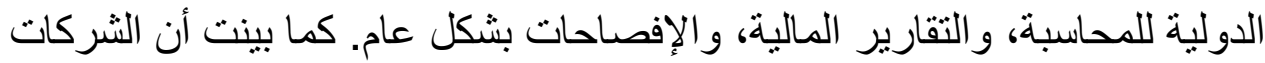

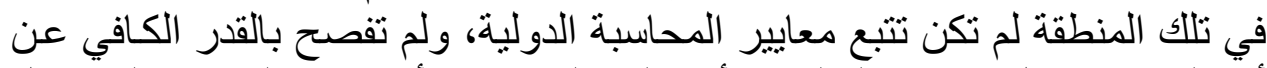

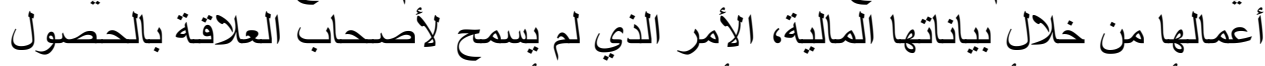

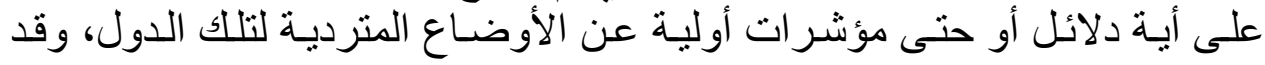

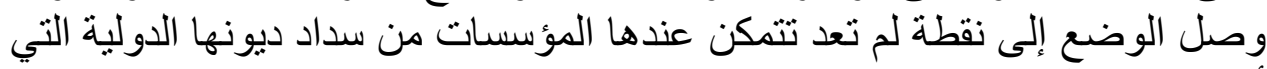

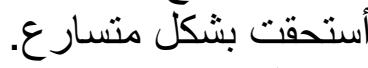

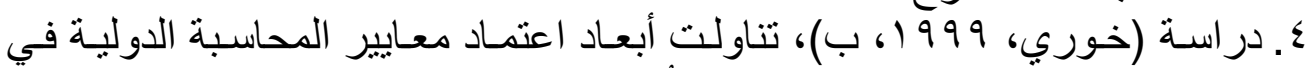

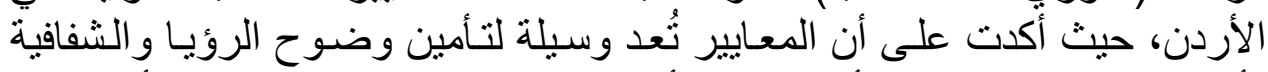

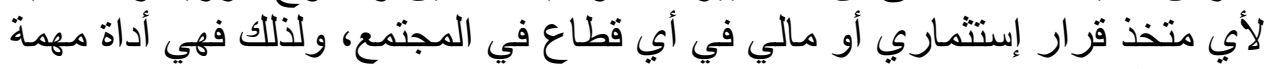

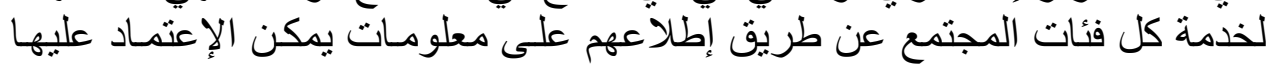

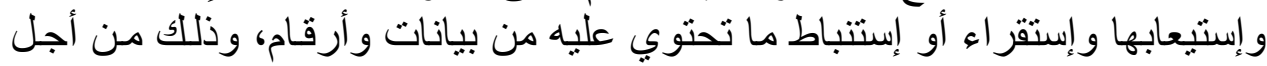
إستخدامها في إنخاذ القرارات المناسية.

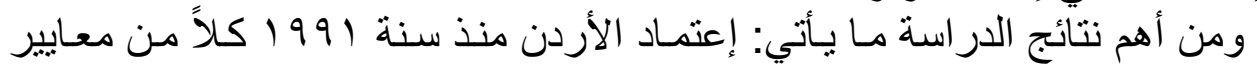

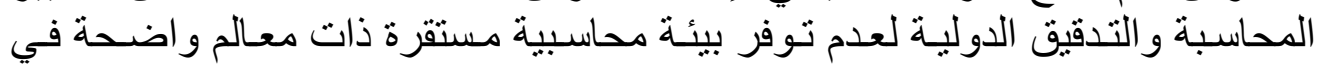

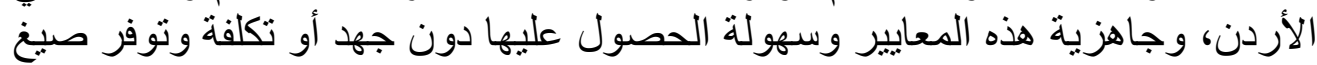

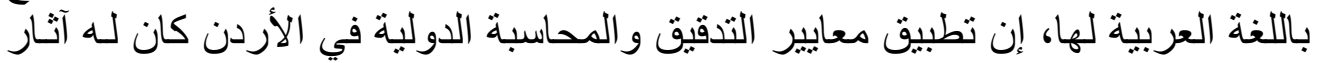

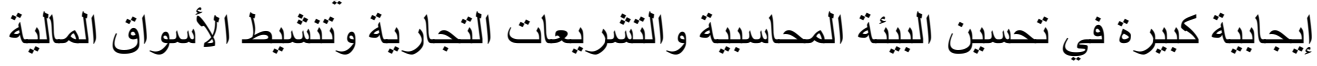

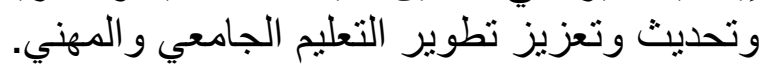

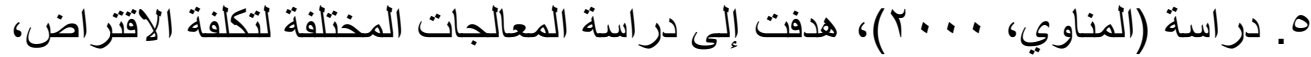

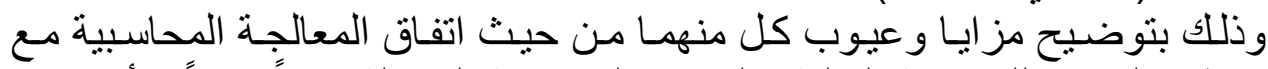

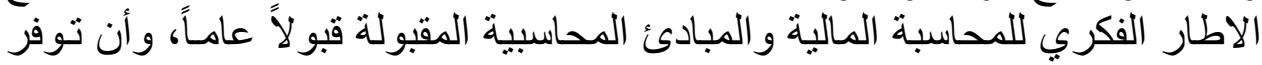

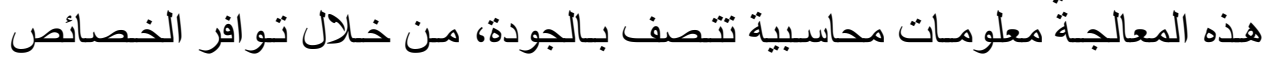
الكيفية في المعلومات الناتجة عن تطبيق هذه السية السياسة.

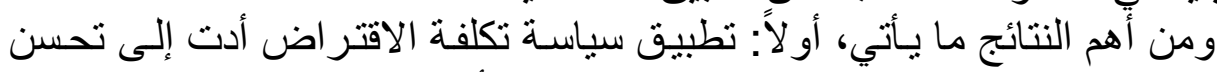

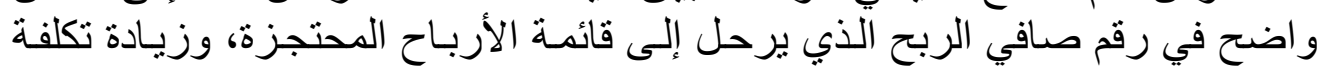


الأصول المسجلة في قائمة المركز المالي وزيادة النقيـة المتولدة عن أنشطة التشغيل

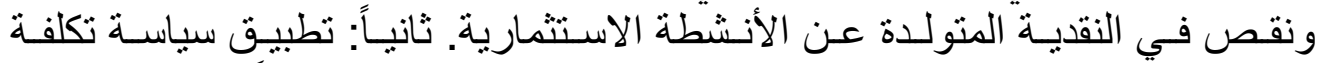

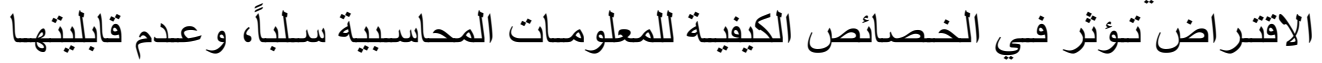

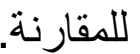
ومن أهم التوصيات ما يأتي، أولاً: ضرورة الحد من تطبيق سياسة رسملة تكلفة

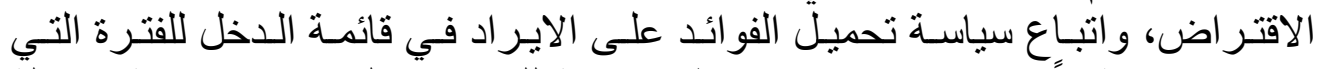

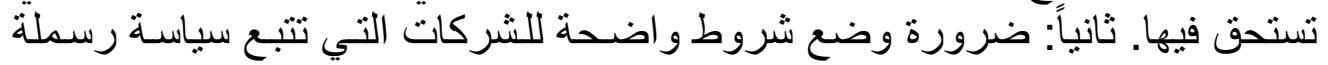

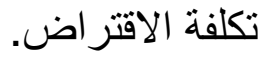

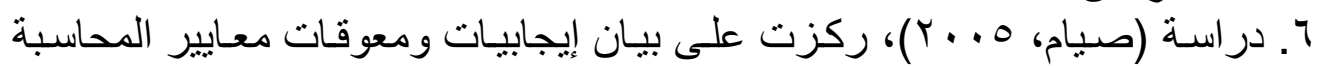

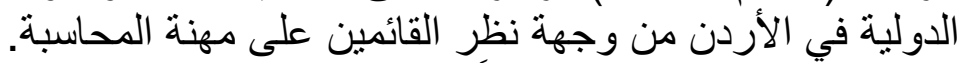

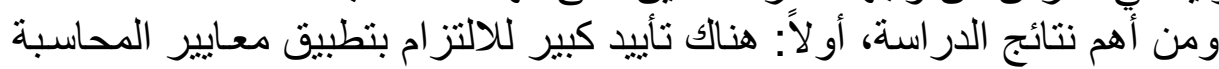

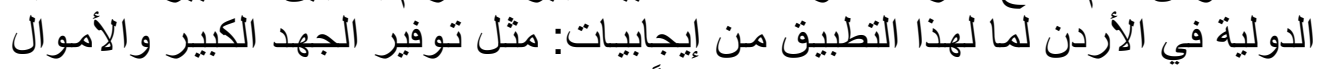

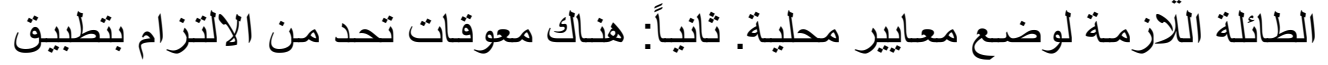

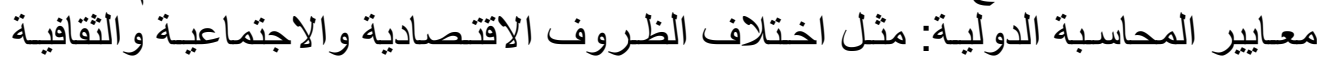

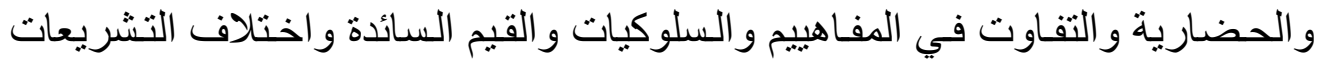

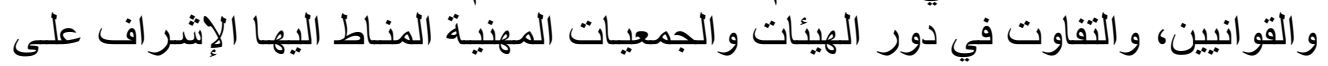

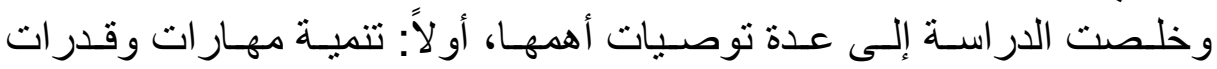

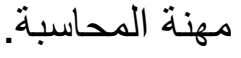

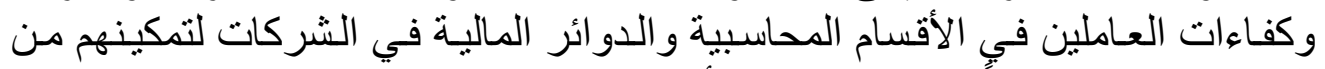

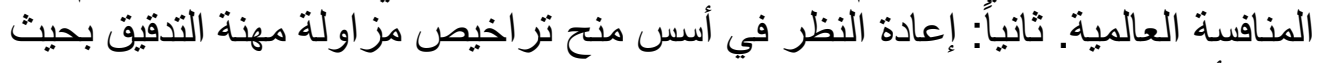

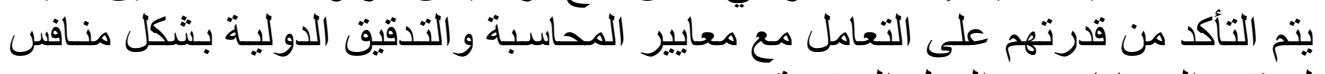

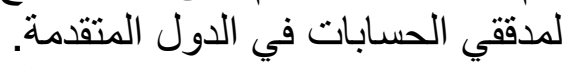

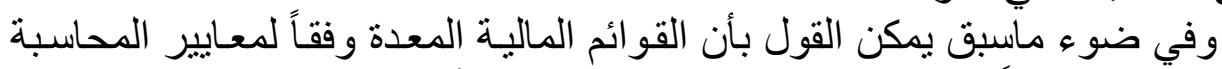

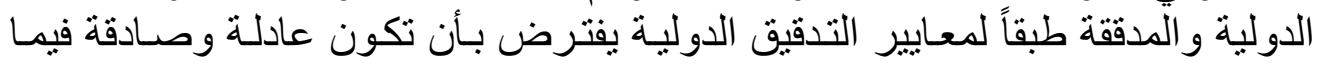

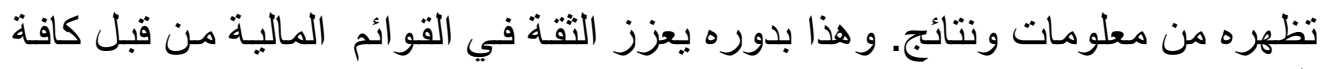

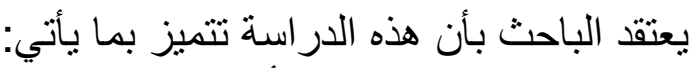

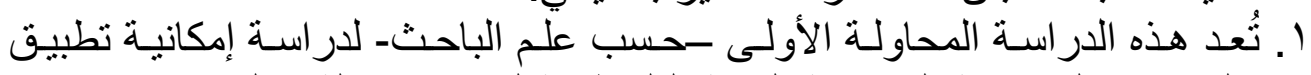

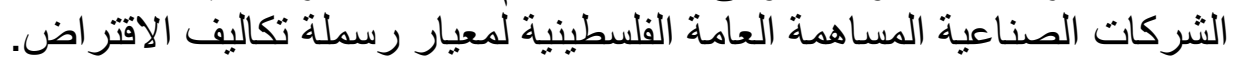

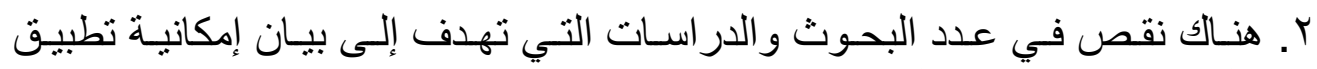

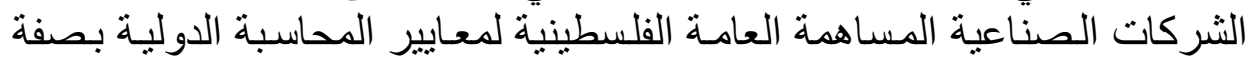
عامة ولمعيار رسملة تكاليف الاقتر اض بصفة لعاصة خاصة، لذللك جاءت هذه الدراسـة

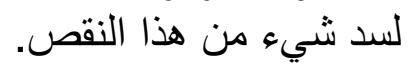




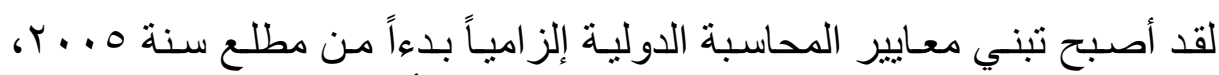

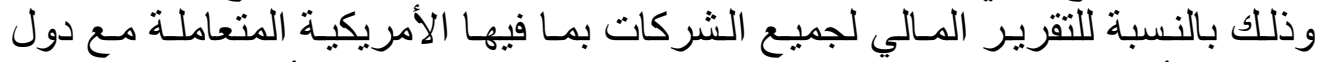

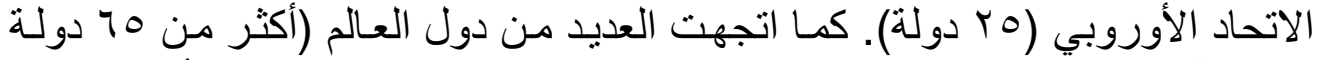

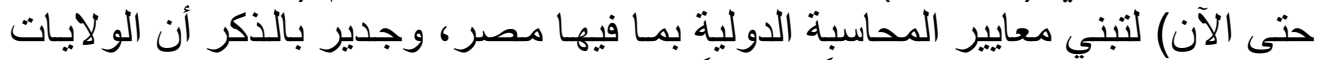

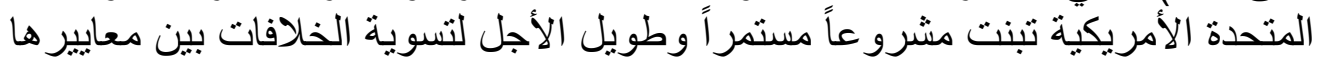

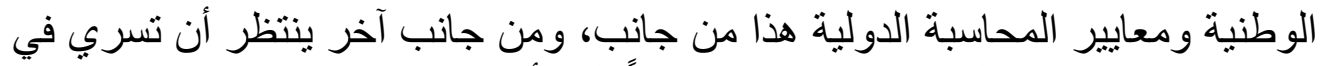

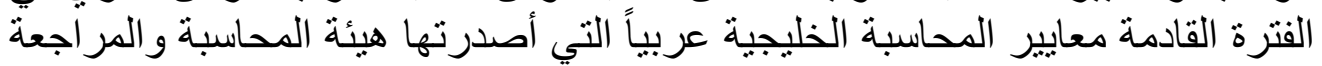

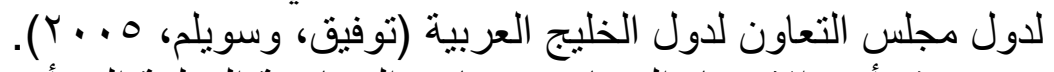

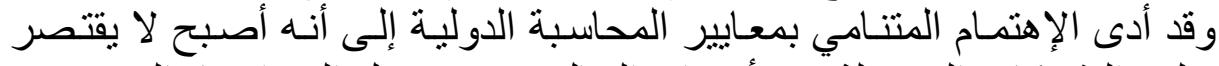

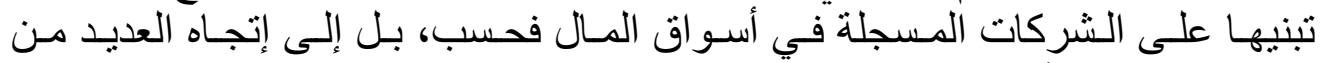

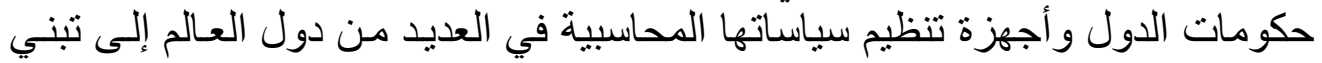

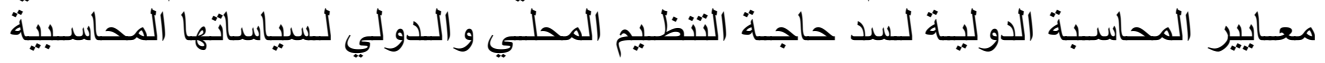
المتعلقة بمختلف جو انب التقرير المالي (Gannon and Ashwal, 2004).

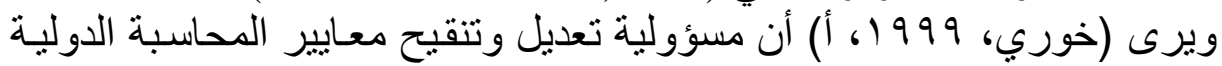

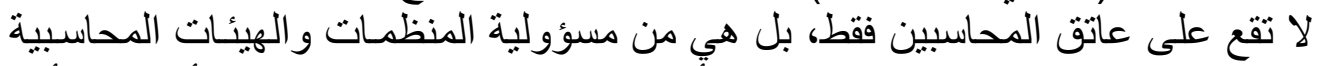

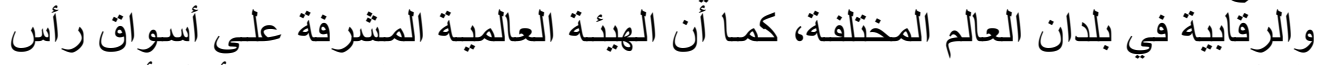

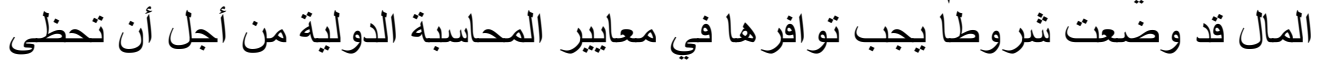
بالقبول و المو افقة من الهيئة العالمية، هي:

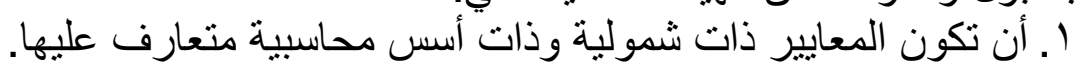

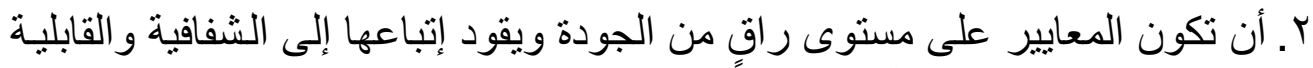

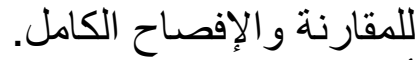

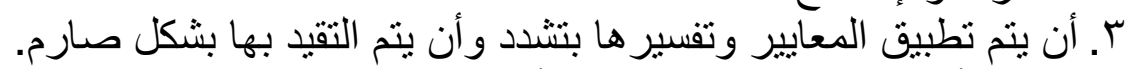

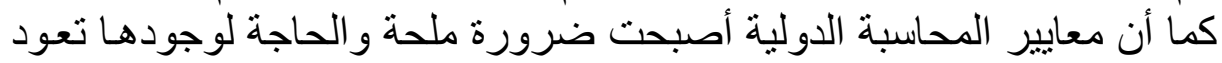

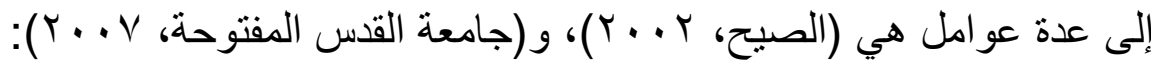

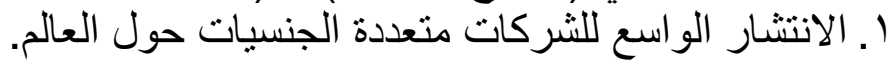

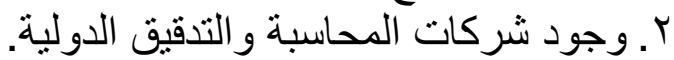

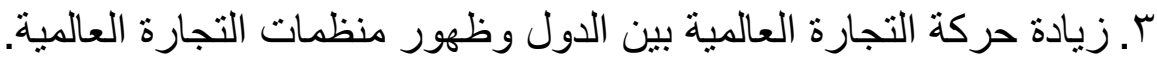
ع. توفير الوقت وتخفيض تكلفة إعداد البيانات المالية من خـال إعداد العداد البيانات المالية

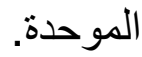

هـ الحاجة الملحة إلى حماية الأمو ال المستثمرة في الأسواق المالية العالمية.

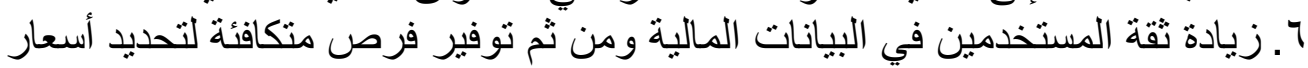

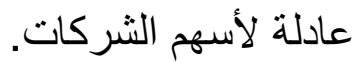
وقد بين (غطاس، لو 99 ( ) منافع إنتشار معايير المحاسبة و التدقيق الدولية وهي:

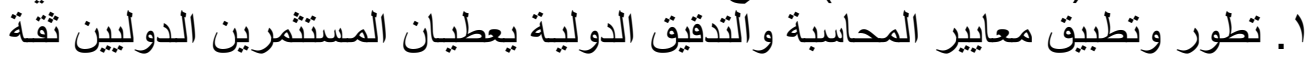

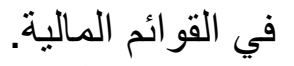
r. إن وجود وتطبيق معايير المحاسبة والتدقيق الدولية يساعدان على تدفق رؤوس

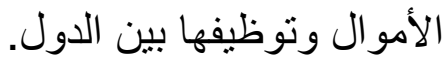


rـ. إن تنسيق معايير الدحاسبة والتدقيق الدولية يسهل من عملية مقارنـة المعلومـات

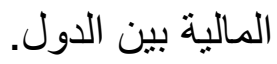

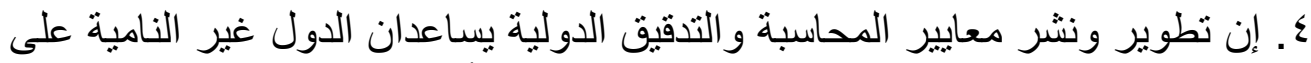

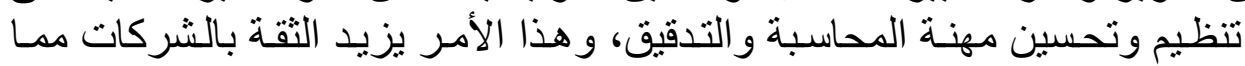
يحقق منافع مهمة لتلك الدول.

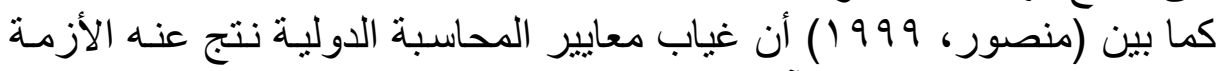

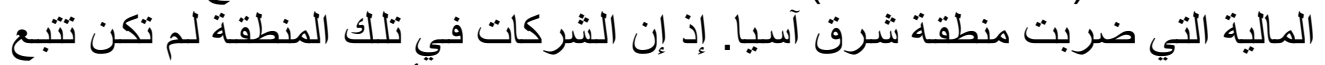

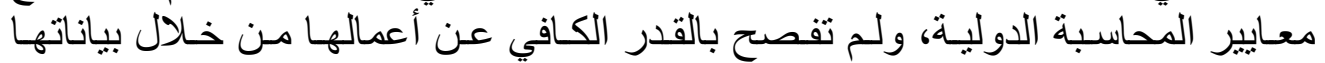

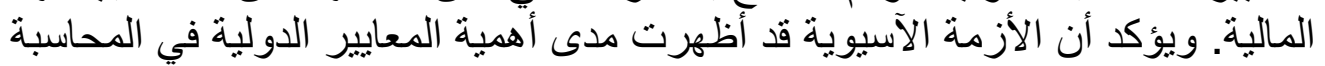

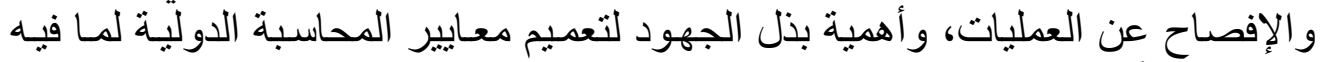

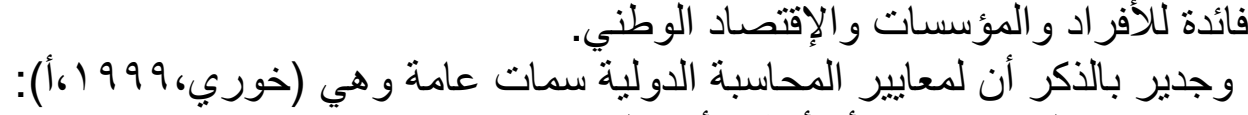

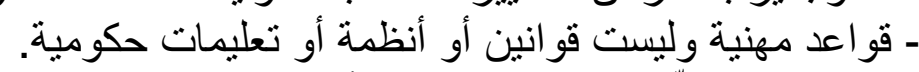
- غير ملزمة إلاّ من الناحية المهنية لأن السيادة للقانية ألقانون.

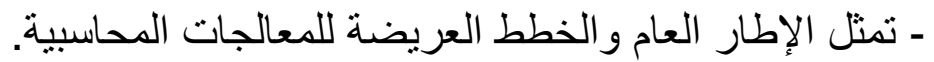
ـ تعتمد على مفهوم العدالة المهنية (الصدق) وليس على العى مفاهيم القانونية أو الصحة

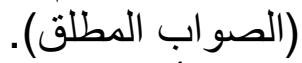

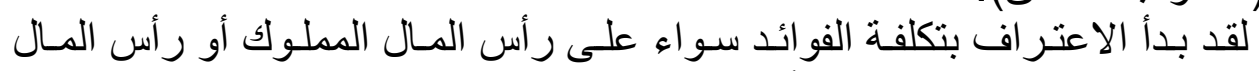

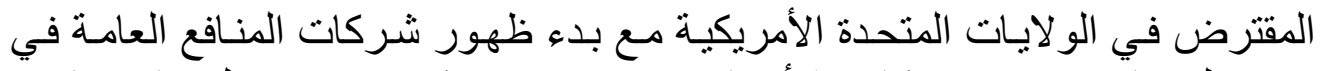

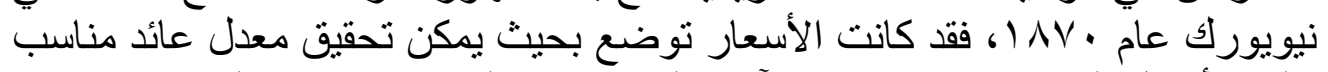

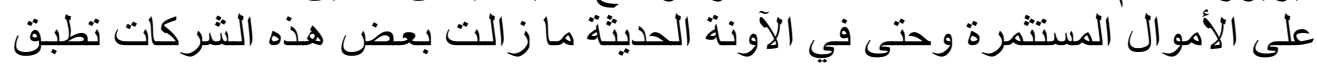

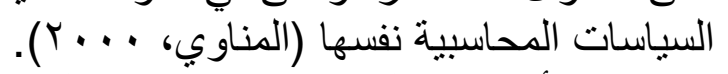

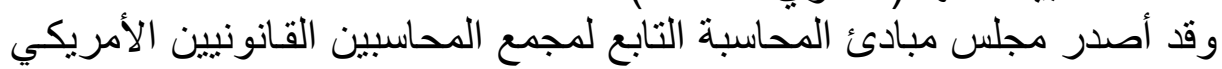

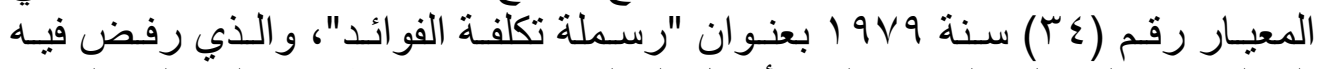

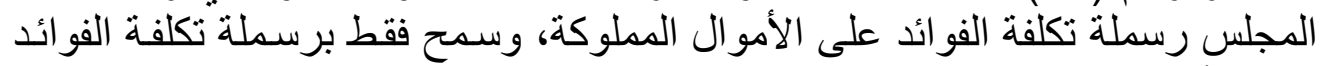

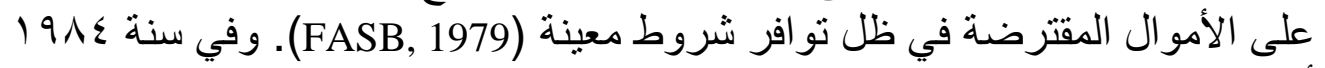

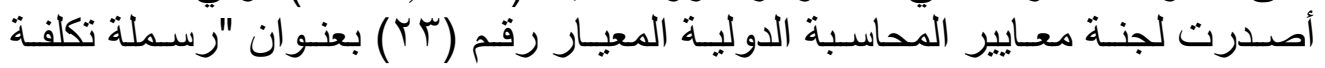

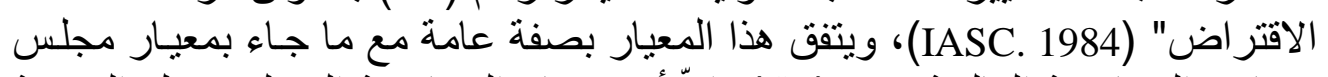

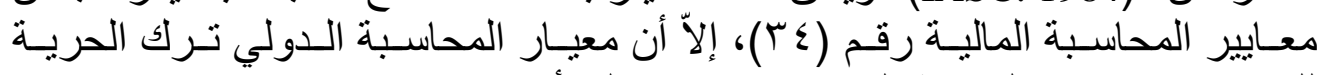

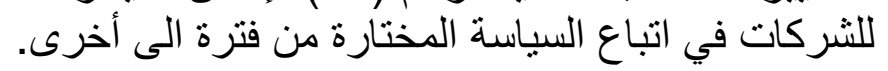

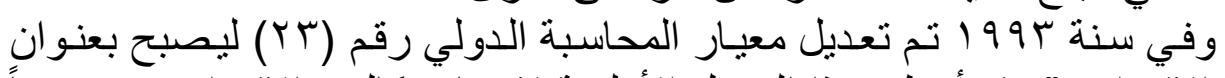

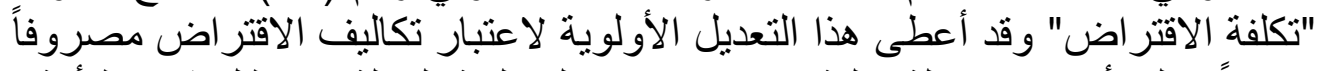

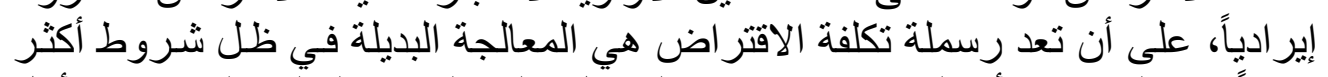

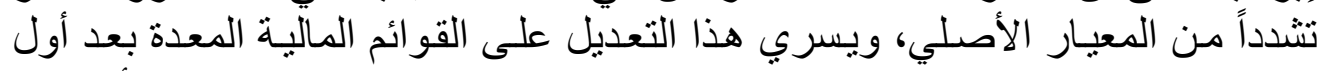

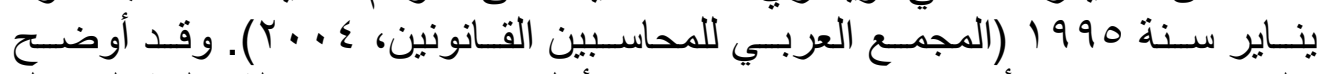

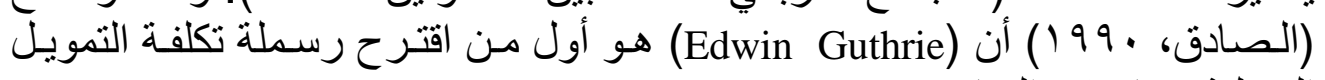
المتعلقة بمقاو لات المباني. 
تعريف تكاليف الاقتراض

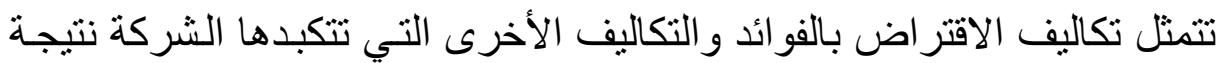

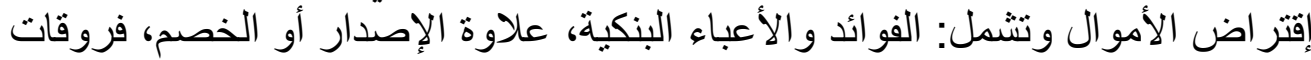

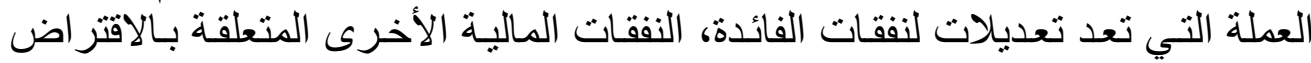

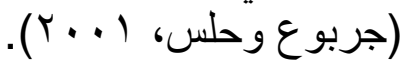

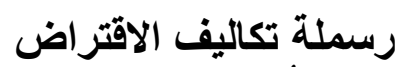

تُعد تكاليف الاقتر اض جز عاً من تكلفة الأصل و إضـافتها إلبها باستخدام معدل

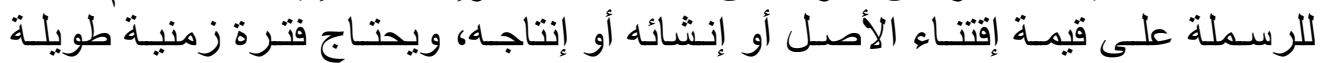

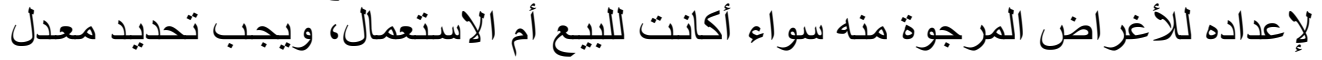

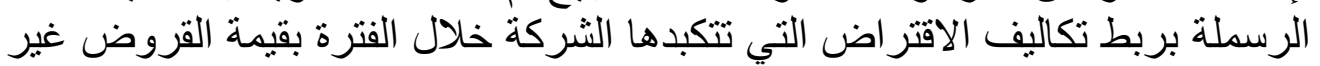

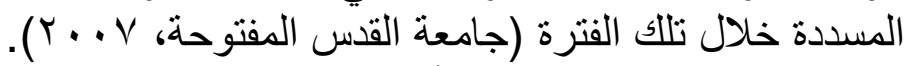

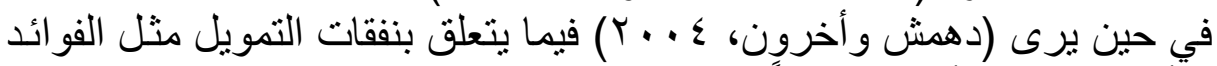

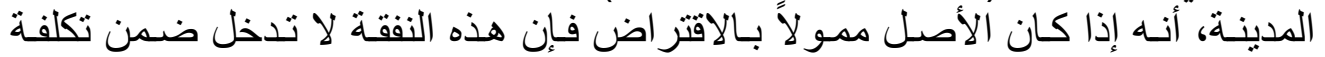

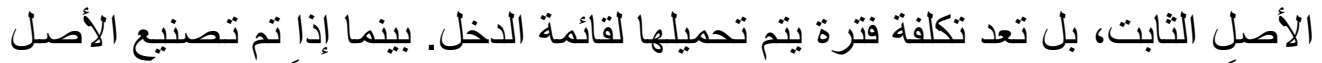

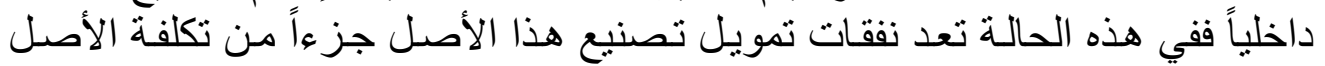
خلال فترة تصنيع الأصل فقط.

\section{معالجة تكاليف الاقتراض}

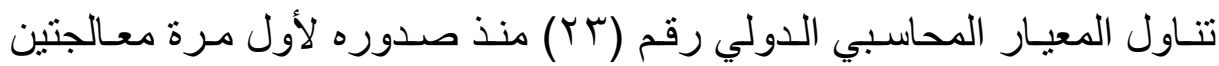

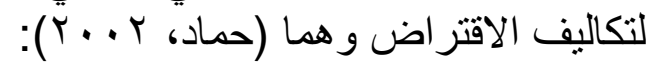

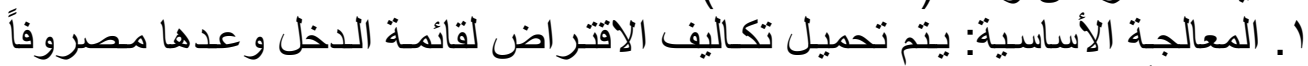

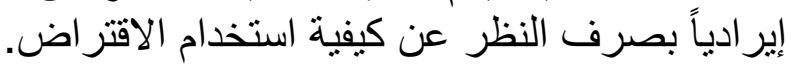

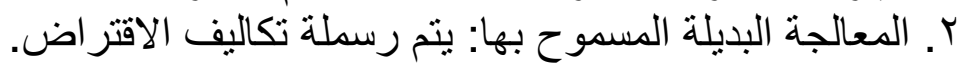

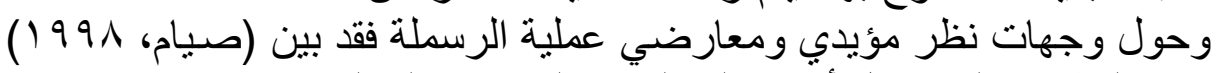

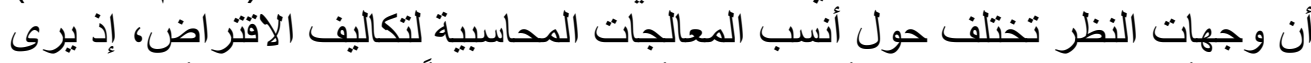

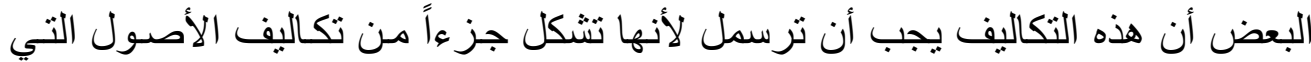

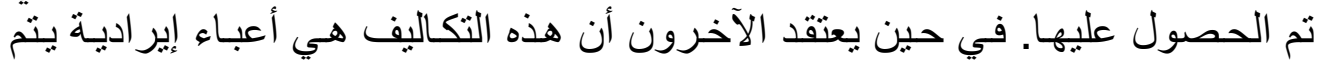

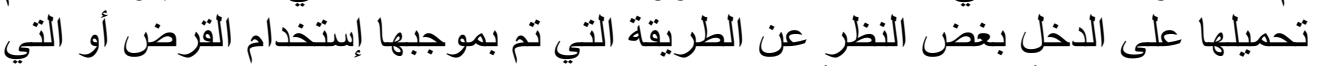

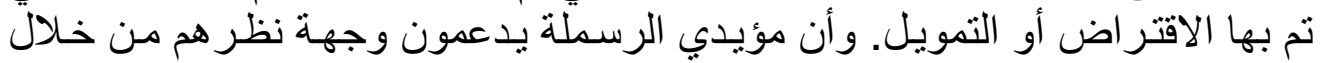

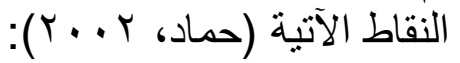

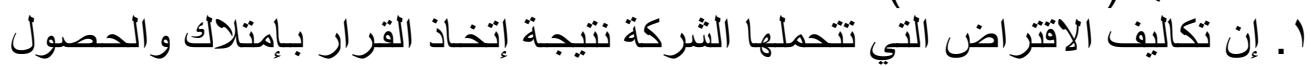

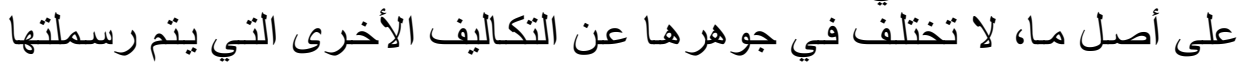

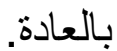




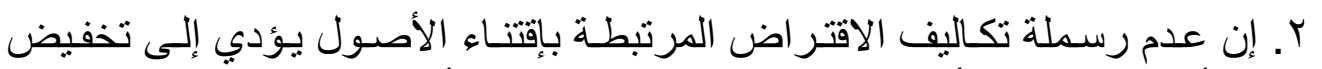

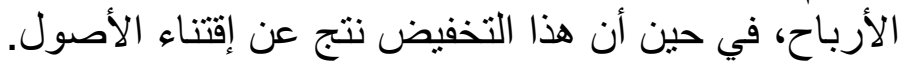

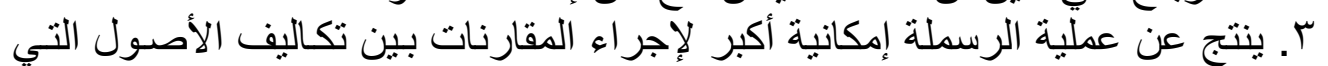

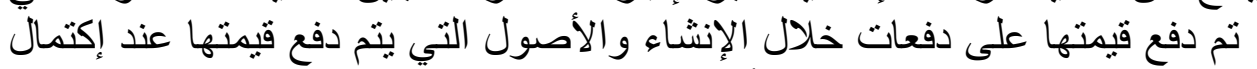

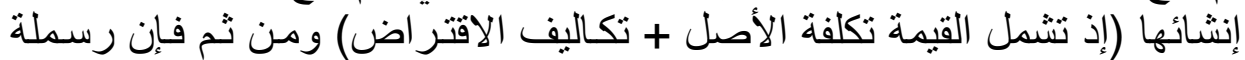

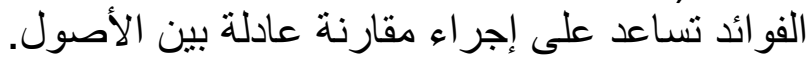

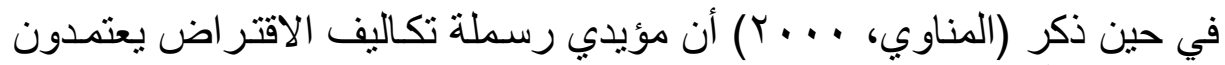

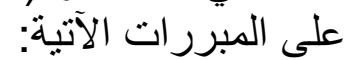

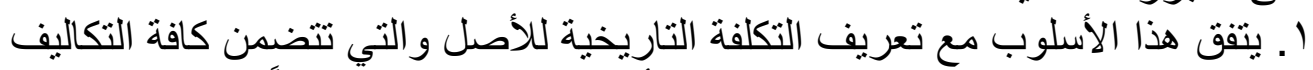

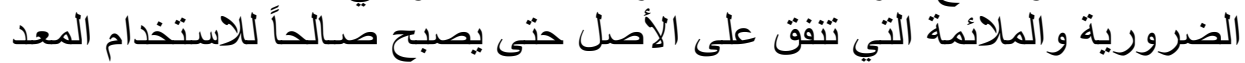

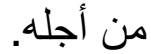

r. تناعد على مقابلة أفضل بين الإير ادات و المصروفات الخاصة بالفتر التبر ات المحاسبية.

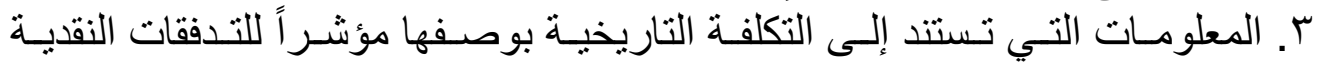
المتوقعة من الأصل تعد أحد الأسباب المؤدية الى عملية الرئل الرسملة.

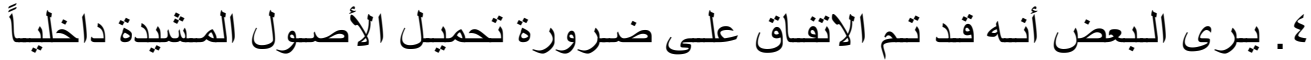

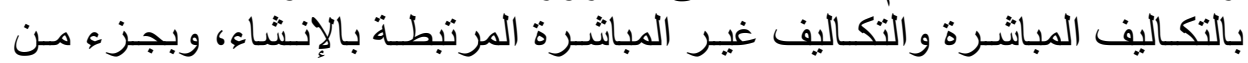

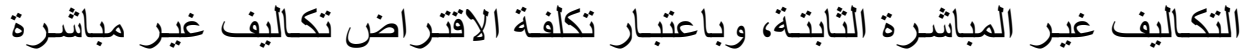

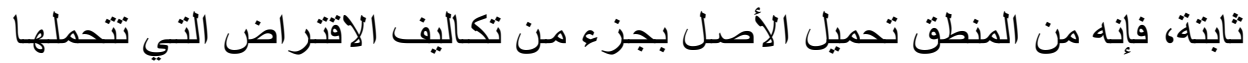

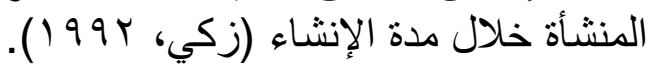

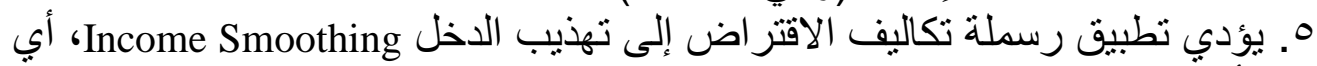

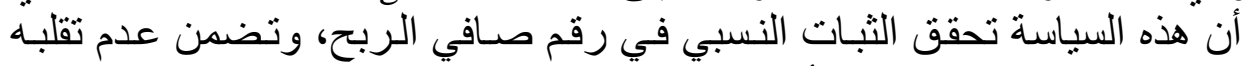

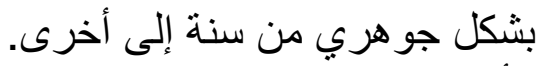

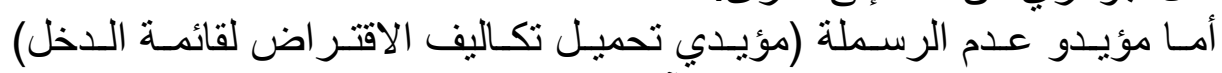

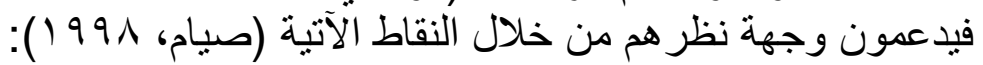

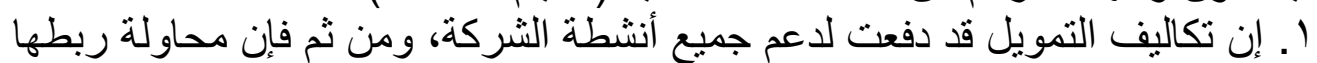

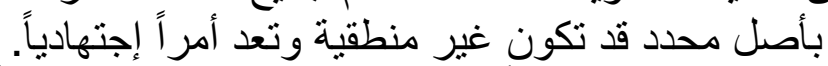

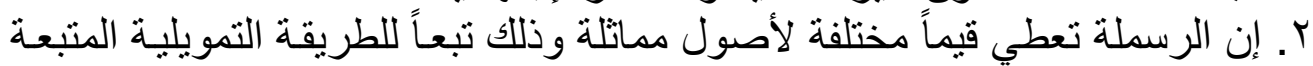

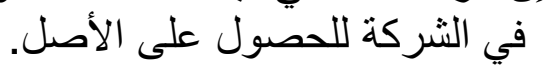
rـ. إن تحميل تكاليف الاقتر اض على على حسابات الدخل يظهر نتائج قابلة للمقارنة ويوفر

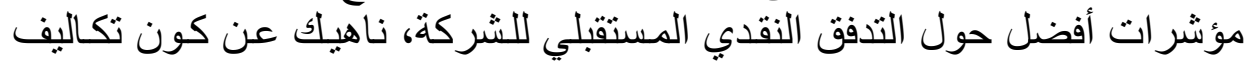

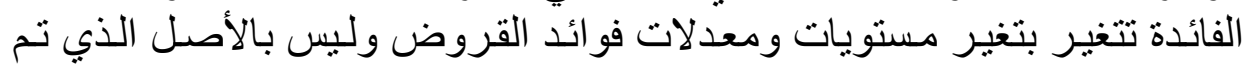
إقتناؤه أو الاقتر اض من أجل الحير الحصول عليه.

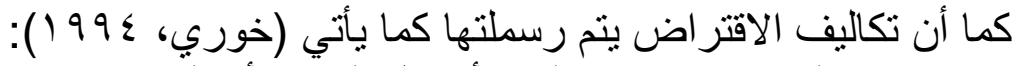

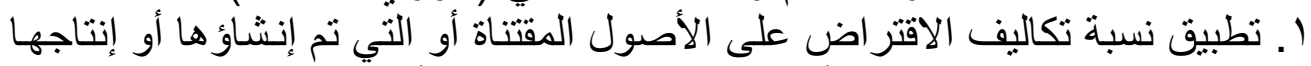
الى مدة طويلة لتجهيز ها للأغر اض الفي المعدة لإستعمالها أو لبيعها.

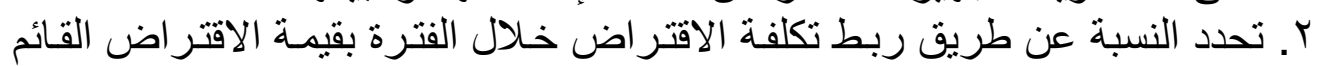

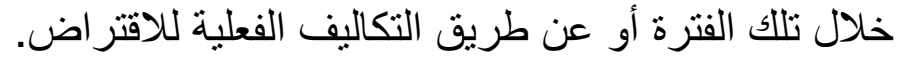




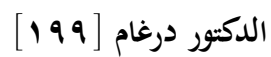

r. تبدأ رسمـلة تكـاليف الاقتر اض حسب رأي معسيير المحساسبة الدوليـة عند تـوفر الثروط الآتية (www.socpa.org.sa): أ. بدءء الإنفاق الفعلي على الأصل.

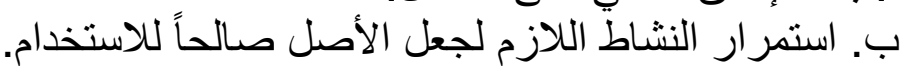

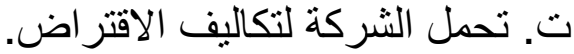

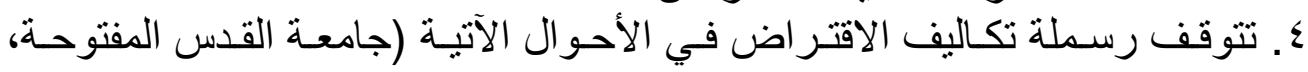

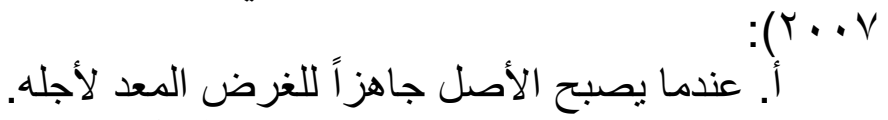

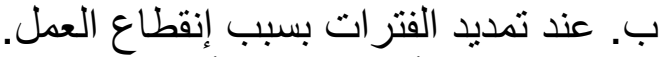

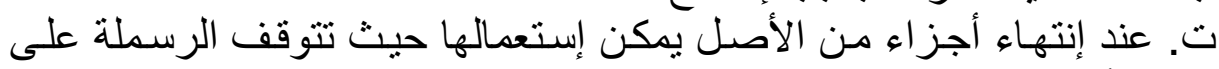

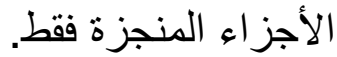

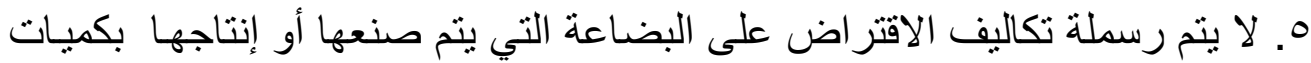
كبيرة و على أساس متكرر. 7 7. لا يجوز أن تزيد قيمة تكاليف الاقتر اض المرسملة على الأصل عن مبلغ تكاليف

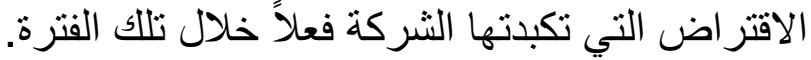

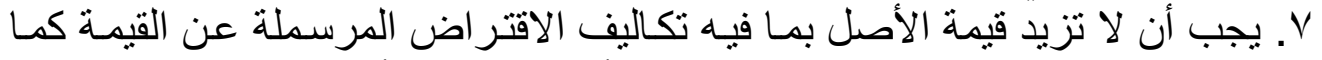

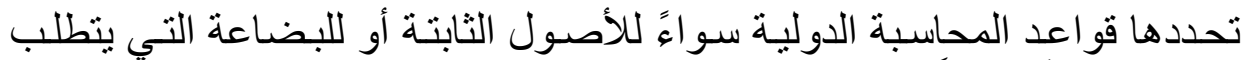
تجهيز ها وقتاً طويلاً.

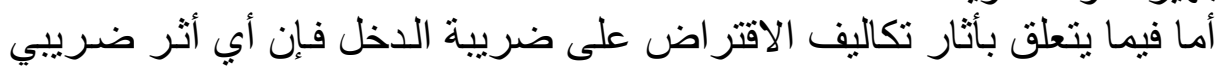

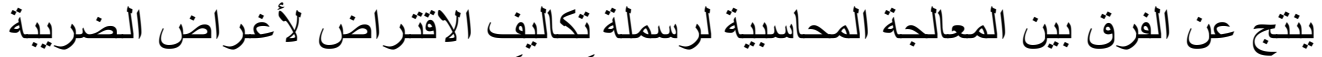
و المعالجة في القو ائم المالية تتم معالجته محاسبياً وفقاً لمعايير الدحاسبة الدولية (صيام، لإلية

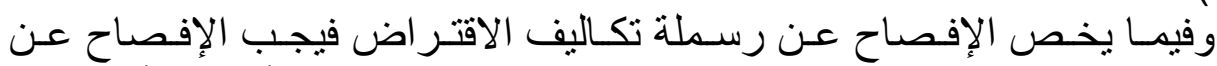

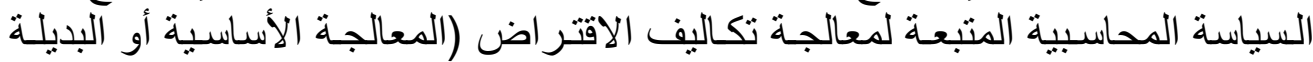

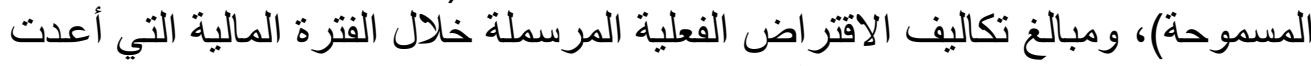

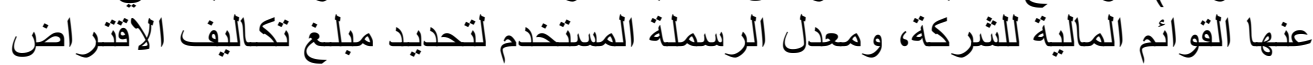

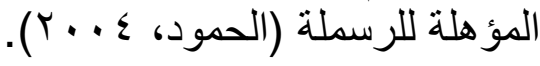

من أجل تحقيق أهداف الدراسة قام الباحث باستخدام الدنهج الوصفي التحليلي

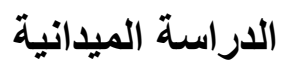
منهجية البحث المثان

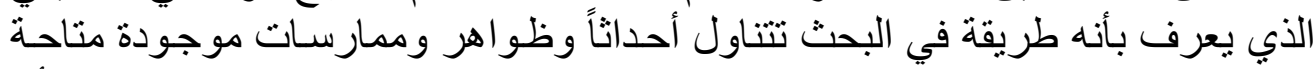

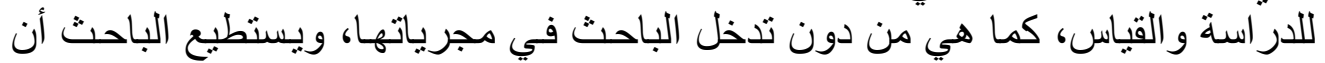

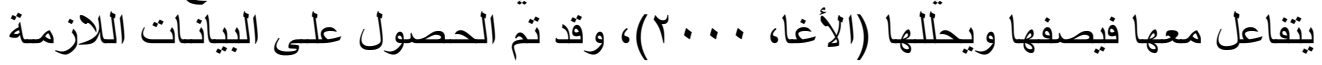

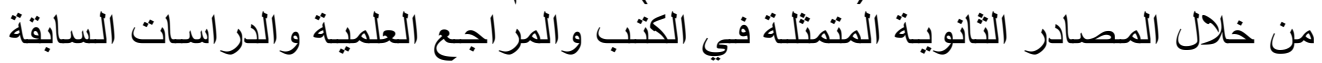

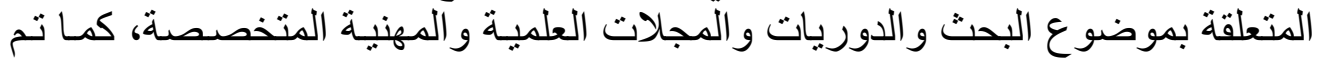


الحصول على البيانات و المعلومات الأولية عن طريق الاستبانة (Questionnaire) التي

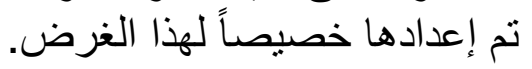

\section{الطرائق و الأساليب الإحصائية المستخذمة}

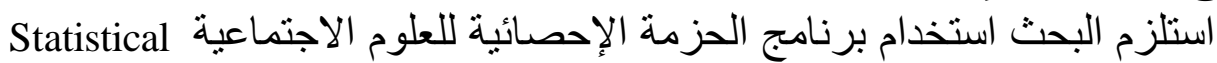
Package for Social Sciences (SPSS)

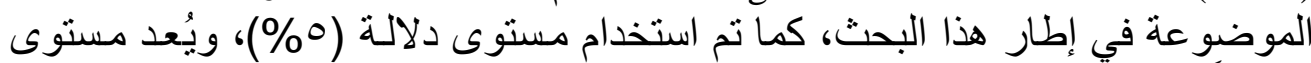

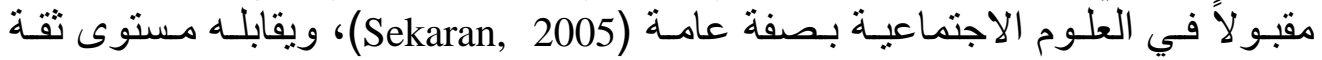
يساوي (09\%) لتفسير نتائج الدراسة التي يجريها الباحث، وتم استخدام الاختبار ات الإحصائية الآتية:

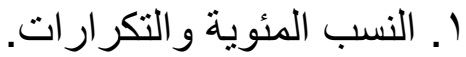

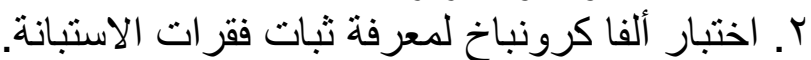

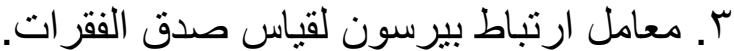

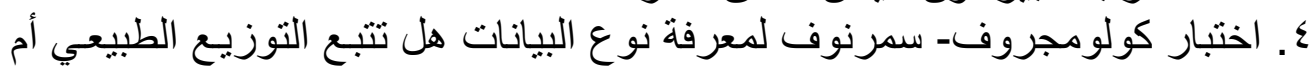
. لا

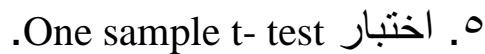

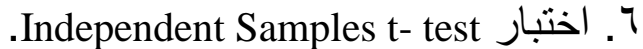

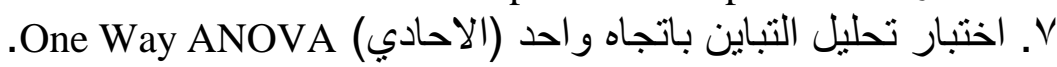

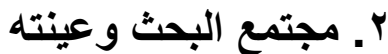

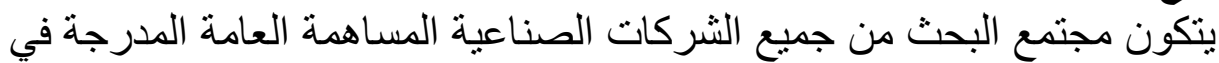

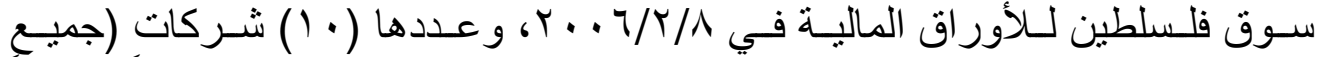

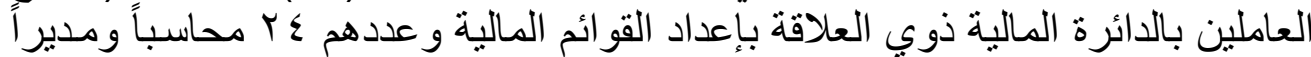

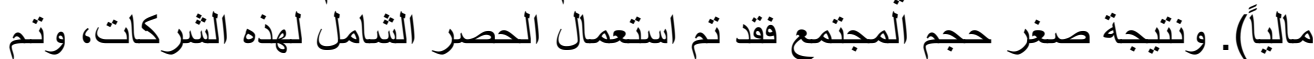
توزيع الاستبانات على المبحوثين باليد، وتم استرداد جميع الاستبانات وقد خضعت الثت الثت

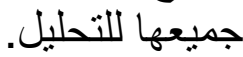

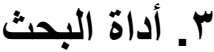

تمت مراجعة أدبيات المحاسبة الإدارية ومحاسبة التكاليف والمحاسبة الدولية

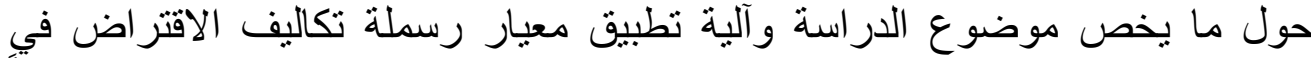

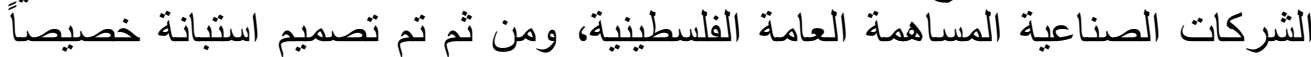
لجمع البيانات بحيث تغطي أسئلة الاستبانة فرضيات البحثية وهئ وقد تم تقسيم الاستبانة

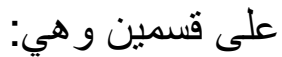
القسم الأول: يحتوي على المعلومات الثخصية للمجتمع ويتكون من (V) فقرات.

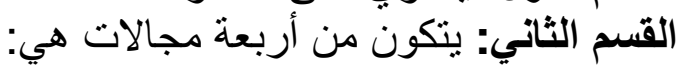
المجال الأولّ: يبين مدى إدر الك إدارة الثركات التهات الصناعية المساهمة العامـة الفلسطينية

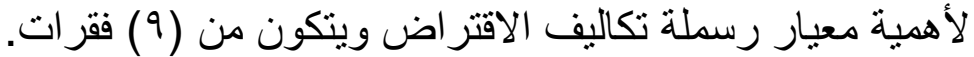

المجال الثاني: يبين مدى تطبيق الثركات الصناعية المساهمة العامة الفلسطينية لمعيار

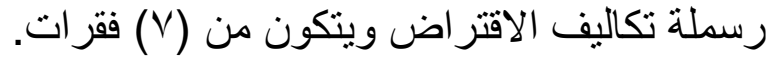




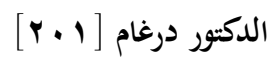

المجـال الثالث: يبـين مـدى إلتزز ام الـشركات الـصناعية المسـاهمة العامـة الفلسطينية

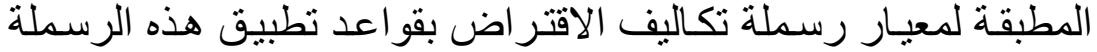

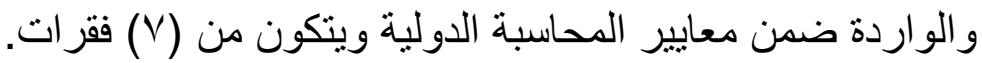

المجال الرابع: يبين مدى تطبيق الشركات الصناعية المساهمة العامة الفلسطينية أسساً

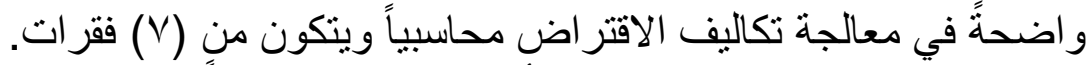

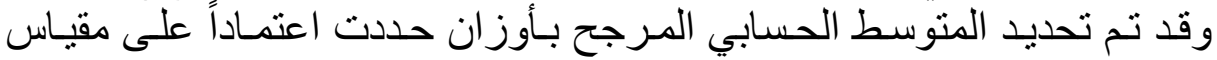
ليكرت ذي النقاط الخمس (Five Point Likert Scale) وذللك على النحو الآتي:

\begin{tabular}{|c|c|c|c|c|c|}
\hline غير مو افق بشدة & غير مو افق & محايد & مو افق & مو افق بشُدة & درجة المو افقة \\
\hline 1 & $r$ & $r$ & $\varepsilon$ & 0 & الوزن النسبي \\
\hline$\% r$. & $\% \varepsilon$. & $\% 7$. & $\% \wedge$. & $\% 1 \ldots$ & الوزن المئوي \\
\hline
\end{tabular}

\section{صدق الاستبانة وثباتها}

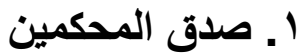

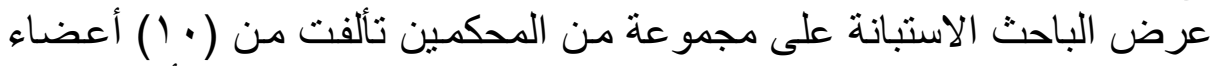

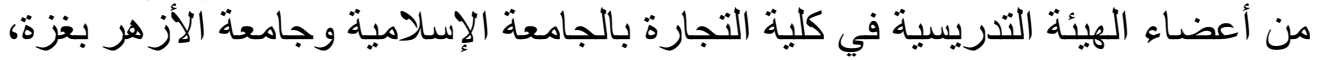

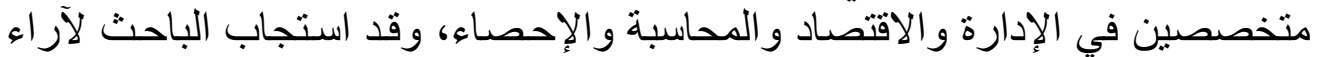

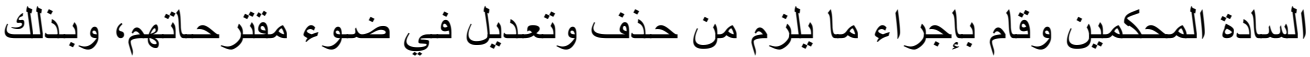
خرجت الاستبانة في صورتها المجاين النهائية.

r. صدق الاتساق الاخلي لفقرات الاستبانة:

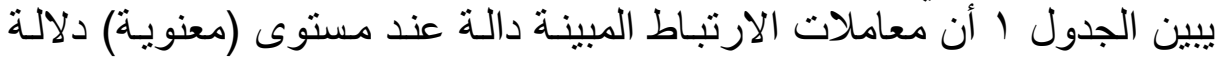

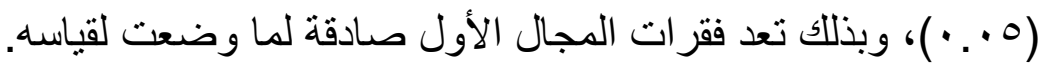

\section{الجدول الجال}

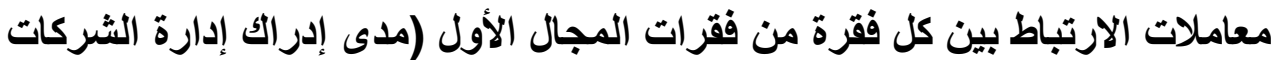

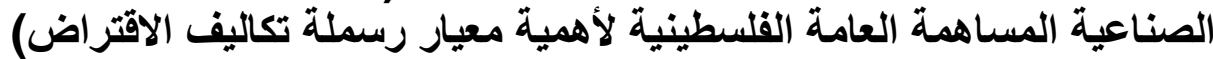

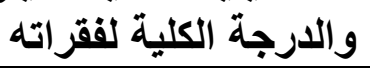

\begin{tabular}{|c|c|c|c|}
\hline 产 & 多羿. & 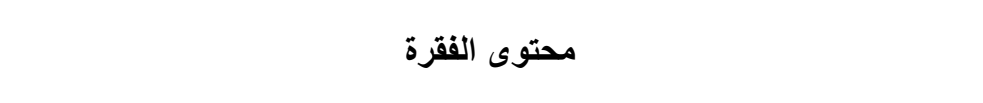 & 寻 \\
\hline$\cdot \cdots 1$ & $\cdot . T \leqslant Y$ & تدرك إدارة الثركة أهية إعداد القو ائم المالية وفقاً لمعايير المحاسبة الدولية. & 1 \\
\hline$\because \cdots 1$ & $\cdot . T \leqslant \Gamma$ & إعداد القو ائم المالية وفقاً لمعايير المحاسبة الدولية يزيد من ثقة المستفيدين منها. & r \\
\hline$\because \cdots$ & $\cdot .7 \vee \wedge$ & تلتوفر لدى إدارة الشركة المؤهلات العلمية و العملية الخبيرة بمعايير المحاسبة & r \\
\hline$\because \cdots$ & $\cdot . \wedge 74$ & 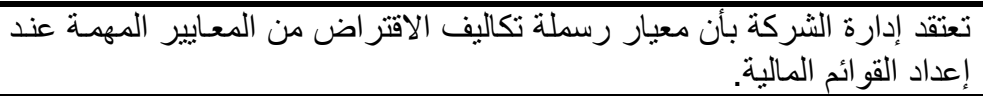 & $\varepsilon$ \\
\hline$\cdot \ldots$ & $\therefore .17$. & يُعد معيار رسملة تكاليف الاقتر اض من المعايير الواضحة المفهوم و التطبيق & o \\
\hline
\end{tabular}




\begin{tabular}{|c|c|c|c|}
\hline 多零 & 象霄. & محتوى الفقرة & 羿 \\
\hline & & بشكل جيد لإدارة الشركة. & \\
\hline$\because \cdots$ & $\cdot \wedge \leqslant \vee$ & الاقتر اضر معلومـات كافيـة لـدى إدارة الـشركة عـن أهميـة معيـار رسـملة تكـاليف & 7 \\
\hline$\because \cdots$ & $\cdot .710$ & تلشبيق معيار رسملة تكاليف الاقتر اض مهُّ لتبيان الوضع المالي بعدالة ووضوح & 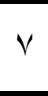 \\
\hline. .11 & $\because \varepsilon 91$ & يعد فهم معيار رسملة تكاليف الاقتر اض من قبل المحاسب المهني أمراً سهلاً. & $\Lambda$ \\
\hline$\because \cdots$ &. $.0 \mathrm{~V} \cdot$ & يمكن تحديد عناصر تكاليف الاقتر اض ورسملتها بشكل و اضـح ودقيق من قبل & 9 \\
\hline
\end{tabular}

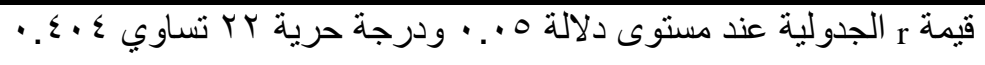

المجال الثاني

يشير الجدول r أن معاملات الارتباط المبينة دالة عند مستوى دلالة (0. . ))، وبذللك تعد فقر ات المجال الثاني صادقة لما وضعت لقارئ لقاسه.

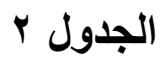

معاملات الارتباط بين كل فقرة من فقرات المجال الثاني (مدى تطبيق الثركات

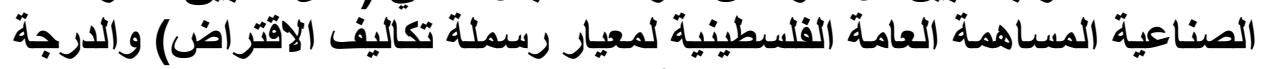
الكلية لفقراته

\begin{tabular}{|c|c|c|c|}
\hline 丞 & 3. & 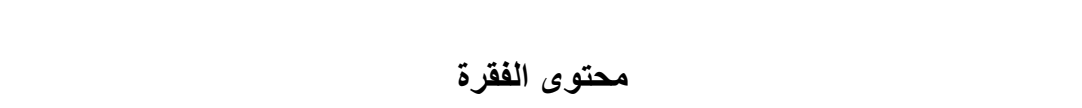 & 争 \\
\hline$\because \cdot r$ & $\because .0 \wedge \mathrm{V}$ & تمتلاك الثركة أصولها الثابتة من خلال تمويلها بالاقتر اض. & 1 . \\
\hline$\because \cdots$ & .710 & تحرص الشركة على تطبيق معيار رسملة تكاليف الاقتر اض. & 11 \\
\hline$\because+1$ & $\cdot \Sigma 71$ & 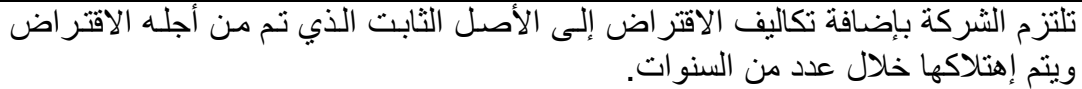 & ir \\
\hline$\because 7 \mathrm{~V}$ & 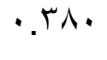 & تقوم الشركة بتحميل تكاليف الاقتر اض على قائمة الدخل بوصفها مصاريف إير اديه. & 14 \\
\hline$\because 19$ & $\ddots \leqslant \vee \uparrow$ & الأصد نفقات تمقيل الأصل الثابت المُصنع داخلياً جزءاً من تكلفة الأصل خلال مدة تصنيع & $1 \varepsilon$ \\
\hline$\because \cdots$ & $\because 7 \vee \varepsilon$ & 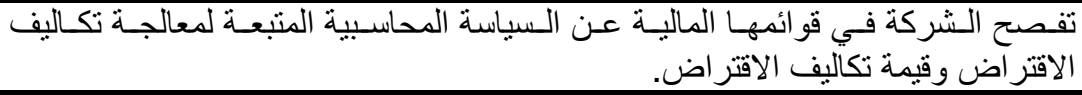 & 10 \\
\hline$\because \cdots$ & .701 & يساعد تطبيـق معيـار رسملة تكاليف الاقتر اض في الحصول على تكلفة أدق لاستثمار & 17 \\
\hline
\end{tabular}




$$
\text { الدكتور درغام [r+r }
$$

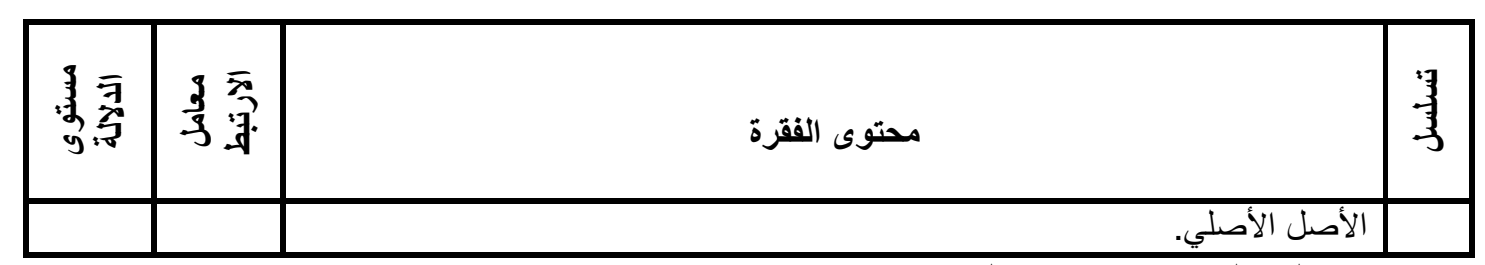

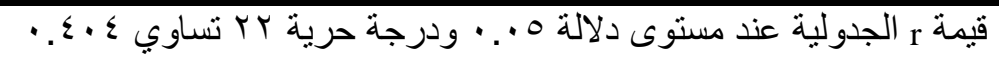

\section{المجال الثالث}

يظهر الجدول ب أن معاملات الارتباط المبينة دالة عند مستوى دلالة (0. . •)، وبذللك تعد فقر ات المجال الثالث صادقة الثارثا لماط وضعت لقياسه.

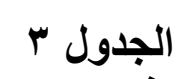

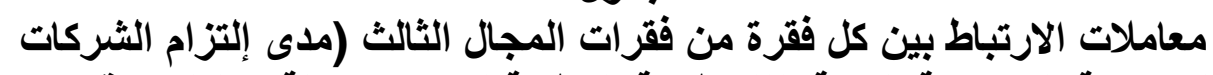

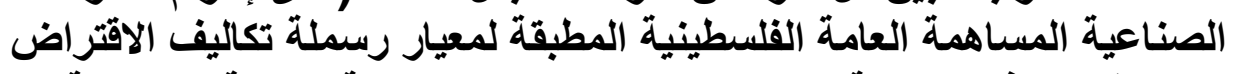

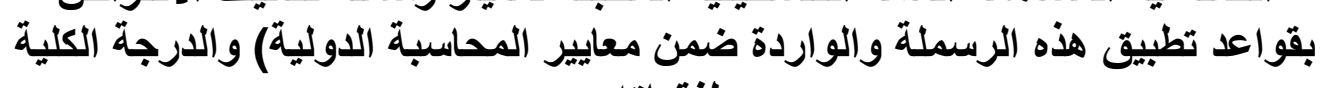

\begin{tabular}{|c|c|c|c|}
\hline 零 & 3.7.7. & محتوى الفقرة & 寻 \\
\hline$\because \cdots$ & $\because V 0 \leqslant$ & 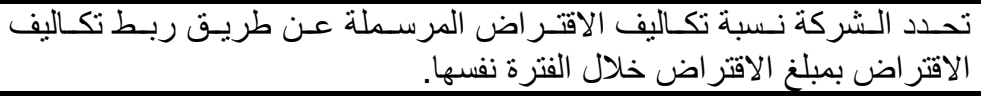 & IV \\
\hline$\because \cdots$ & $.7 V T$ & 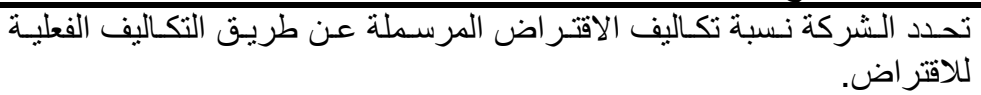 & 11 \\
\hline$\because \cdots$ & $\because \mathrm{Vo}$ & 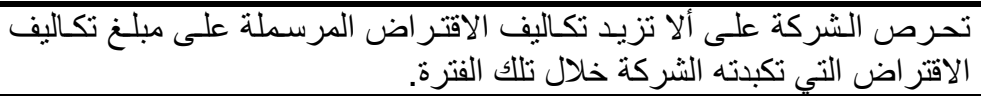 & 19 \\
\hline$\because \cdots$ & $.7 Y \varepsilon$ & للغزتزم الثركة بالتوقف عن رسملة تكاليف الاقتر اض عندما يصبح الأصل جـاهزاً & r. \\
\hline$\because \cdots$ & $\because .0 \mathrm{~V}$ & رسملتهما. الشركة بالإفصـاح في قو ائمها المالية عن قيمـة تكاليف الاقتر اض التي تم & Y) \\
\hline$\because \cdots$ & $\because V Y T$ & الدولية. الثركة بقو اعد رسملة تكاليف الاقتر اض الواردة ضسمن معايير المحاسبة & Tr \\
\hline$\because \varepsilon$ & .070 & رسملة تكاليف الاقتر اض تؤدى إلى نتائج صحيحة. & Tr \\
\hline
\end{tabular}
لفقراته

$$
\text { قيمة r الجدولية عند مستوى دلالة ه . . ودرجة حرية بr تساوي ع • ع. }
$$

يوضح الجدول 乏 أن معاملات الارتباط المبينة دالة عند مستوى دلالة (0. . •)؛

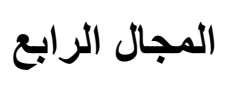

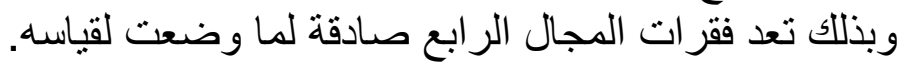

\section{الجدول ؛}


معاملات الارتباط بين كل فقرة من فقرات المجال الِّرابع (مدى تطبيق الشركات الماتِ

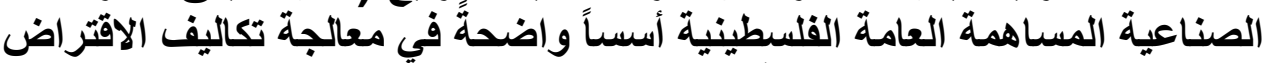
محاسبياً) و الدرجة الكلية لفقراته

\begin{tabular}{|c|c|c|c|}
\hline 美弯 & 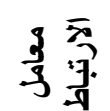 & محتوى الفقرة & 寻 \\
\hline$\because$. vo & $\cdot . \mathrm{rV} \cdot$ & 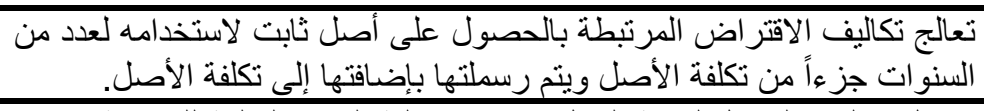 & \\
\hline$\because \cdots 1$ & 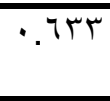 & 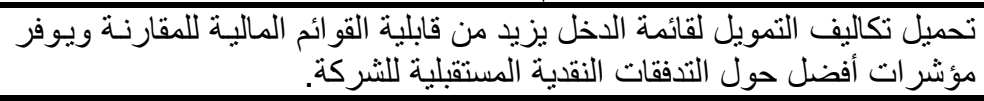 & 。 \\
\hline$\cdot .+\Gamma$ & $\therefore \varepsilon v$. & اعتقاد إدارة الثُركة أن رسملة تكاليف الاقتراض تزيد من سعر السهم السوقي. & 19 \\
\hline$\because \cdot 7$ & $.0 \leqslant r$ & الدخلق إدارة الشّركة أن تحميل تكاليف الاقتراض لقائمسة الدخل يخفض ضريبة & \\
\hline .. & $\because . . \cdot 9$ & 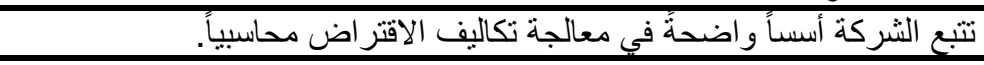 & ri \\
\hline. .04 & 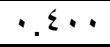 & تتبع الثر كة معدل رسملة معين في تحديد مبلغ تكاليف الاقتتراض المرسملة. & $\overline{r 9}$ \\
\hline$\because . \cdots 1$ & $.7 \% 0$ & تكاليف الاقتراض المر المتوسطة. المرجح لتكاليف الأقتراض كمعدل رسملة في تحديد & \\
\hline
\end{tabular}

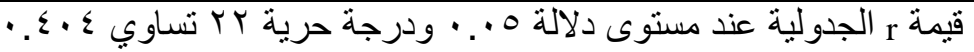

مeliability تبات الاستبانة

ا ـ طريقة التجزئة النصفية Split-Half Coefficient

تم إيجاد معامل ارتباط بيرسون بئه بين معدل الأسئلة فرديـة الرتبة ومعدل الأسئلة

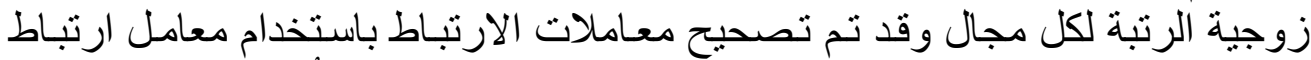

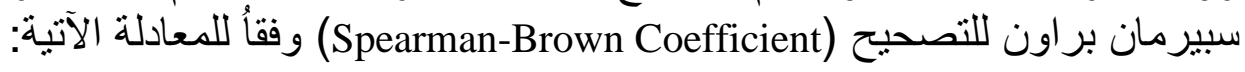
معامل الثبات = ثبات كبير نسبياً لفقر ات الاستبانة.

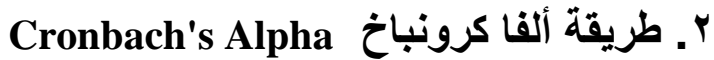

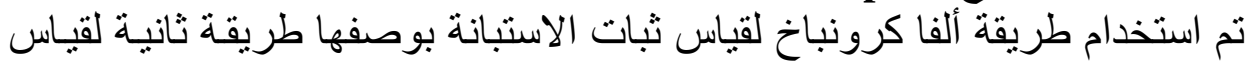

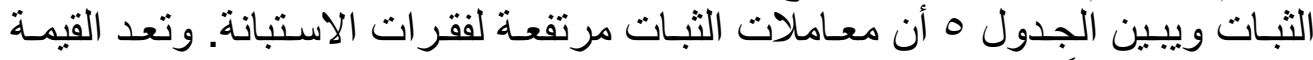

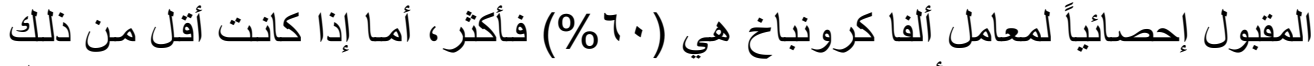

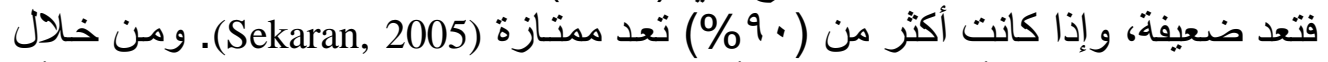

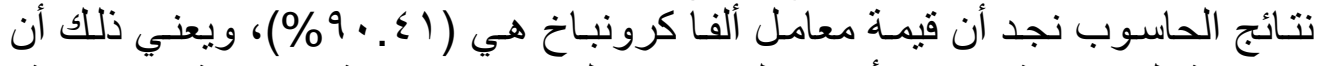

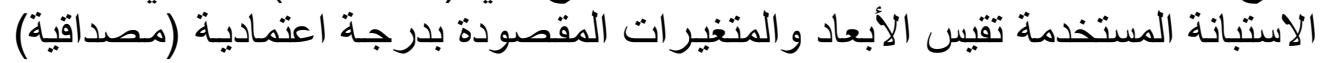
عالية. 
معامل الثبات (طريقة التجزئة النصفية و ألفا كرونباخ)

\begin{tabular}{|c|c|c|c|c|c|}
\hline \multirow[b]{2}{*}{ كرونباخ ألفا } & \multicolumn{3}{|c|}{ طريقة التجزئة النصفية } & \multirow[b]{2}{*}{ الفقرات } & \multirow[b]{2}{*}{ المجال } \\
\hline & المنتوية & معامل الارتباط & الارتباط & & \\
\hline$\cdot .1001$ & $\because \cdots$ & $\therefore \wedge .9 \vee<4$ & $\cdot .7 \Lambda \cdot r$. & 9 & الأول \\
\hline$\cdot .7 \Lambda \cdot V$ & $\because \cdots$ & $\because$ VONYTV & .71 .7 & $\mathrm{~V}$ & الثاني \\
\hline$\because \vee \wedge \varepsilon r$ & $\therefore \cdots$ & $\cdot . \wedge \leqslant \vee r Y q$ &. $\mathrm{VTOO}$ & V & الثالث \\
\hline$\cdot . \vee \backslash \wedge \wedge$ & $\because \cdot$ &.$\Lambda \cdot \pi Y 00$ & $.7 V 0 \leq$ & V & 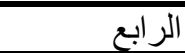 \\
\hline$\cdot . \wedge \wedge \vee 0$ & $\because \cdots$ &.$\wedge 901 Y \mu$ & $\cdot . \Lambda \mid Y \varepsilon$ & $r$. & لجميع الفقر ات \\
\hline
\end{tabular}

تحليل البيانات

تم في هذا الجزء تحليل البيانات الخاصة بالقسم الأول من الاستبانة والتي تحساول

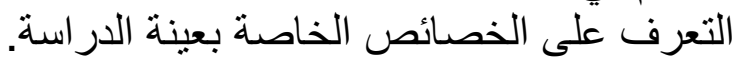

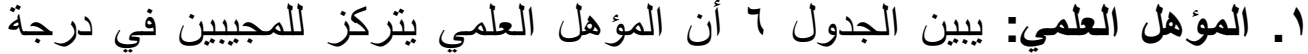

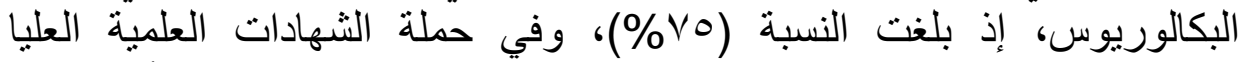

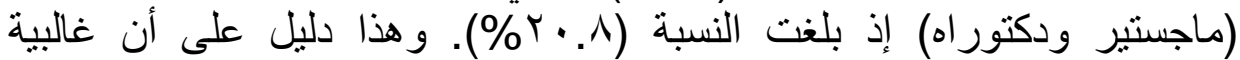

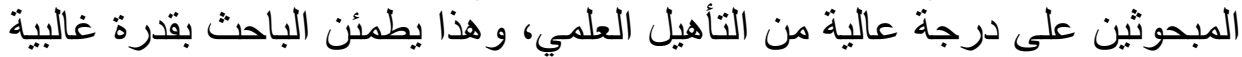

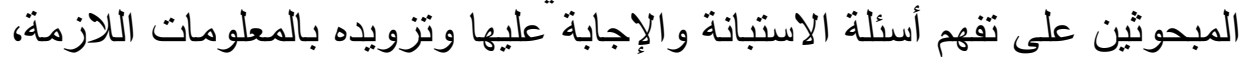
كما أن المؤهل العلمي مؤشر على قدرة وكفاءة المبحوثين.

\begin{tabular}{|c|c|c|}
\hline \multicolumn{3}{|c|}{ الجدول 7} \\
\hline النسبة المئوية & التكرار & المؤهل العلمي \\
\hline$\varepsilon . r$ & 1 & دبلوم \\
\hline Vo.. & 11 & بكالوريوس \\
\hline 17.7 & $\varepsilon$ & ماجستير \\
\hline$\varepsilon . r$ & 1 & دكتور اه \\
\hline $1 \cdots$ & $T \varepsilon$ & المجموع \\
\hline
\end{tabular}

r. التخصص العلمي: نلاحظ من الجدول V أن التخصص العلمي للمبحوثين وكما كان

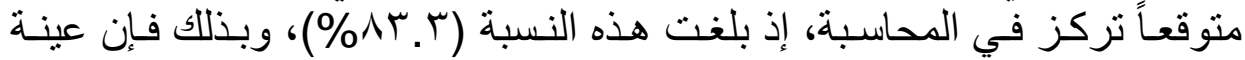

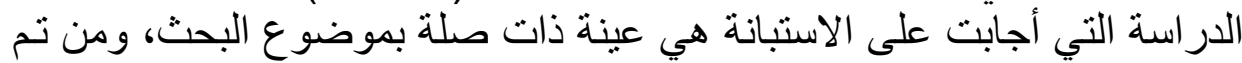

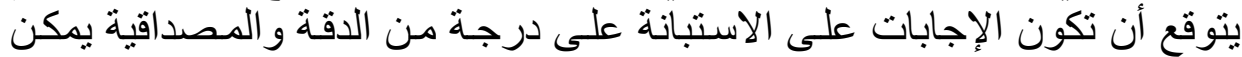

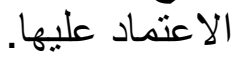




\begin{tabular}{|c|c|c|}
\hline النسبة المئوية & التكرار & التخصص العلمي \\
\hline הז.r & r. & محاسبة \\
\hline 17.8 & $\varepsilon$ & إدارة أعمال \\
\hline$\because \cdot$ & . & اقتصـاد \\
\hline $1 \ldots$ & $r \xi$ & المجموع \\
\hline
\end{tabular}

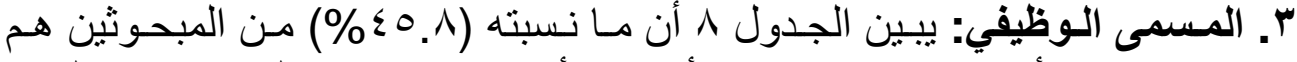

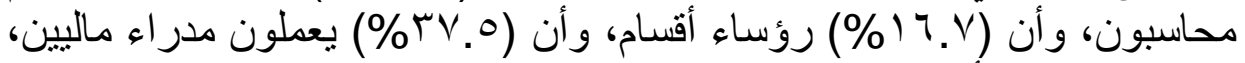

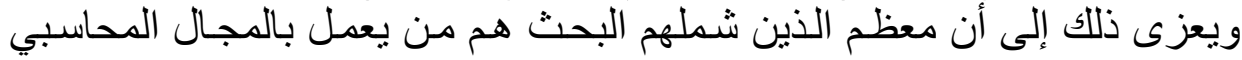

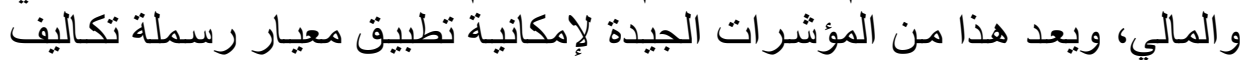
الاقتر اض في الثركات الصناعية المساهمة العامة.

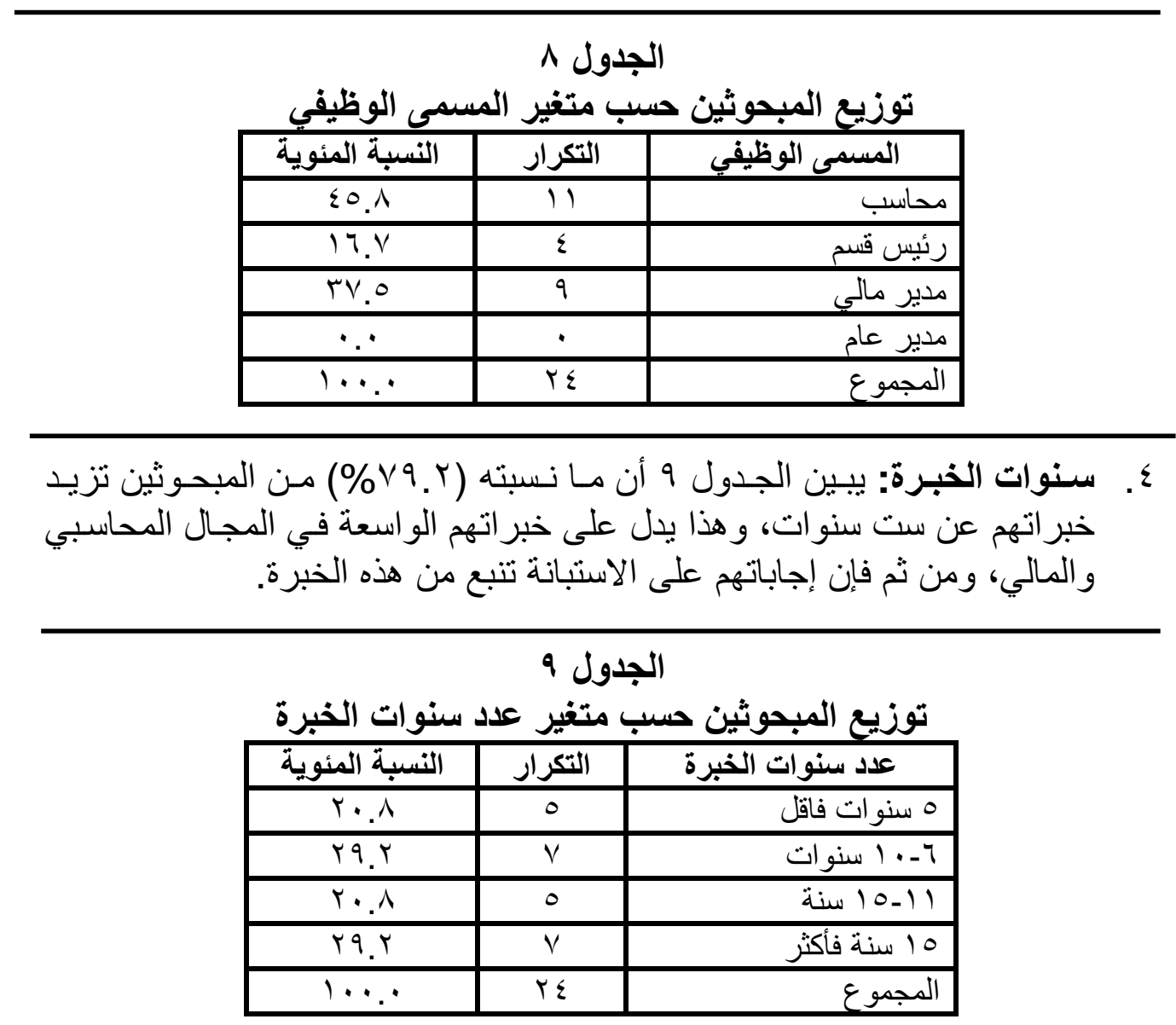




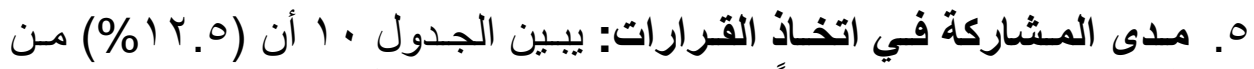

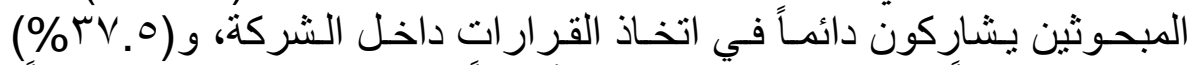

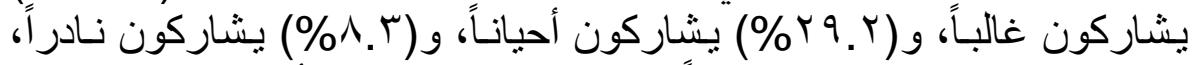

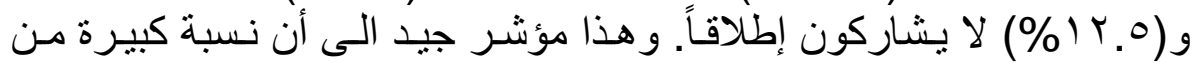

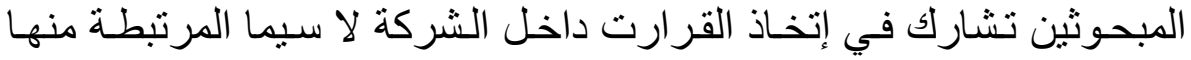

بالنواحي الدحاسبية وآلمالية.

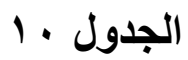

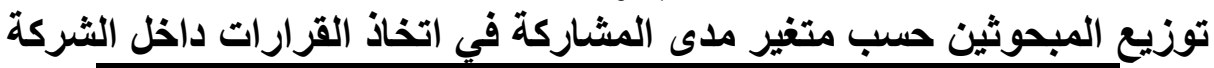

\begin{tabular}{|c|c|c|}
\hline النسبة المئوية & 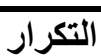 & مدى المشاركة في اتخاذ القرارات داخل الثركة \\
\hline $1 Y .0$ & $r$ & دائماً \\
\hline$r Y_{.0}$ & $\bar{q}$ & غالبًا \\
\hline$\overline{r q . r}$ & $\bar{v}$ & أحيانًا \\
\hline$\Lambda . \Gamma$ & $\bar{r}$ & نادراً \\
\hline IY.0 & $\bar{r}$ & لا ينت ذلك إطلاقاً \\
\hline $1 \cdots \cdot$ & $r \varepsilon$ & 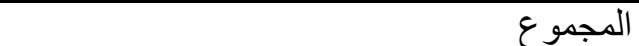 \\
\hline
\end{tabular}

7. عدد الدورات التدريبية في مجال معايير المحاسبة الدولية: يتضح من الجدول

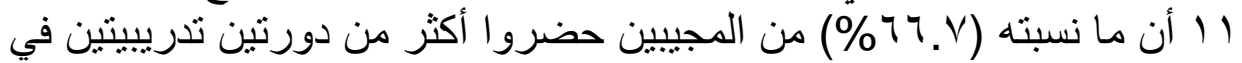

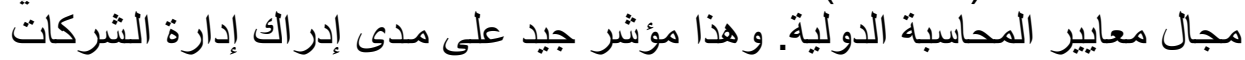

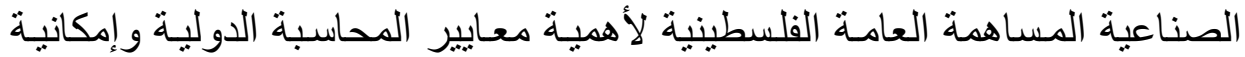
تطبيق معيار رسملة تكاليف الاقتر اض في تلك الثركات.

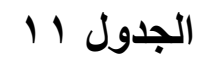

توزيع المبحوثين حسب متغير عدد الدورات التدريبية

\begin{tabular}{|c|c|c|}
\hline النسبة المئوية & 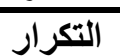 & عدد الدورات التدريبية \\
\hline$\pi r . r$ & A & دورة \\
\hline
\end{tabular}




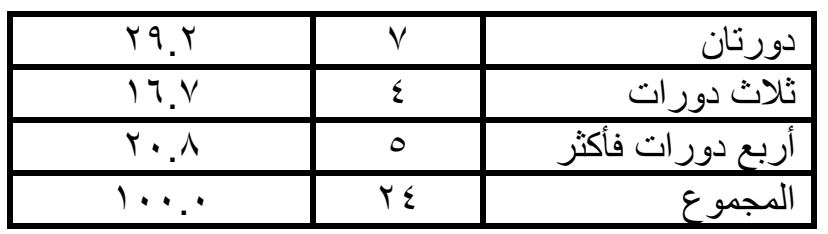

V. القتاعة الثخصية بأهمية إعداد القوائم الماليـة وفقاً لمعايير المحاسبة الدوليـة:

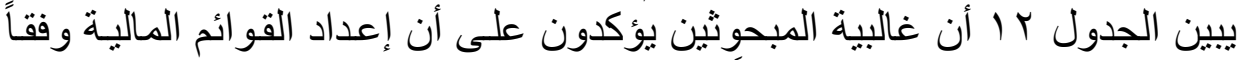

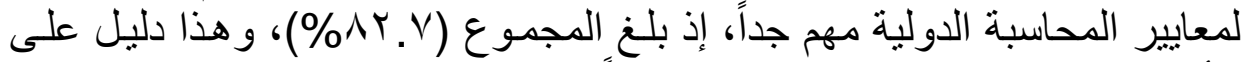

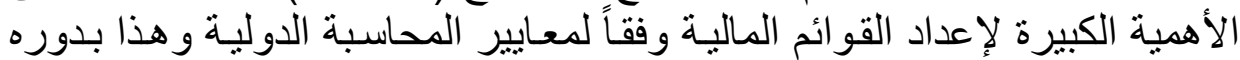
يزيد من ثقة المستفيدين من هذه القو ائم.

\section{الجدول باعة الجيجا}

توزيع المبحوثين حسب متغير مدى القتاعة الشخصية بأهمية إعداد القوائم المالية وفقاً لمعاييز المحاسبة الداعة الدولية المبية

\begin{tabular}{|c|c|c|}
\hline النسبة المئوية & التكرار & مدى القتاعة الثخصية بأهمية إعداد القوائم المالية \\
\hline $01 . \varepsilon$ & $1 \varepsilon$ & مهمة جداً \\
\hline r. & $\Lambda$ & مهمة \\
\hline$\Lambda . r$ & $r$ & متوسطة الأهمية \\
\hline$\because \cdot$ & . & غير مهمة \\
\hline$\because \cdot$ & . & غير مهمة إطلاقًاً \\
\hline $1 \cdots$ & $r \varepsilon$ & المجموع \\
\hline
\end{tabular}

\section{اختبار وتحليل فرضيات البحث}

اختبار التوزيع الطبيعي (اختبار كولمجروف- سمرنوف (1- Sample K-S)

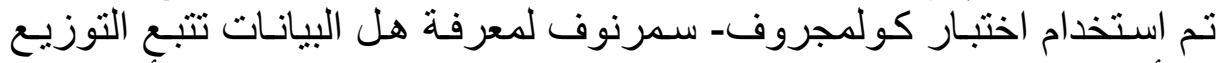

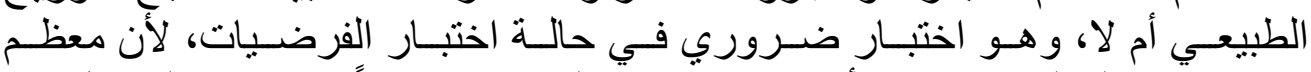

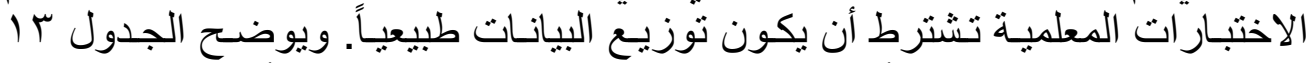

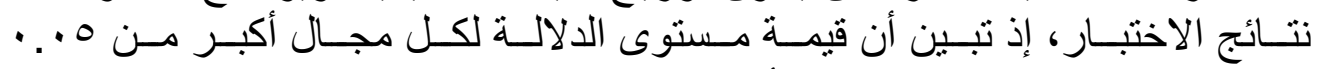
( sig > > 0.05)، وهذا يدل على أن البيانـات تتبع التوزيع الطبيعي ويجب استخدام الاختبار ات المعلمية.

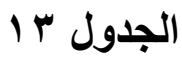

اختبار التوزيع الطبيعي ( One-Sample K-S) 


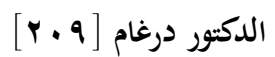

\begin{tabular}{|c|c|c|c|c|}
\hline الحسابي & الدلالة & قيمة الاختبار Z & الفقرات & المجال \\
\hline ५.9人 & $.0 \% \wedge$ & $\cdot \wedge \cdot \varepsilon$ & 9 & الأول \\
\hline$r .094$ & • & .0 .0 & V & الثاني \\
\hline T.901 & $\because V \vee \cdot$ & $.77 \leqslant$ & V & الثالث \\
\hline$r .077$ & $\cdot . \mathrm{\Lambda} \mathrm{V}$ & $\cdot .9 \cdot \varepsilon$ & V & الر ابع \\
\hline r.VVT & .990 & $\cdot . \leqslant 1 V$ & $r$. & جميع المجالات \\
\hline
\end{tabular}

تحليل فرضيات البحث

تم استخدام اختبار tللعينة الو احدة (One Sample t-test) لتحليل فقر ات الاستبانة

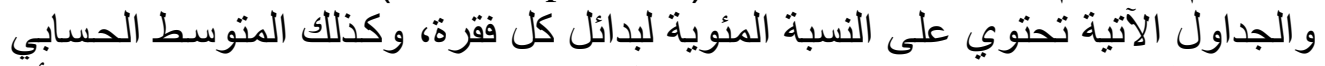

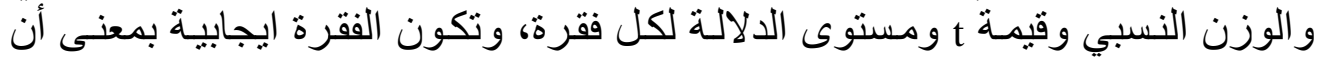

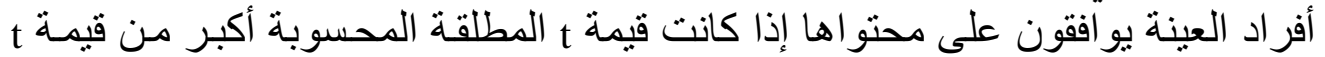

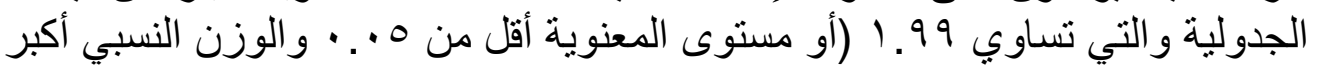

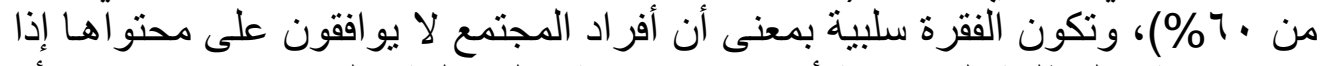

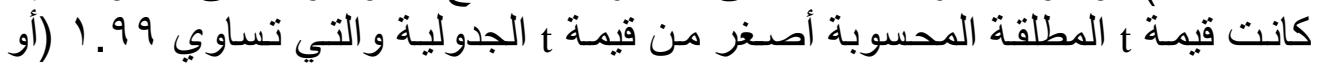

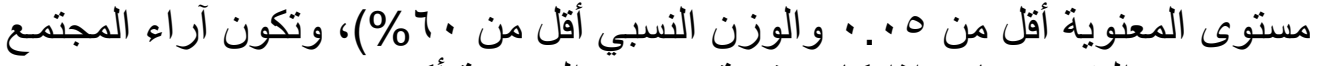

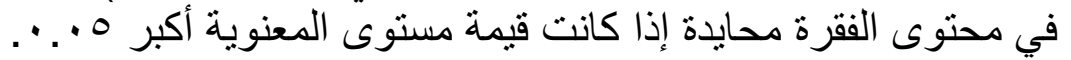

نتائج الفرضية الأولى: تدرك إدارة الشركات الصناعية المساهمة العامـة القلسطينية

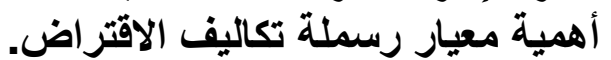

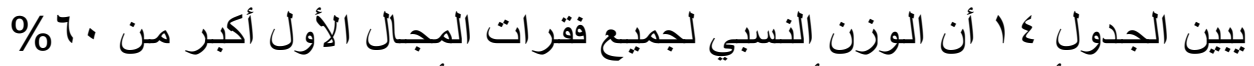

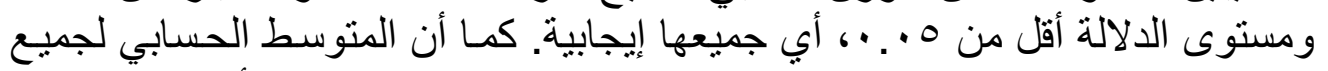

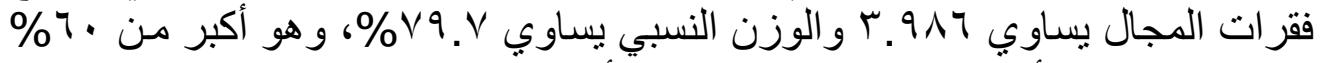

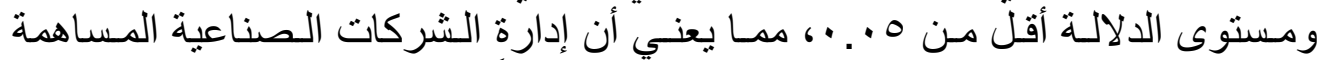
العامة الفلسطينية تدرك أهمية إعداد القو ائم المالية وفقاً لمعايير المحاسبة الدولية بصفة المانة

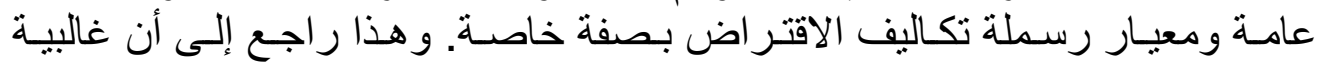

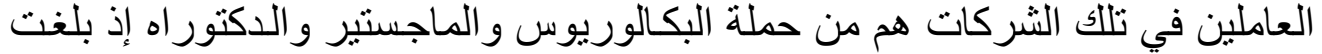

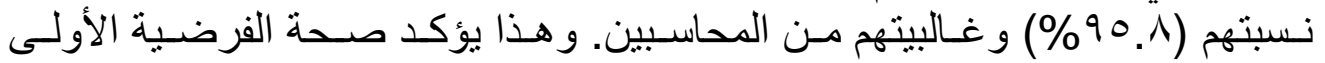




\begin{tabular}{|c|c|c|c|c|c|}
\hline 曻劣 & 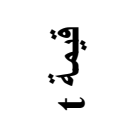 & $\begin{array}{l}\overline{7} \\
.39 \\
3\end{array}$ & 可 $\overline{3}$ & 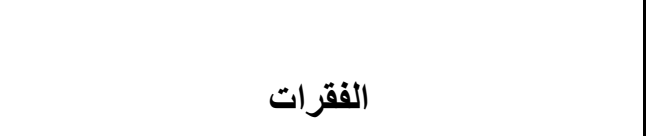 & 寻 \\
\hline$\because \cdots$ & V.rT. & 10." & $\varepsilon$. ro. & 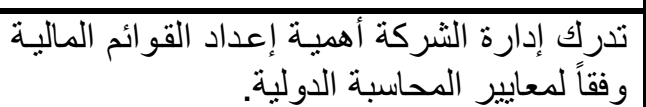 & 1 \\
\hline$\because \cdots$ & IY.As. & $9 \cdot .1$ & $\leqslant .0 \leqslant r$ & 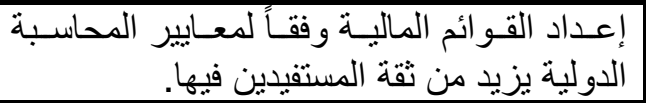 & r \\
\hline$\because \cdots$ & $0.9 \leqslant \mu$ & $\wedge \cdot . \wedge$ & $\varepsilon . \varepsilon r$ & 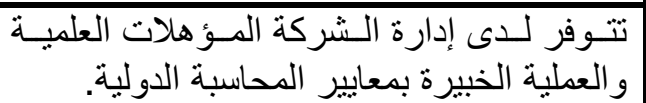 & r \\
\hline$\because \cdots$ & $0 . \cdot \leq r$ & $V V_{0} 0$ & r.Avo & 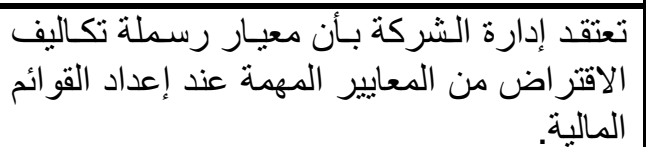 & $\varepsilon$ \\
\hline$\because \cdots$ & אוז. & vo." & r.vo. & 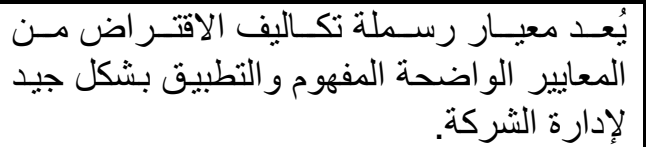 & 0 \\
\hline$\because \cdots$ & $r . v V$ & VI.V & r.0Nr & 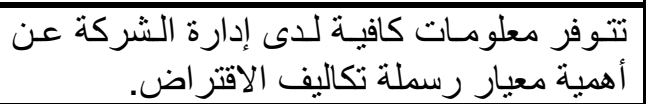 & 7 \\
\hline$\because \cdots$ & $9 . .$. & $\wedge r_{0} 0$ & $\varepsilon .1$ Yo & 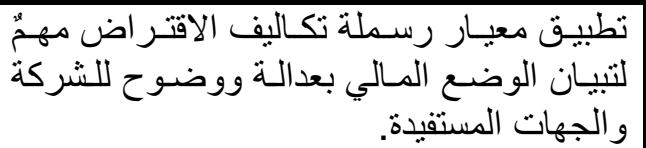 & $\checkmark$ \\
\hline$\because \cdots$ & $\varepsilon .911$ & V৭. & $r .90 \Lambda$ & 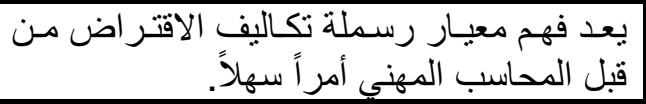 & $\wedge$ \\
\hline$\because \cdots$ & $\varepsilon .7 Y \wedge$ & vo." & r.vo. & 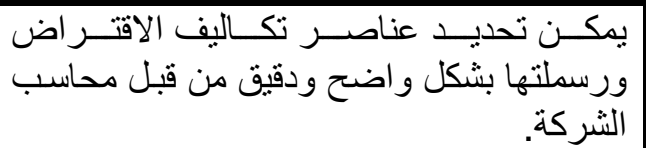 & 9 \\
\hline$\because \cdots$ & 1.771 & Vq.V & r.9人7 & لجميع الفقرات & \\
\hline
\end{tabular}

نتائج الفرضية الثانية: تطبق الثركات الصناعية المساهمة العامة الفلسطينية معيار

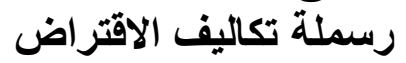

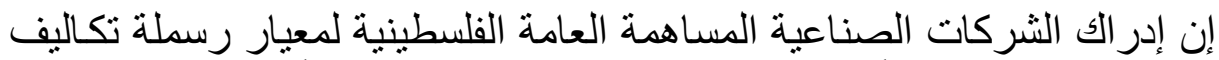

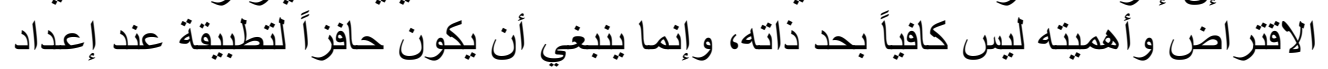

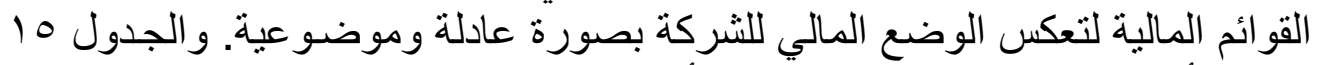

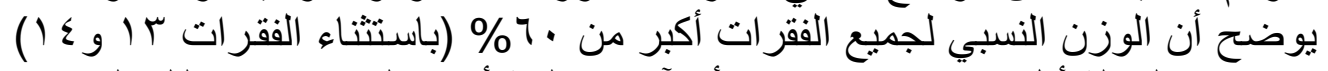

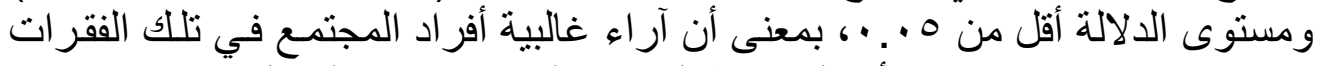

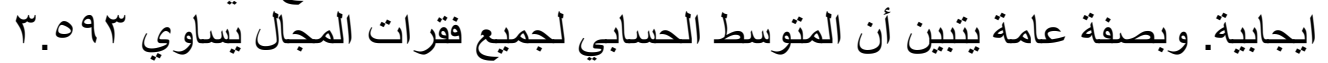

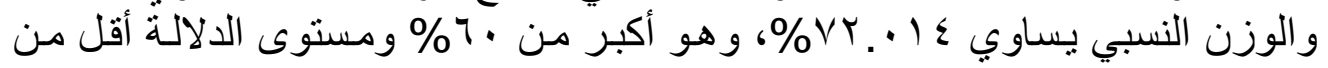




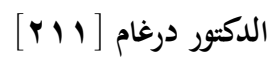

ه. . ، ممـا يعني أن الشركات الصناعية المساهمة العامـة الفلسطينية تطبق معيـار رسملة تكاليف الاقتر اض إلى حدٍ كبير ـ و هذا يؤكد صحة الفرضية الثنانية وقبولها.

\begin{tabular}{|c|c|c|c|c|c|}
\hline & تك & . & 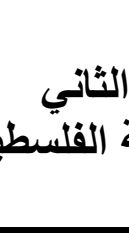 & 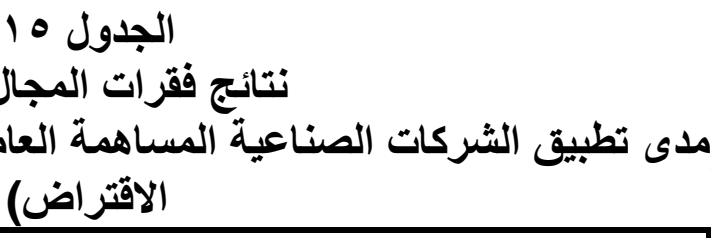 & \\
\hline 桑牙 & "3. & 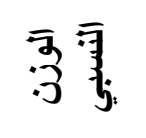 & 可高费 & الفقرات & 寻 \\
\hline . & r.A74 & VT.r & r.Tार & 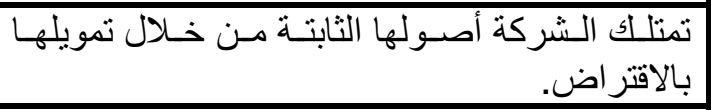 & 1. \\
\hline$\cdots v$ & T.9Tr & vi.v & T.0人T & الاقتر اض الشركة على تطبيق معيار رسملة تكاليف & 11 \\
\hline & $\varepsilon .9 V$ & vo. & r.Vo. & 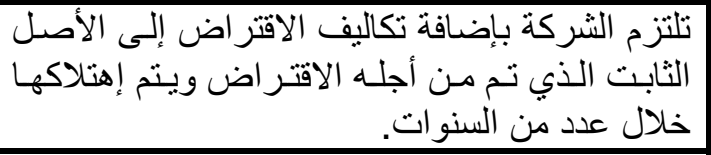 & ir \\
\hline $.0 Y \varepsilon$ & $.7 \leqslant V$ & or.o & T.AVO & 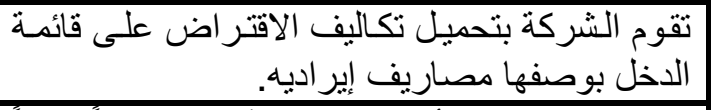 & ir \\
\hline$\because \cdot v 1$ & 1.190 & $T V .0$ & T.TYo & 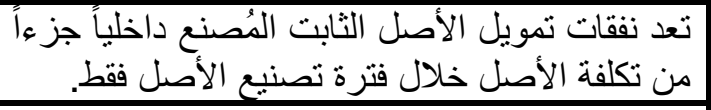 & $1 \varepsilon$ \\
\hline & 纟.OTV & VV.O & r.Avo & 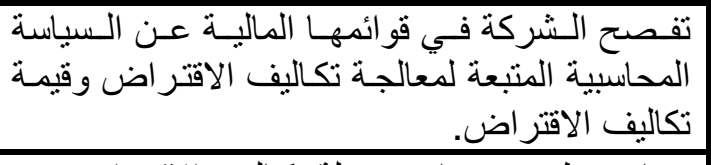 & 10 \\
\hline & $\longrightarrow . \wedge \varepsilon \Gamma$ & A..V & $\varepsilon . \wedge r$ & 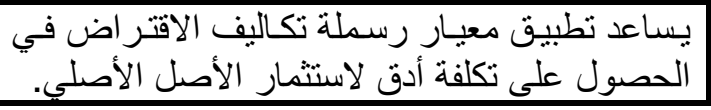 & 17 \\
\hline$\cdots$ & $\xi .079$ & $V T_{.} \cdot 1 \varepsilon$ & $r .094$ & لجميع الفقرات & \\
\hline
\end{tabular}

نتـائج الفرضسية الثالثة: تلتزم الشركات الصناعية المساهمة العامسة القلسطينية

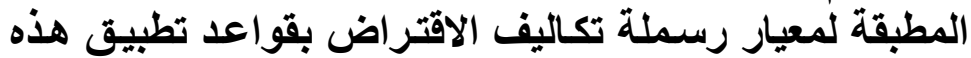
الرسملة والواردة ضمن معايير المحاسبة الدولية. 


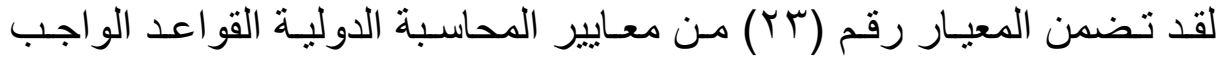

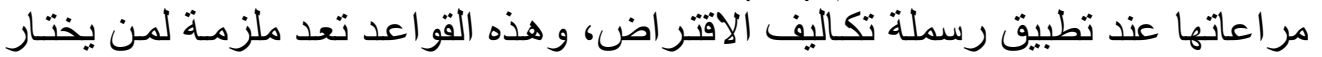

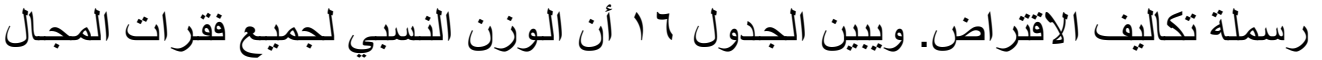

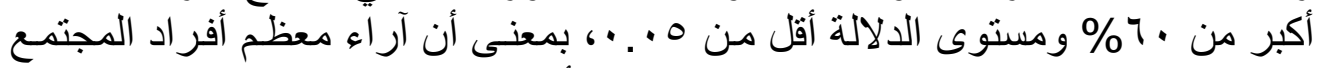

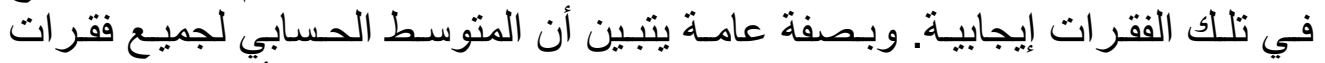

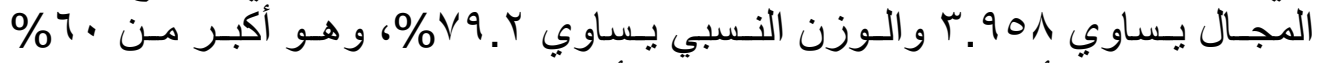

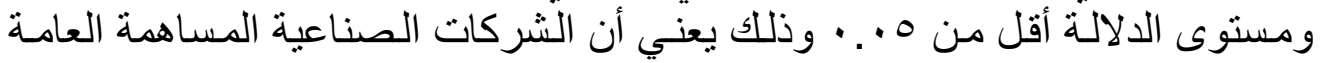
الفلسطينية المطبقة لمعيار رسملة تكاليف الاقتر اض تلتزم بقو اعد تطبيق هذه الرسملة

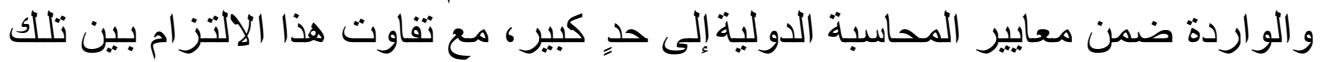
القو اعد. و هذا يؤكد صحة الفرضية الثالثة وقبولها.

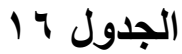

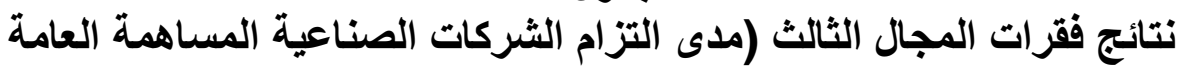

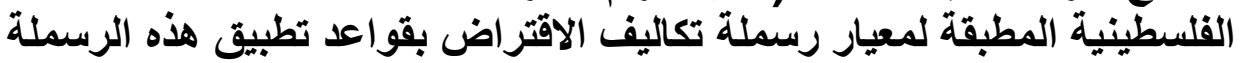
والواردة ضمن معايير المحاسبة الدولية)

\begin{tabular}{|c|c|c|c|c|c|}
\hline 寻学 & 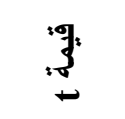 & 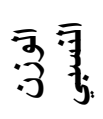 & 可 & 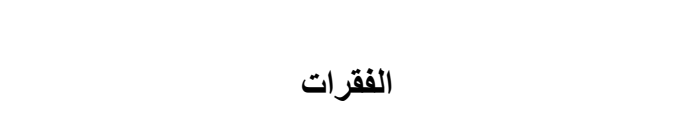 & 寻 \\
\hline$\because \cdots 7$ & $r . r_{1}$ & $V Y .0$ & r.0YT & 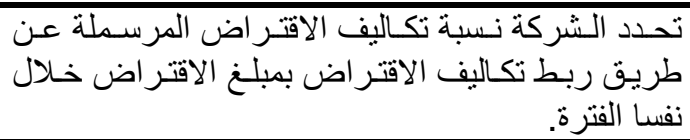 & iv \\
\hline$\cdots 1$. & r.А९ & vo. & r.vo. & تحريق التكاليف الفعلية للافتر اضليف الاقتر اض المرسـلة عـن & 11 \\
\hline & $\varepsilon .911$ & VQ.r & r.901 & 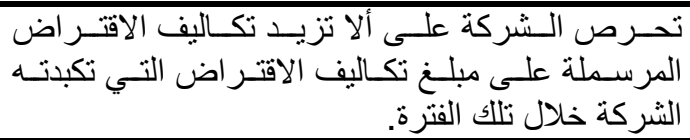 & 19 \\
\hline$\because \cdots 1$ & r.V10 & vo. & r.vo. & 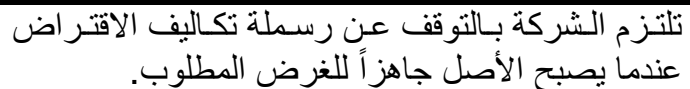 & $r \cdot$ \\
\hline$\because \cdots$ & 0.940 & 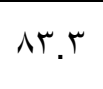 & 纟.17V & 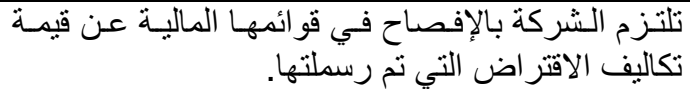 & r) \\
\hline$\because$ & $0 . \wedge \vee \leqslant$ & $\wedge \cdot . \cdot$ & & تلتزن معايير المحاسبة الدولية. تكاليف الاقتر اض الواردة & rt \\
\hline$\therefore \cdots$ & $1 \cdot .101$ & $\wedge 9 . \mathrm{r}$ & $\varepsilon .201$ & رسملة تكاليف الاقتر اض يؤدي إلى نتائج صحيحة. & $r \mu$ \\
\hline$\because \cdots$ & V.YVT & $V q . r$ & $r .901$ & ل لجميع الفقرات & \\
\hline
\end{tabular}

نتائج الفرضية الرابعة: تطبق الثركات الصناعية المساهمة العامة الفلسطينية أسساً

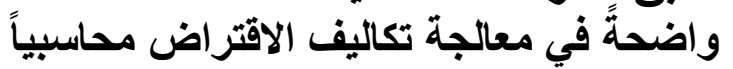

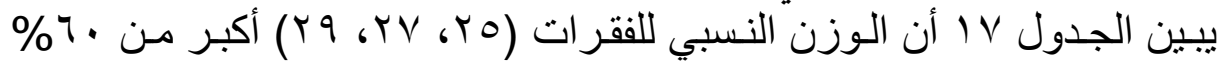

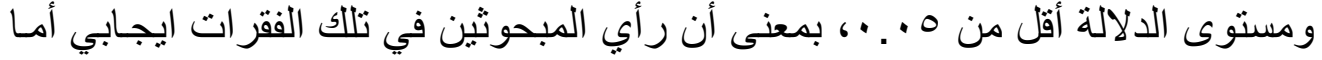




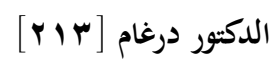

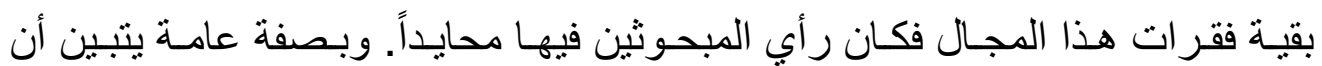

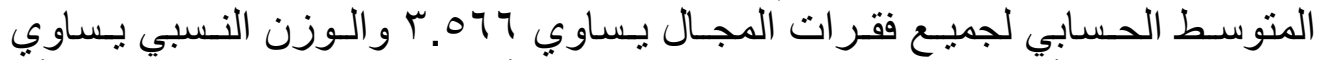

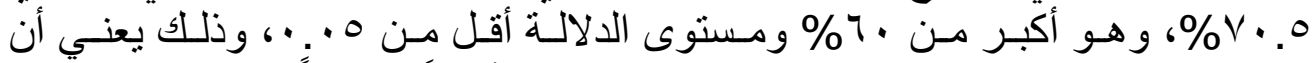

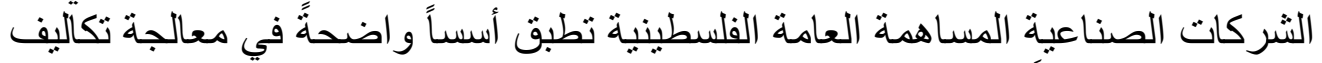
الاقتر اض محاسبياً إلى حدٍ كبير ـ و هذا يؤكد صحة الفرضية الرية الر ابعة وقبو لها.

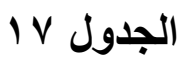

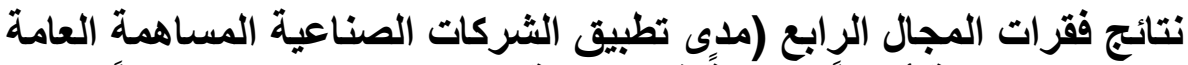

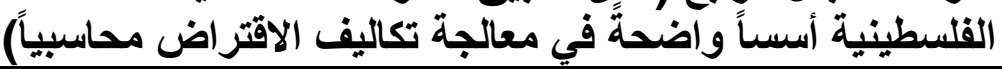

\begin{tabular}{|c|c|c|c|c|c|}
\hline 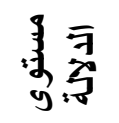 & :बु, & 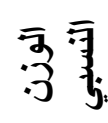 & 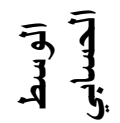 & الفقرات & 当 \\
\hline$\because \cdots$ & 0.181 & Vq. & r.901 & 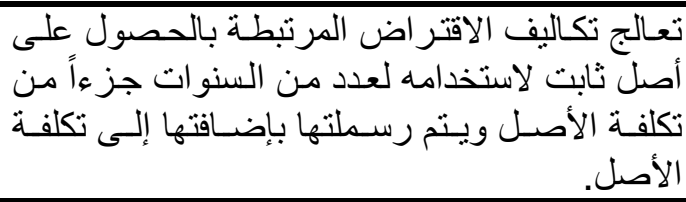 & $r \varepsilon$ \\
\hline .119 & 1.179 & $7 V .0$ & סעr.r & 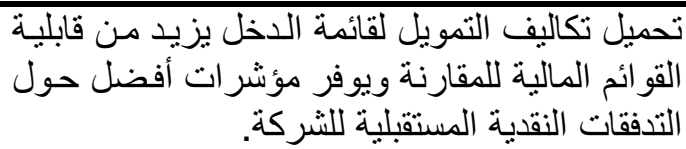 & ro \\
\hline ו & r.rqA & 79.7 & $r . \leqslant 0 \wedge$ & 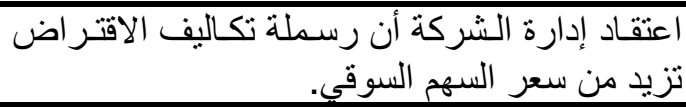 & $r 7$ \\
\hline$\because$ r^o & 1.97 & $T E . Y$ & r.Y.A & 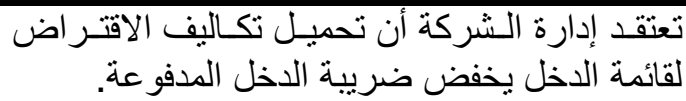 & $r V$ \\
\hline$\because \cdots$ & 0.117 & $V 7 . V$ & سז. r & الافتبـر اض الشركة محاسبياً. & rᄉ \\
\hline.$V T$ & $1 . \wedge \wedge 1$ & $77 . V$ & אسז.ץ & 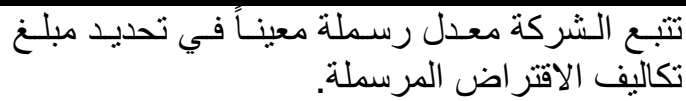 & rq \\
\hline$\because 10$ & Y.TYV & $V \cdot$. & r... & 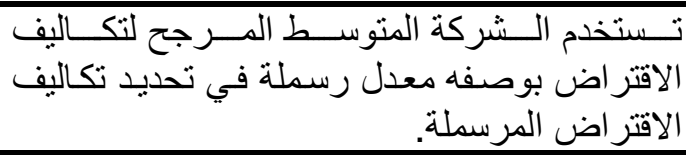 & r. \\
\hline$\because v V$ & T.YMI & $V \cdot .0$ & r.077 & لجميع الفقر ات & \\
\hline
\end{tabular}

نتائج القرضية الخامسة: لا توجد فروق ذات دلالـة إحصائية عند مستوى معنويـة

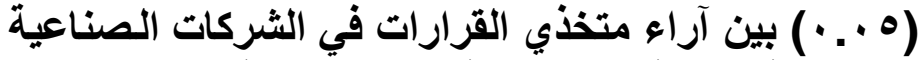

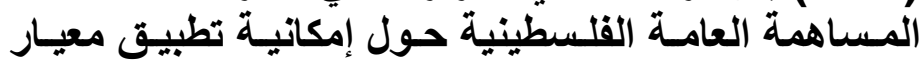

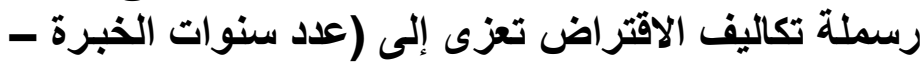




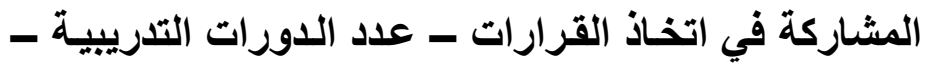

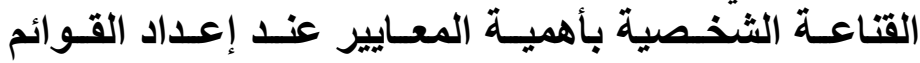

(المالية).

ويتفرع من هذه الفرضية الفرضيات الفر عية الآتية:

هـ ا: لا نوجد فروق ذات دلالة إحصائية عند مستوى معنوية العاتية (0 . . •) بين العاملين

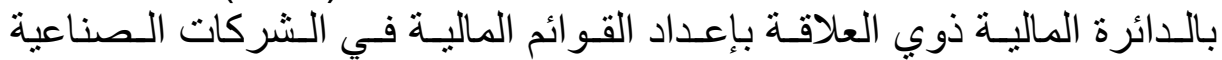

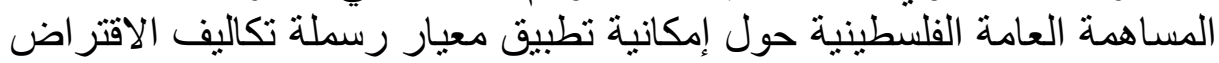

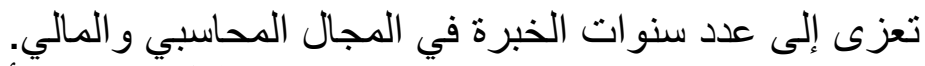

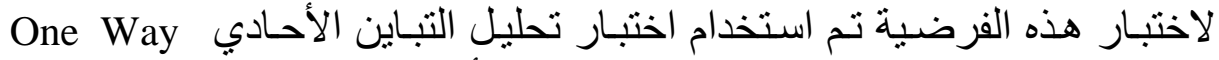

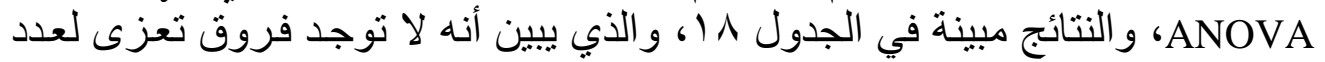

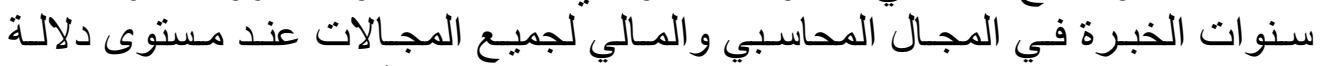

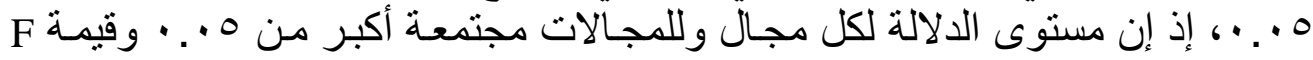

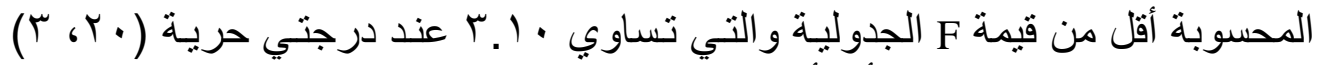

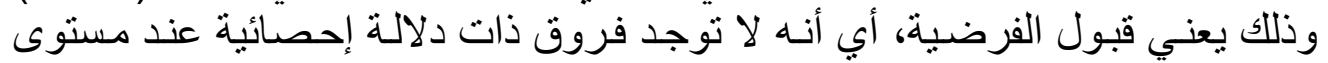

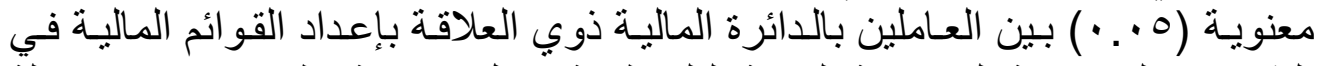

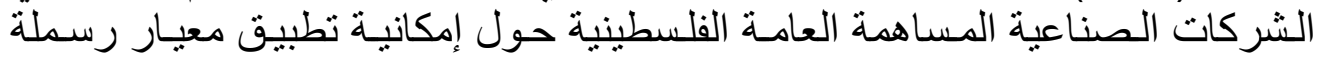
تكاليف الاقتر اض تعزى إلى عدد سنوات الخبرة. وهذا دليل على أن تطبيق المعايير

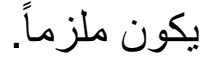

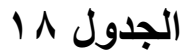

نتائج تحليل التباين الأحادي (One Way ANOVA) طبقاً لمتغير عدد سنوات الخبرة

\begin{tabular}{|c|c|c|c|c|c|c|}
\hline الالالة مستوى & " قيمة " & المربعات متوسط & الحرية & المربعات & مصدر التباين & 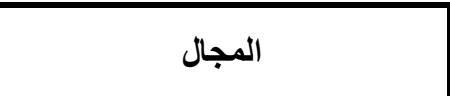 \\
\hline \multirow{3}{*}{$.0 \vee 9$} & \multirow{3}{*}{.$T V Y$} & $\cdot Y \backslash \Lambda$ & $r$ & $.70 \xi$ & بين المجموعات & \multirow{3}{*}{ 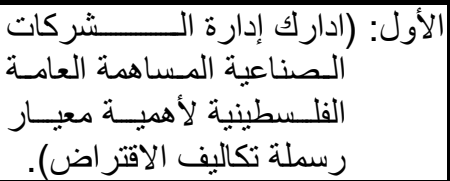 } \\
\hline & & $\cdot$ TY & r. & $7 . \leqslant 9$. & داخل المجمو عات & \\
\hline & & & Tr & $\vee .1 \leq \varepsilon$ & المجموع & \\
\hline \multirow{3}{*}{.97.} & \multirow{3}{*}{$\because 91$} & $\because .49$ & r & $\because \wedge \mathrm{A}$ & بين المجموعات & \multirow{3}{*}{ 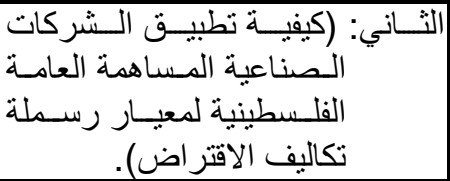 } \\
\hline & &.$r 4 q$ & $r$. & 0.101 & داخل المجمو عات & \\
\hline & & & Tr & $0.9 \mathrm{VV}$ & المجموع & \\
\hline \multirow[b]{3}{*}{$\cdot 7 \wedge r}$. & \multirow[b]{3}{*}{$.0 . v$} & .19 & $r$ & $.0 \mathrm{VI}$ & بين المجمو عات & \multirow{3}{*}{ 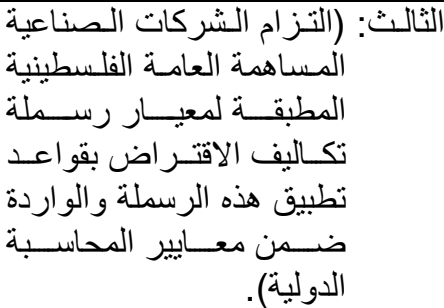 } \\
\hline & &. rvo & $r \cdot$ & $V .0 .7$ & داخل المجمو عات & \\
\hline & & & rt & A. $\cdot V \vee$ & المجموع & \\
\hline .994 & $\because . r q$ & $\because 1$ & $r$ & $\because \cdot r$ & بين المجمو عات & الر ابــع: (مــدى تطبيـق الـشركات \\
\hline
\end{tabular}




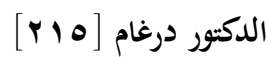

\begin{tabular}{|c|c|c|c|c|c|c|}
\hline الدلالة & " قيمة " & المربعات & الدرية & المربعات & مصدر التباين & 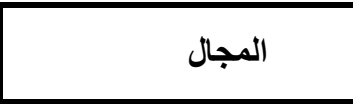 \\
\hline & & $\cdot r \varepsilon r$ & $r$. & 7.17. & داخل المجمو عات & الـصناعية المســاهمة العامــة \\
\hline & & & Tr & 7.19. & المجموع & 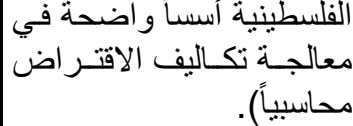 \\
\hline \multirow{3}{*}{$\cdot .9 \vee \varepsilon$} & \multirow{3}{*}{$\cdot . V r$} & $\because .17$ & $r$ & $\because \cdot \varepsilon 9$ & بين المجمو عات & \multirow{3}{*}{ جميع المجالات } \\
\hline & & - YYY & $r$. & $\varepsilon . \varepsilon 07$ & داخل المجمو عات & \\
\hline & & & rT & $\varepsilon .0 .0$ & المجموع & \\
\hline
\end{tabular}

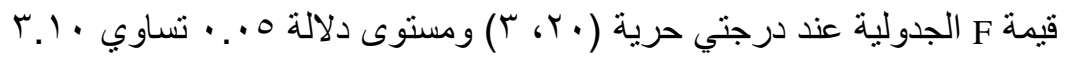

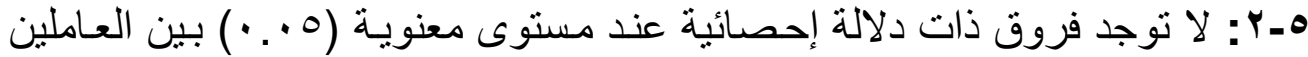

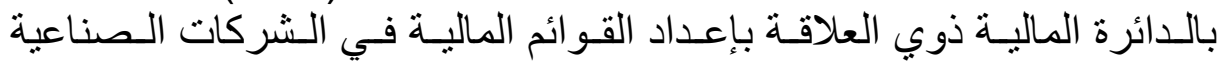
المساهمة العامة الفلسطينية حول إمكانية تطبيق معيار رسملة تكاليف الاقتر اض

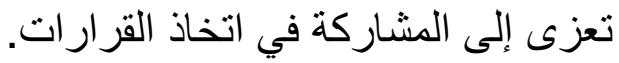

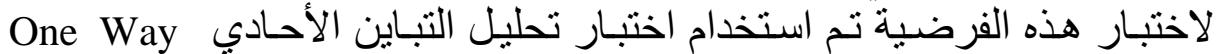

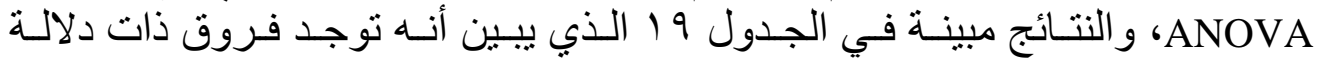

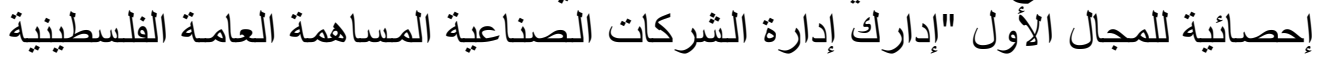

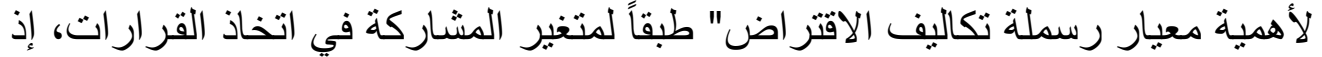

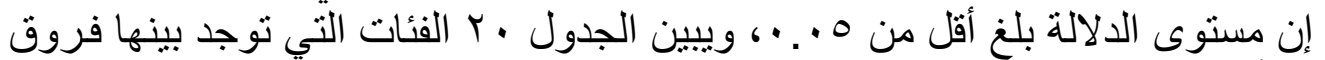
وفقاً لاختبار (Tamhane test)، كما يبين الجدول 9 أنغ أنه لا توجد فروق تعزى لمتغير

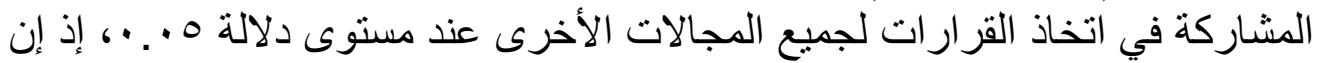

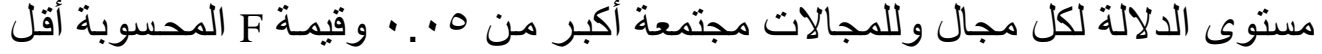

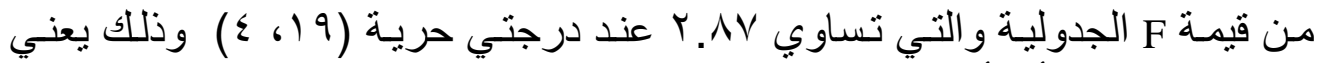

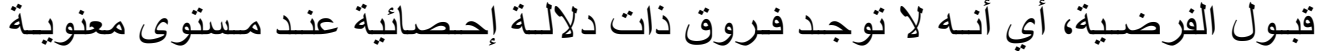

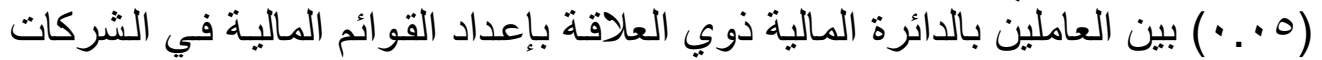

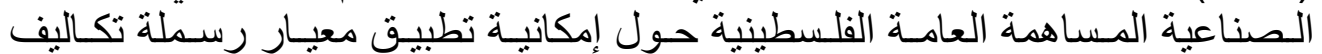

الاقتر اض تعزى إلى المشاركة في اتخاذ القرارات.

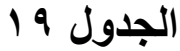

نتائج تحليل التباين الأحادي (One Way ANOVA) طبقاً لمتفير المشاركةٌ في اتخاذ القرارات

\begin{tabular}{|c|c|c|c|c|c|c|}
\hline الدالاية & F قيمة F & | متوسط المربعات & الحرية & 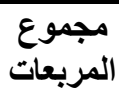 & مصدر التباين & المجال \\
\hline \multirow[t]{2}{*}{$\because$ ro } & \multirow[t]{2}{*}{ T. $\leqslant 0 \leqslant$} &.$V T r$ & $\varepsilon$ & $r .0 r$ & بين المجمو عات & \multirow{2}{*}{ 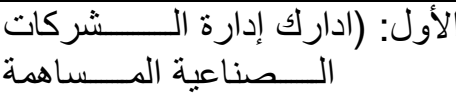 } \\
\hline & & $\because r 10$ & 19 & $\varepsilon .91$ & داخل المجمو عات & \\
\hline
\end{tabular}




\begin{tabular}{|c|c|c|c|c|c|c|}
\hline مستوي الدلاكة & | قيمة F & |لمربعات & الحرية & المربعات & مصدر التباين & 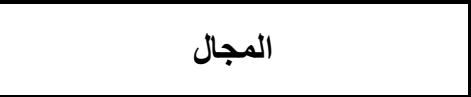 \\
\hline & & & $r$ & $v .1 \leq \varepsilon$ & المجموع & 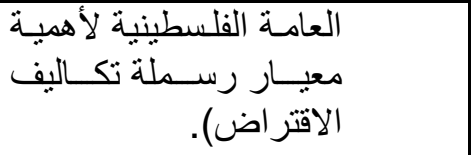 \\
\hline \multirow{3}{*}{$\cdot \leqslant \leqslant \cdot$} & \multirow{3}{*}{$.9 \wedge \leqslant$} &.$r 00$ & $\varepsilon$ & 1.19 & بين المجمو عات & \multirow{3}{*}{ 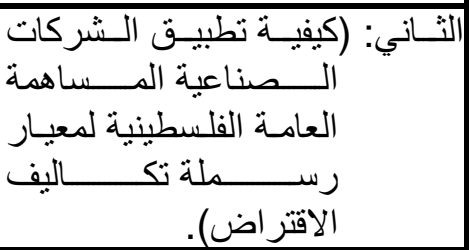 } \\
\hline & & $\cdot . r 09$ & 19 & $\varepsilon .91 \wedge$ & داخل المجمو عات & \\
\hline & & & $r$ & $0.9 \mu V$ & المجموع & \\
\hline \multirow[b]{3}{*}{$\cdot . Y \wedge 1$} & \multirow[b]{3}{*}{$1 . T V Y$} &.$\leqslant 0 \%$ & $\varepsilon$ & $1 . \wedge 1$. & بين المجمو عات & \multirow{3}{*}{ 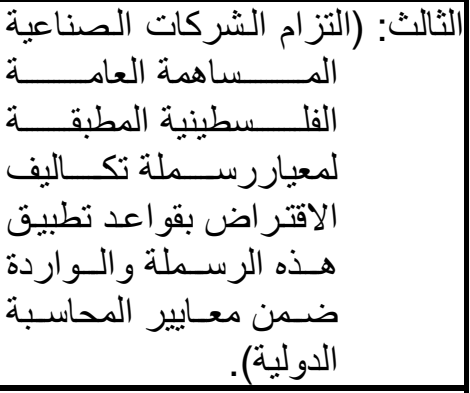 } \\
\hline & & . & 19 & $7 . Y 7 V$ & داخل المجموعات & \\
\hline & & & $r$ & A. $\cdot V V$ & المجموع & \\
\hline \multirow{3}{*}{ ( } & \multirow{3}{*}{ I.YYI } &. r. & $\varepsilon$ & $1 . \varepsilon \cdot 9$ & بين المجمو عات & \multirow{3}{*}{ 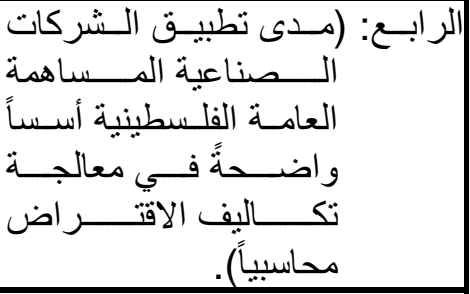 } \\
\hline & & $\because Y \wedge \wedge$ & 19 & $0 .\{\lambda 1$ & داخل المجمو عات & \\
\hline & & & r & $7 . \wedge 9$. & المجموع & \\
\hline \multirow{3}{*}{$\cdot .114$} & \multirow{3}{*}{ r.IV. } &.$r 0 \mu$ & $\varepsilon$ & $1.51 T$ & بين المجموعات & \multirow{3}{*}{ جميع المجالات } \\
\hline & &. .117 & 19 & $r .9 r$ & داخل المجمو عات & \\
\hline & & & rT & $\varepsilon .0 .0$ & المجموع & \\
\hline
\end{tabular}

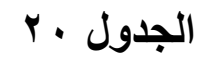

اختبار تامهان (Tamhane test) للفروق بين المتوسطات حسب متغير المشاركة في اتخاذ القرارات للمجال الأول

\begin{tabular}{|c|c|c|c|c|}
\hline نادراً & أحياناً & غالباً & دائماً & الفرق بين المتوسطات \\
\hline & & &. .1111 & غالباً \\
\hline & & .0110 & .7497 & أحياناً \\
\hline & מחזח. & .1019 & $.97 \pi$. & نادر اً \\
\hline$\cdot r v \cdot$ & • & $\therefore \wedge 1 \leqslant \wedge$. & .9909. & لا يتم ذلك إطلاقاً \\
\hline
\end{tabular}


هـr: لا توجد فروق ذات دلالة إحصائية عند مستوى معنويـة (0 . . • بين العاملين

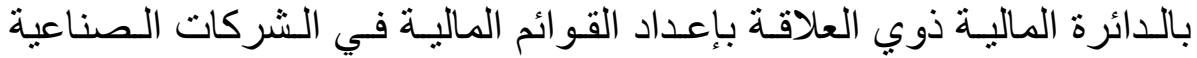

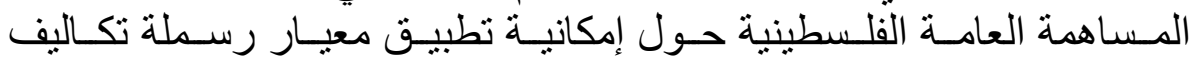

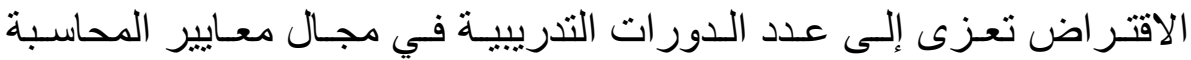
الدولية.

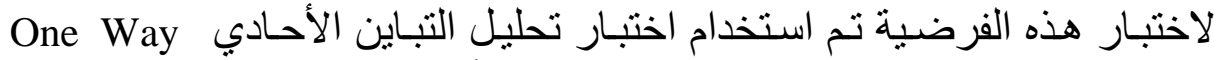

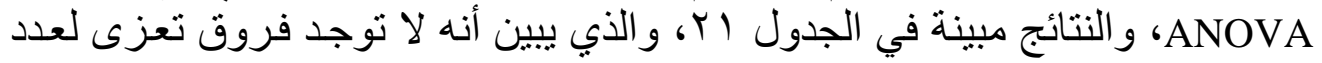

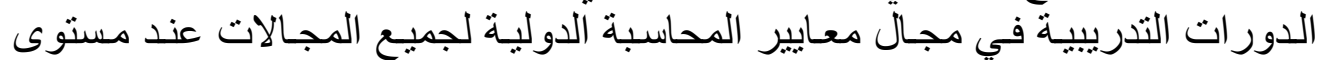

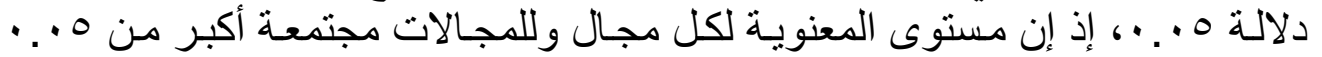

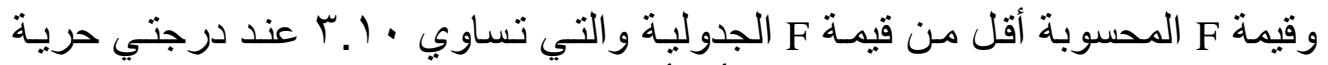

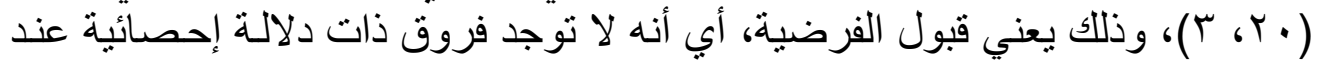

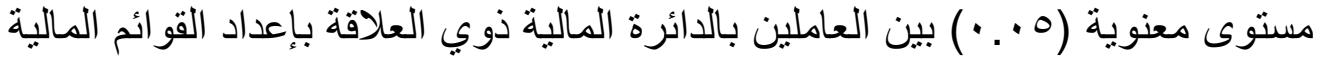

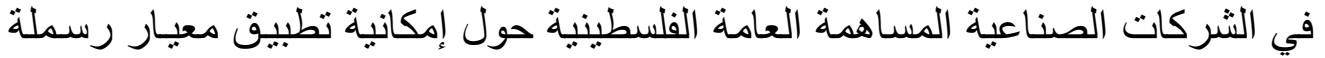
تكاليف الاقتر اض تعزى إلى عدد الدورات التدريبية.

\begin{tabular}{|c|c|c|c|c|c|c|}
\hline \multicolumn{7}{|c|}{ نتائج تحليل التباين الأحادي (One Way ANOVA الجدول) طبقاً لمتغير عدد الدورات } \\
\hline |الدلالة & قيمة F & |لمربعات & الدرجة & المربعوت & مصدر التباين & المجال \\
\hline \multirow{3}{*}{$\cdot .979$} & \multirow{3}{*}{$\cdot . \wedge r$} & $\because \times 9$ & $r$ & $\because \cdot \wedge \wedge$ & بين المجمو عات & \multirow{3}{*}{ 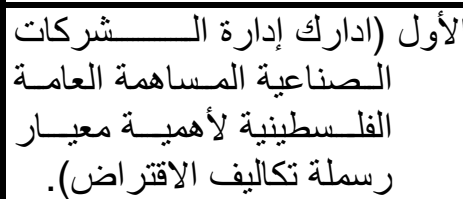 } \\
\hline & & . ror & $r$. & $V .07$ & داخل المجمو عات & \\
\hline & & & Tr & V. $.1 \leq \leqslant$ & المجموع & \\
\hline \multirow{3}{*}{$\cdot \varepsilon r \mu$} & \multirow{3}{*}{$.90 \leqslant$} & $\cdot r \leqslant \wedge$ & $r$ & $\because V \leqslant r$ & بين المجمو عات & \multirow{3}{*}{ 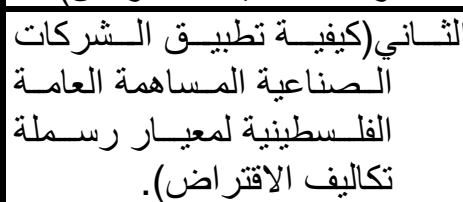 } \\
\hline & & - r. & $r$. & $0.19 \varepsilon$ & داخل المجمو عات & \\
\hline & & & Tr & $0.9 \mathrm{rV}$ & المجموع & \\
\hline \multirow[b]{3}{*}{$\cdot r T \leqslant$} & \multirow[b]{3}{*}{$1 . \leq \pi}$. & $\because \leqslant \vee 0$ & $r$ & $1 . \leqslant Y 7$ & بين المجمو عات & \multirow{3}{*}{ 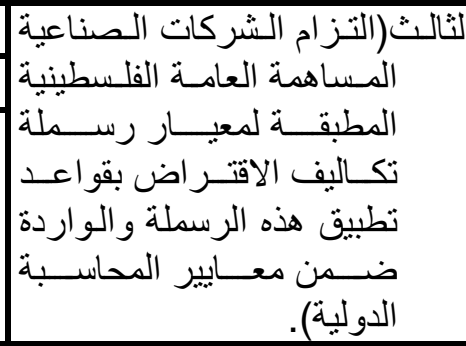 } \\
\hline & & . & $r$. & 7.701 & داخل المجمو عات & \\
\hline & & & r & $\Lambda . \vee \vee \vee$ & المجموع & \\
\hline \multirow{3}{*}{$\cdot .799$} & \multirow{3}{*}{ 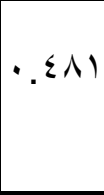 } & $.10 \varepsilon$ & $r$ & $\cdot . \leqslant 7 T$ & بين المجمو عات & \multirow{3}{*}{ 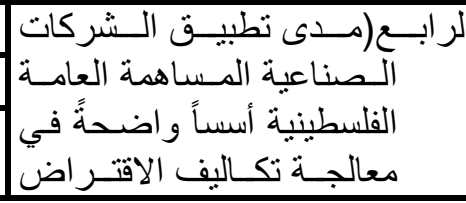 } \\
\hline & & . ITI & $r$. & $7 . \Sigma Y T$ & داخل المجمو عات & \\
\hline & & & rT & ૫. .9. & المجموع & \\
\hline
\end{tabular}




\begin{tabular}{|c|c|c|c|c|c|c|}
\hline |مستوي & Fيمة F & متوسطات & | درجة & المربعوع & مصدر التباين & المجال \\
\hline & & & & & & محاسبياً). \\
\hline \multirow{3}{*}{. .091} & \multirow{3}{*}{. $.70 r$} &. $.1 \% \varepsilon$ & $\bar{\mu}$ &.$\varepsilon \cdot 1$ & بين المجمو عات & \multirow{3}{*}{ جميع المجالات } \\
\hline & & $\cdot . r .0$ & T. & $\varepsilon .1 \cdot \varepsilon$ & داخل المجمو عات & \\
\hline & & & $\overline{r T}$ & $\varepsilon .0 .0$ & المجموع & \\
\hline
\end{tabular}

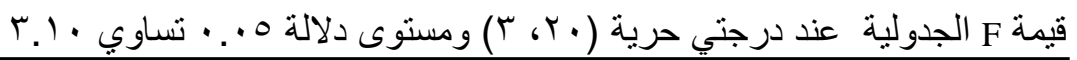

هـ ـ إ لا توجد فروق ذات دلالة إحصائية عند مستوى معنويـة (0 . . • ) بين العاملين

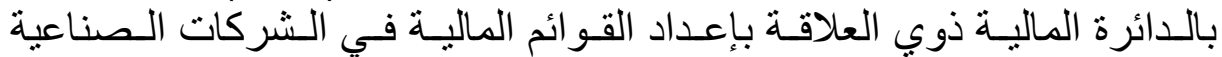

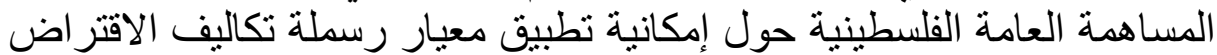

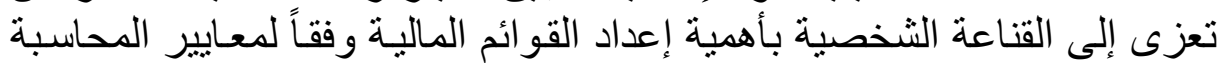

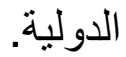

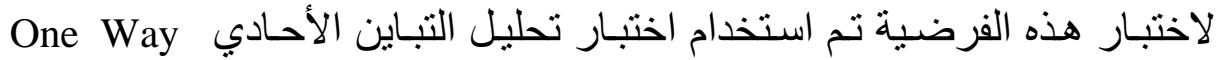

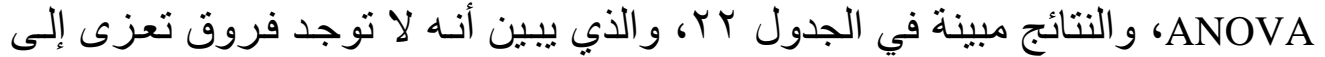

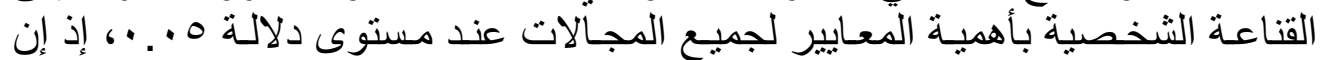

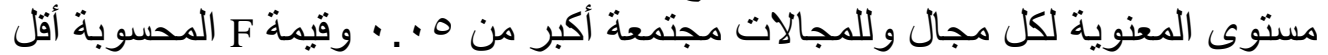

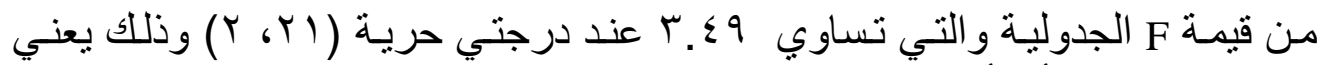

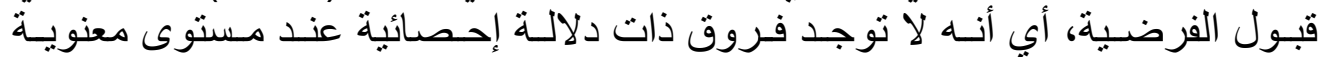

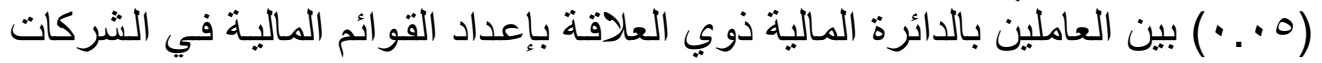

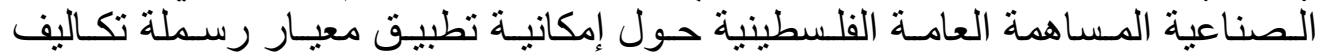
الاقتر اض تعزى إلى القناعة الشخصية بأهمية المعايير.

\begin{tabular}{|c|c|c|c|c|c|c|}
\hline \multicolumn{7}{|c|}{ 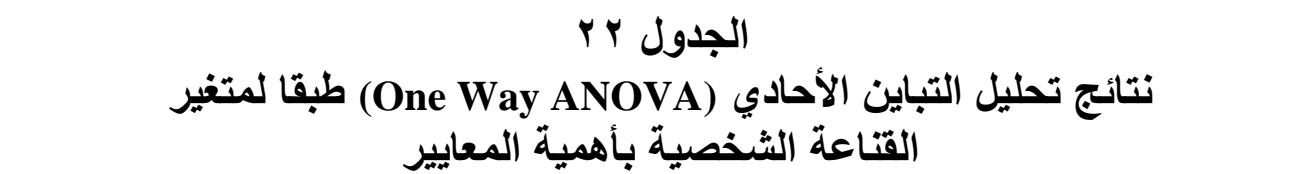 } \\
\hline الدلالة & قيمةت & متربعات & |لدرجة & المربعوع & مصدر التباين & المجال \\
\hline \multirow{3}{*}{$\because \cdot \vee \leqslant$} & \multirow{3}{*}{$r . q \leq q$} & $\because \vee \wedge \wedge$ & $r$ & $1.07 \mathrm{~V}$ & بين المجمو عات & \multirow{3}{*}{ 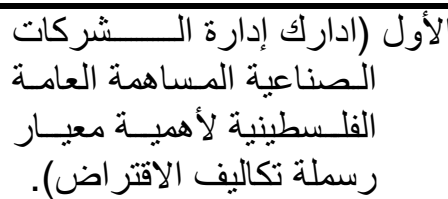 } \\
\hline & &. . & rI & $0.0 \mathrm{VV}$ & داخل المجموعات & \\
\hline & & & r & $V .1 \leq \varepsilon$ & المجموع & \\
\hline \multirow{3}{*}{$\cdot . \wedge r v$} & \multirow{3}{*}{.189} & $\because .0$ & $r$ & $.1 \cdots$ & بين المجمو عات & \multirow{3}{*}{ 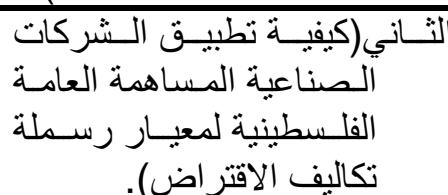 } \\
\hline & &. YYA & rI & $0 . \wedge \mu V$ & داخل المجمو عات & \\
\hline & & & rr & $0.9 \mu \mathrm{V}$ & المجموع & \\
\hline
\end{tabular}




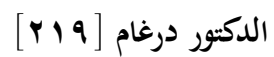

\begin{tabular}{|c|c|c|c|c|c|c|}
\hline |لدالية & Fقيمة & متوسطات & الحرية & المربعات & مصدر التباين & 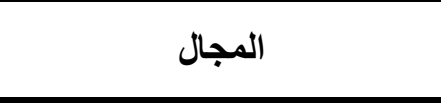 \\
\hline \multirow[b]{3}{*}{$\cdot \wedge \vee \neg$} & \multirow[b]{3}{*}{ • } & $\because 0$ & r & $.1 \cdot 1$ & بين المجمو عات & \multirow{3}{*}{ 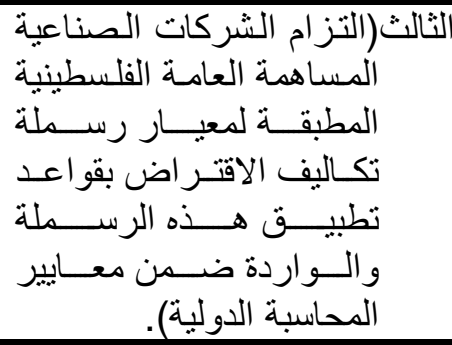 } \\
\hline & &.$r \Lambda$. & YI & $V .9 V V$ & داخل المجمو عات & \\
\hline & & & r & A. $\cdot V \vee$ & المجموع & \\
\hline \multirow{3}{*}{$\cdot . \wedge .0$} & \multirow{3}{*}{$\cdot r \mid 9$} & $\because \times 1$ & r & $. .1 \leq 1$ & بين المجمو عات & \multirow{3}{*}{ 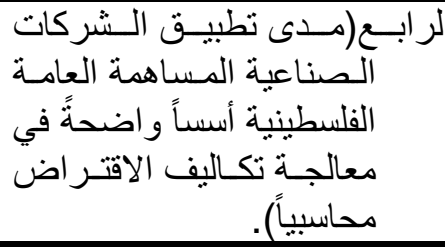 } \\
\hline & & 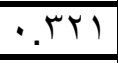 & YI & $7.8 \leq 9$ & داخل المجمو عات & \\
\hline & & & Tr & $7 . \wedge 9$. & المجموع & \\
\hline \multirow{3}{*}{$\cdot .7 r 0$} & \multirow{3}{*}{$\cdot\{\wedge 1$} & $\because 99$ & r & $.19 \mathrm{~V}$ & بين المجمو عات & \multirow{3}{*}{ جميع المجالات } \\
\hline & & 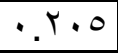 & YI & $\varepsilon . \mu \cdot \Lambda$ & داخل المجمو عات & \\
\hline & & & $r T$ & $\varepsilon .0 .0$ & المجموع & \\
\hline
\end{tabular}

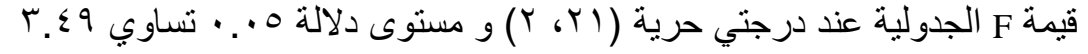

النتائج والتوصيات والدراسات المقترحة

النتائج

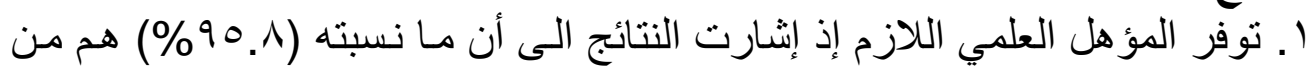

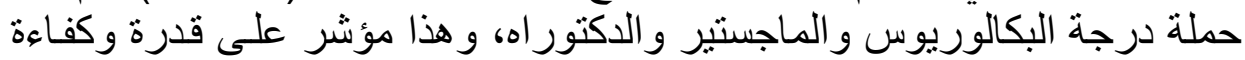

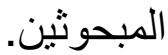

Y. يتمتع رؤساء أقسام المحاسبة والمدر اء المـاليين في الشركات الصناعية المساهمة

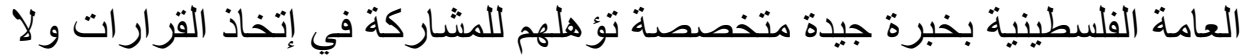

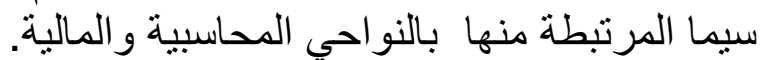

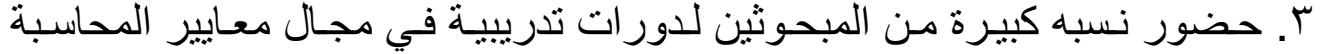

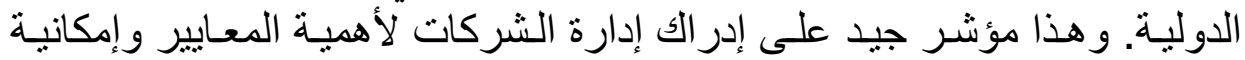
تطبيق معيار رسملة تكاليف الاقتر اض في تلآلك الشركات. ع. أكد غالبية المبحوثين على أهمية إعداد القوائم المالية وفقاً لمعايير المحاسبة الدولية،

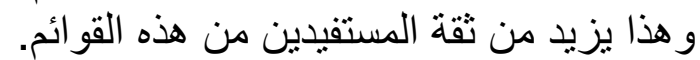

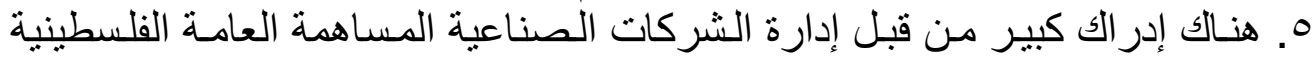

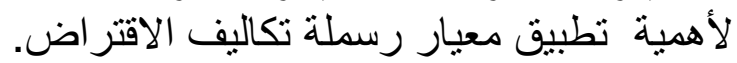

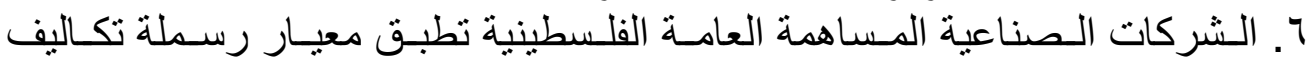

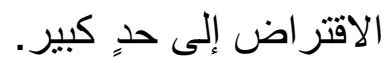

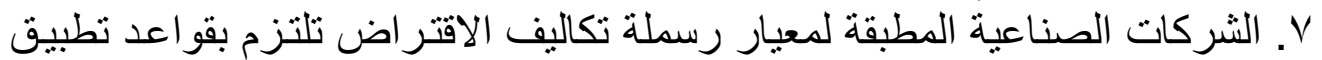

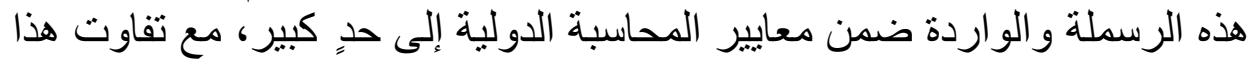
الالتز ام بين تلك القو اعد. 
^ـ الثركات الصناعية المساهمة العامـة الفلسطينية تطبق أسساً واضحةً في معالجـة تكاليف الاقتر اض محاسبياً إلى حدٍ كبير.

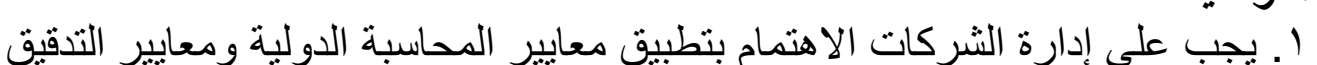

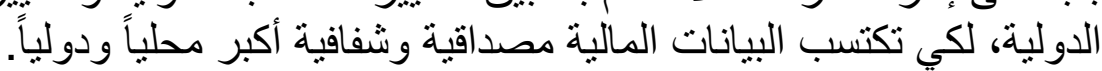

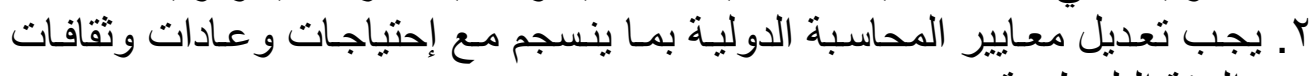
البيئة الفلسطينية. r. إلزام الشركات الصناعية الفلسطينية بتطبيق معـايير المحاسبة الدوليـة ومعـايير

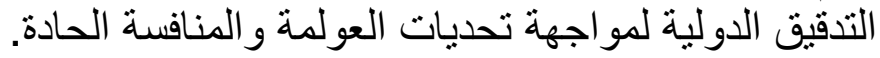

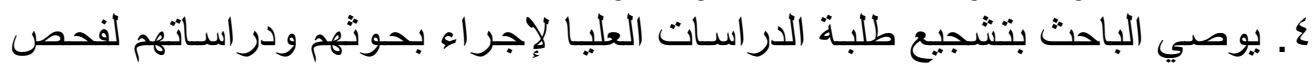

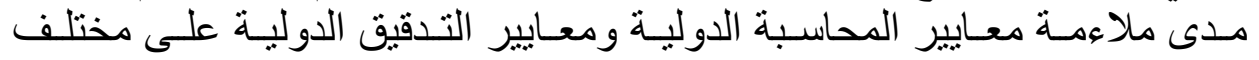
القطاعات الاقتصادية و غير الاقتصادية الفلسطينية.

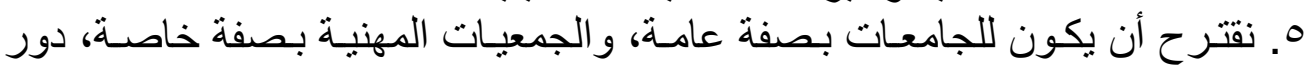

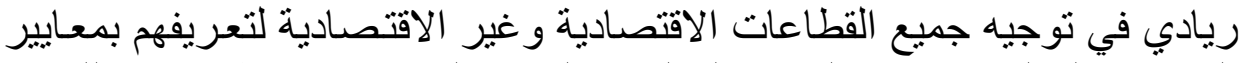
الدحاسبة الدولية ومعايير التدقيق الدولية، و الدنافع المتوقعة من تطبيقها، وذلك من الإني

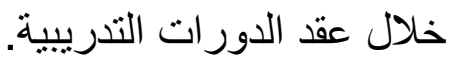

الاراسات المستقبلية المقترحة

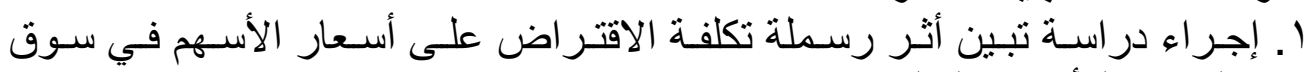
فل ألسطين للأوراق المالية. r. إجر اء در اسة تبين قياس تكلفة الاقتر اض واضية وأثره في الخصائص الكيفية للمعلومات المحاسبية في الثركات الصناعية الفلسطينية.

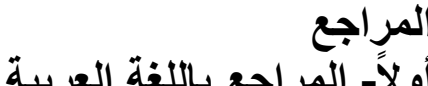

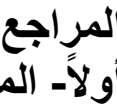

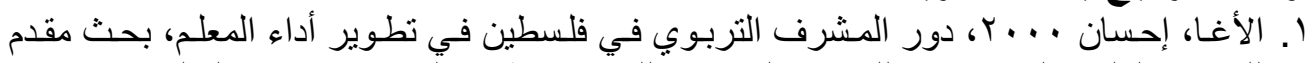

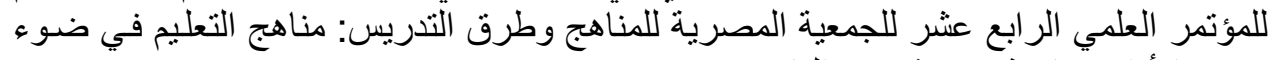

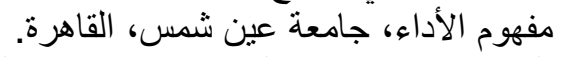

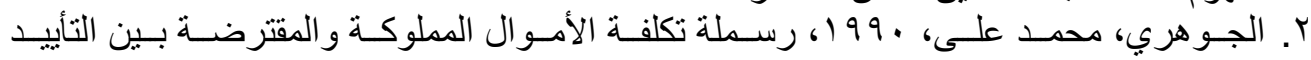

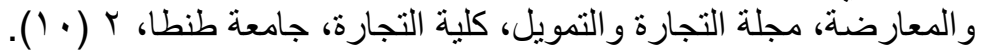

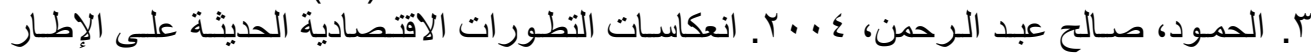
العلمي لنظرية الدحاسبة بالتركيز على معايير المحاسبة الدولية. مجلة جامعة الملك عبد العزيلة العزيز:

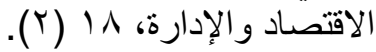

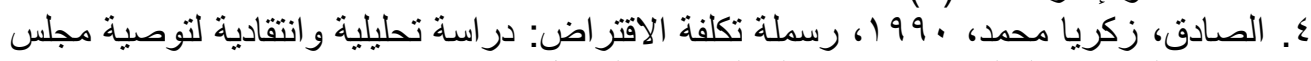
معايير المحاسبة المالية FASB، مجلة التجارة والتمويل، ( (· (1). 


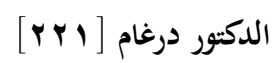

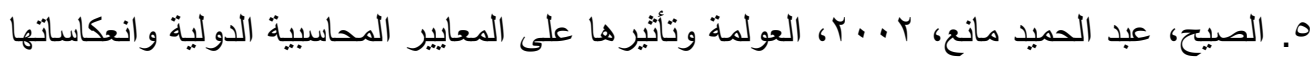

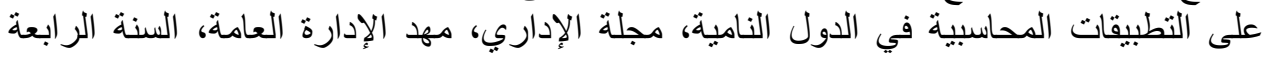
و العشرون، العدد التسعون.

7. المجمـع العربي للمحاسبين القانونين، معـايير المحاسبة الدوليـة الصادرة عن اتحساد المحاسبين

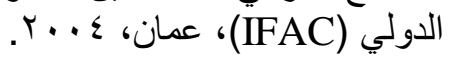

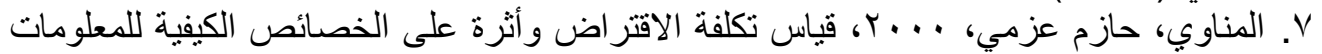

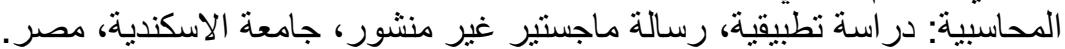

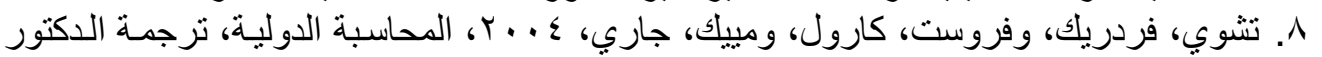

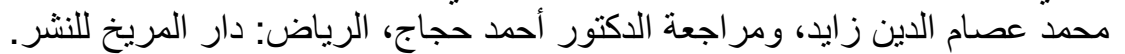

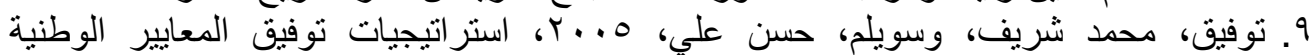

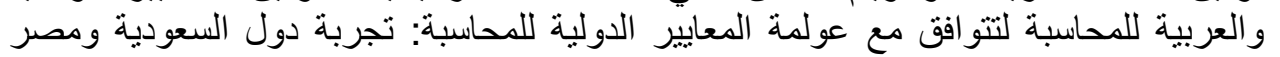

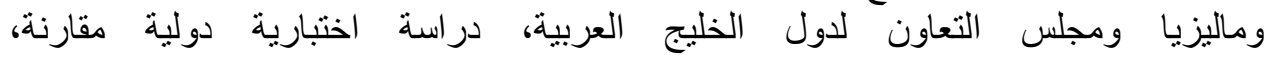
.WWw.infotechaccountants.com

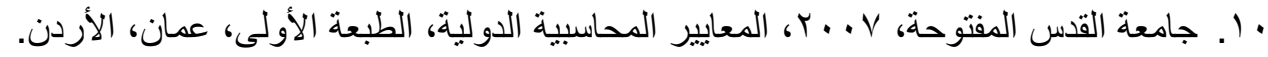

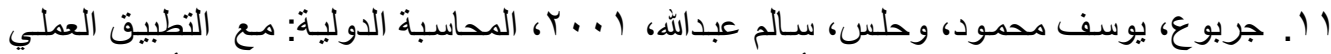

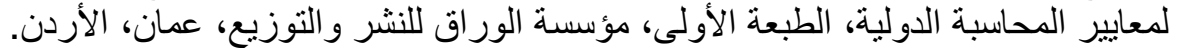

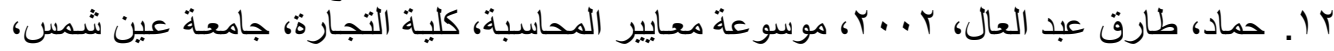

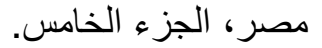

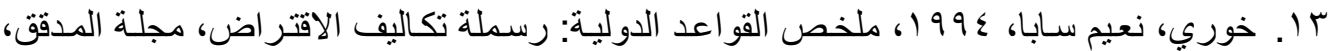

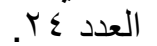

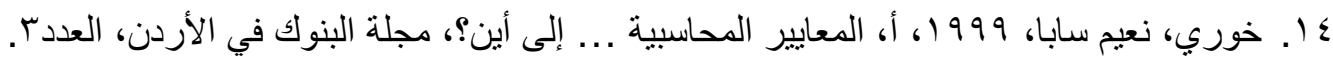

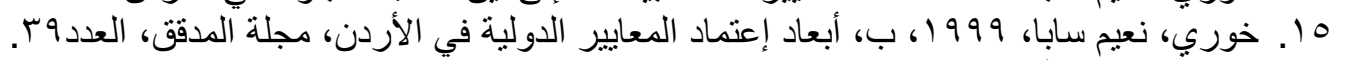

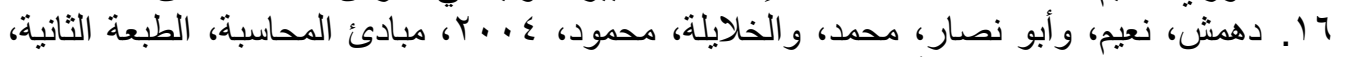

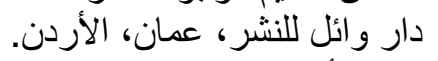

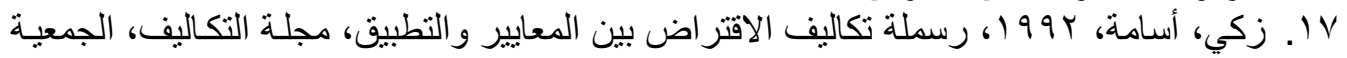

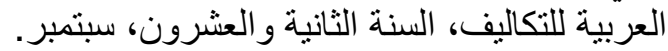

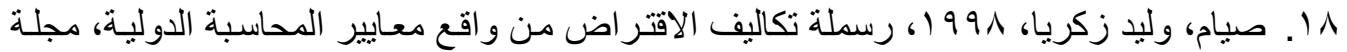

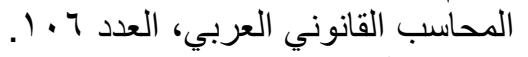

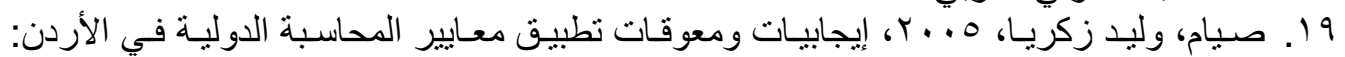

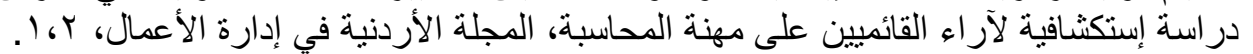

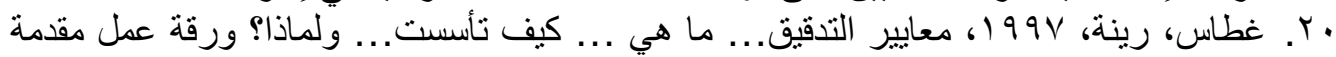

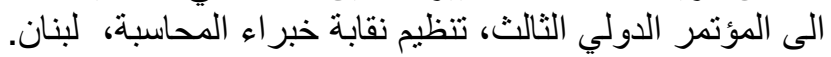

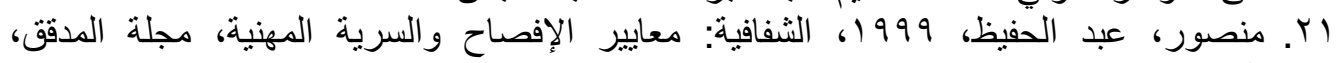

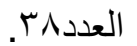

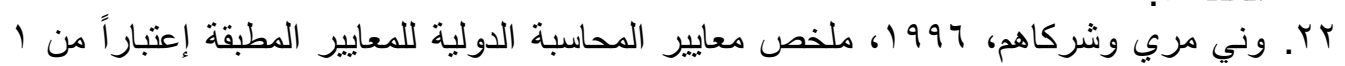

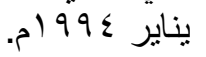

\section{ثانياً- المراجع باللغة الأجنبية}

1. Gannon D. J., and Ashwal Alex. (2004). Financial Reporting goes Global, Jornual of Accountancy - Online Issues.

2. FASB, SFAS No. 34. (1979). Capitalization of Interest Cost, Stamford Conn, FASB.

3. IASC, IAS No. 23. (1984). Capitalization of Borrowing Costs, Supplement to, The Management Accountant, March 1984. 
4. Sekaran, Uma. (2005). Research Methods For Business With Spss 13.0 Set, (4 ${ }^{\text {th }}$ ed.). New York: John Wiley and Sons.

5. www.socpa.org.sa

6. www.infotechaccountants.com. 